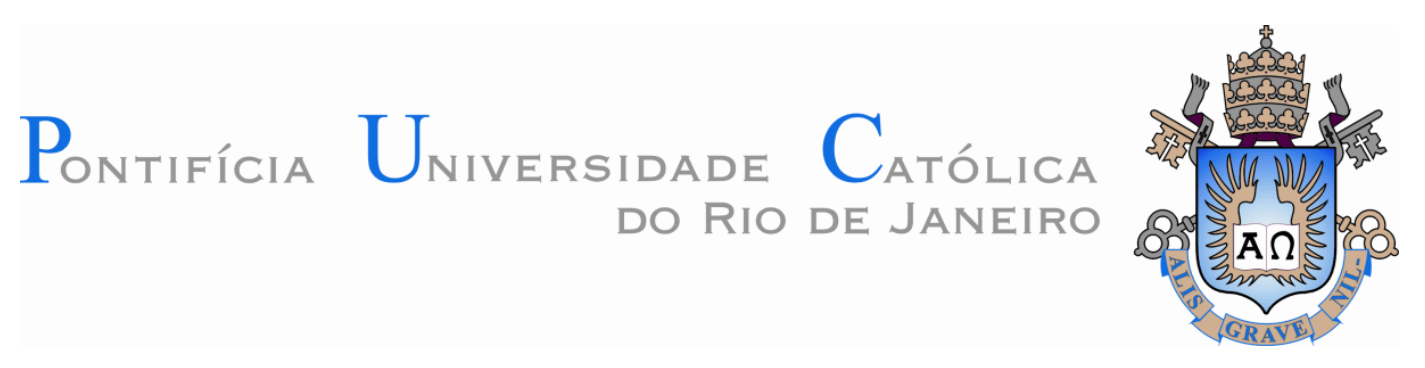

Renato Gutiérrez Escobar

Investigação do Fraturamento Hidráulico por Modelagens Analítica e Numérica

Dissertação de Mestrado

Dissertação apresentada ao programa de Pós-Graduação em Engenharia Civil do Departamento de Engenharia Civil da PUC-Rio como requisito parcial para obtenção do título de Mestre em Engenharia Civil.

Orientador: Prof. Celso Romanel Co-orientadora: Profa. Deane de Mesquita Roehl

Rio de Janeiro Março de 2016 
Renato Gutiérrez Escobar

\section{Investigação do Fraturamento Hidráulico por Modelagens \\ Analítica e Numérica}

Dissertação apresentada como requisito parcial para obtenção do título de Mestre pelo Programa de Pós-Graduação em Engenharia Civil do Departamento de Engenharia Civil do Centro Técnico Científico da PUC-Rio. Aprovada pela Comissão Examinadora abaixo assinada.

Prof. Celso Romanel

Orientador

Departamento de Engenharia Civil - PUC-Rio

Profa. Deane de Mesquita Roehl

Co-Orientadora

Departamento de Engenharia Civil - PUC-Rio

Prof. Marco Antonio Meggiolaro

Departamento de Engenharia Mecânica - PUC-Rio

Prof. Paulo Dore Fernandes

PETROBRAS

Prof. Márcio da Silveira Carvalho

Coordenador Setorial do

Centro Técnico Científico - PUC-Rio

Rio de Janeiro, 15 março de 2016 
Todos os direitos reservados. É proibida a reprodução total ou parcial do trabalho sem autorização da universidade, da autora e do orientador.

\section{Renato Gutiérrez Escobar}

Graduou-se em Engenharia de Petróleos na Universidade Industrial de Santander- Colômbia, em 2013. No ano 2014 ingressou no curso de Mestrado em Engenharia Civil da Pontifícia Universidade Católica do Rio de Janeiro, na área de Geotecnia, onde vem desenvolvendo investigações na linha de pesquisa em Fraturamento Hidráulico de Poços de Petróleo.

Ficha Catalográfica

Gutiérrez Escobar, Renato.
Investigação do Fraturamento Hidráulico por
Modelagens Analítica e Numérica / Renato Gutiérrez
Escobar; orientador: Celso Romanel; co-orientadora:
Deane de Mesquita Roehl- 2016,
117 f. : il;(color); 29,7 cm.
Dissertação (Mestrado) - Pontifícia Universidade
Católica de Rio de Janeiro, Departamento de Engenharia
Civil, 2016.
Inclui bibliografia
1. Engenharia Civil - Teses. 2. Método dos elementos
finitos. 3. Fraturamento Hidráulico. 4. Elementos coesivos
acoplados. 5. Propagação de fraturas I. Romanel, Celso.
II. Roehl, Deane de Mesquita III. Pontifícia Universidade
Católica do rio de Janeiro. Departamento de Engenharia
Civil. IV. Título.
(1)

CDD: 624 


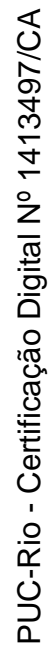

Dedico esta dissertação aos meus pais Martha Escobar e Alfonso Gutiérrez 


\section{Agradecimentos}

A Deus pela guia, fortaleza, acompanhamento, e bênçãos dadas durante toda minha vida.

A meus orientadores Celso Romanel pela orientação para o desenvolvimento deste trabalho e a Deane Roehl pelo acompanhamento em todos os momentos, orientação, dedicação e incentivo durante a dissertação de mestrado, obrigado pelos conhecimentos transmitidos.

A meus pais Martha Escobar e Alfonso Gutierrez pelo apoio, guia, amor, dedicação, exemplo e boa educação dada durante toda minha vida.

A meus irmãos Sergio e Alfonso Gutierrez pelo apoio, incentivo e carinho dado durante todo este tempo.

A meus colegas de pesquisa Cristian Mejía e Markos Bendezu pelos conselhos, dedicação e conhecimentos transmitidos no desenvolvimento da pesquisa.

Agradeço ao instituto Tecgraf pela oportunidade de trabalhar, aprender e pesquisar sobre temas de grão relevância na indústria do petróleo. 


\section{Resumo}

Gutiérrez Escobar, Renato; Romanel, Celso; Roehl, Deane de Mesquita. Investigação do Fraturamento Hidráulico por modelagens analítica e numérica. Rio de Janeiro, 2016. 117p. Dissertação de Mestrado Departamento de Engenharia Civil, Pontifícia Universidade Católica do Rio de Janeiro.

O processo de fraturamento hidráulico tem sido amplamente usado para aumentar o volume de petróleo e gás extraído na indústria petroleira. Durante a injeção de fluido, uma região determinada do reservatório é fraturada com a finalidade de aumentar a permeabilidade do meio poroso, de tal forma que o fluxo do fluido desde o reservatório para o poço seja favorecido notoriamente. Porém, este processo pode ocasionar danos ambientais tais como contaminação de aguas subterrâneas, vazamentos de gás, fraturas indesejadas nas camadas capeadoras pela injeção de agua e atividade sísmica fazendo primordial um estudo rigoroso do fraturamento hidráulico com a finalidade de reduzir os riscos potenciais associados a esta operação. Umas das metodologias usadas para projetar o fraturamento hidráulico é a simulação computacional. É possível determinar o volume injetado e a potência da bomba de injeção necessária para obter a geometria de fratura (comprimento, abertura e altura) desejada. A modelagem numérica através de elementos coesivos acoplados do processo de fraturamento hidráulico pode ser efetuada considerando o processo transiente ou permanente, tendo geometrias da fratura e curvas de injeção diferentes. Neste trabalho foi simulado numericamente o modelo KGD nos regimes de fluxo transiente e permanente para dois casos de estudo, (1) injeção numa única camada e (2) injeção em três camadas com contraste de tensões e poropressões entre elas. O estudo numérico foi desenvolvido usando o método dos elementos finitos com modelo de zona coesiva no software Abaqus o qual foi comparado com as soluções analíticas do KGD no regime dominado pela rigidez (Vértice-K) para uma camada e de Simonson e Fung para três camadas.

\section{Palavras-chave}

Método dos elementos finitos; elementos coesivos acoplados; fraturamento hidráulico; propagação de fraturas. 


\section{Abstract}

Gutiérrez Escobar, Renato; Romanel, Celso (Advisor); Roehl, Deane de Mesquita (Co-advisor). Investigation of hydraulic fracturing through analytical and numerical models. Rio de Janeiro, 2016. 117p. MSc. Dissertation - Departamento de Engenharia Civil, Pontifícia Universidade Católica do Rio de Janeiro.

The hydraulic fracturing process has been widely used to improve oil and gas recovery in the petroleum industry. During the fluid injection, the desired section of rock formation is fractured in order to increase the permeability of the medium that can facilitate the flow of oil to a producing well. However, this process can lead to potential environmental risks such as seismic activity, unwanted fractures in cap layers by water injection, water contamination and gas leakage making primordial to develop a rigorous study in order to reduce this environmental risks associated to hydraulic fracturing. One of the studies developed to design the hydraulic fracturing is computational simulation to determine the fluid volume and hydraulic horsepower required in order to produce the wanted fracture geometry (length, opening and height). The numerical modelling of fracturing process by using fully coupled cohesive element hydraulic can be carried out considering either a steady state or a transient analysis, which modify the fracture geometry and injection pressure. In this work, the KGD model is simulated in transient and steady analysis for two cases: (1) injection in a single layer formation and (2) injection in tri-layered formation with stress and porepressure contrast between them. The numerical simulation of a hydraulic fracturing is carried out using the finite element method with the zone cohesive model in Abaqus whose results are compared with analytical solutions of toughness-dominated propagation regime for the one layer formation model and Simonson and Fung analytical solutions for tri-layered formations model.

\section{Keywords}

Finite element method; coupled cohesive element; Hydraulic fracturing; Fracture propagation 


\section{Sumário}

1 Introdução 16

1.1. Definição do problema 16

1.2. Motivação e Objetivos 18

$\begin{array}{ll}\text { 1.3. Estrutura da dissertação } & 18\end{array}$

2 Revisão bibliográfica $\quad 20$

2.1. Equações governantes do fraturamento hidráulico 20

2.1.1. Deformação do meio poroso 20

2.1.2. Fluxo de fluido no meio poroso 22

2.1.3. Fluxo do fluido no interior da fratura 23

2.1.4. Propagação da fratura 24

2.2. Modelos analíticos de fraturas induzidas hidraulicamente 24

2.2.1. Sneddon (1946) e Sneddon \& Elliot (1946) 25

2.2.2. Modelo de Khristianovic-Geertsma-de Klerk (KGD) 27

2.2.3. Modelo Perkins-Kern-Nordgren (PKN) 29

2.2.4. Penny-Shaped ou modelo radial 31

2.2.5. Simonson (1978) 34

2.2.6. Fung et al (1987) 36

2.3. Regimes de propagação de fraturas 38

3 Métodos dos elementos finitos com modelo de zona coesiva 43

3.1. Modelo da zona coesiva 43

3.2. Resposta constitutiva dos elementos coesivos 44

3.2.1. Comportamento antes do dano 45

3.2.2. Iniciação do dano 46

3.2.3. Evolução do dano 46

3.3. Resposta constitutiva do fluido no elemento coesivo 50

3.3.1. Fluxo Tangencial 51

3.3.2. Fluxo normal 52

3.4. Tamanho do elemento coesivo 53 
4 Metodologia numérica do fraturamento hidráulico 54

4.1. Passos da simulação do fraturamento hidráulico 54

4.1.1. Passo inicial 54

4.1.2. Geostático 55

4.1.3. Passo de injeção 55

4.2. Modelo coesivo $\quad 57$

4.3. Regularização viscosa 61

4.4. Comprimento do intervalo injetado 64

4.5. Análise permanente vs Análise transiente 67

4.6. Modelo sintético de três camadas com barreiras impermeáveis 78

5 Comparação dos resultados analíticos e numéricos 88

5.1. Modelo de uma camada 89

5.2. Regime de propagação de fratura 91

5.3. Validação dos modelos de três camadas 93

5.3.1. Comparação com o modelo analítico de Simonson 93

5.3.2. Comparação com o modelo analítico de Fung 95

6 Analise paramétrica dos fatores atuantes no fraturamento hidráulico 97

6.1. Viscosidade do fluido de fraturamento 97

6.2. Vazão de injeção 99

6.3. Fator de intensidade de tensões 101

6.4. Condutividade Hidráulica 103

6.5. Módulo de Young 105

$\begin{array}{ll}\text { 6.6. Coeficiente de Poisson } & 107\end{array}$

7 . Conclusões e sugestões 111

7.1. Conclusões 111

$\begin{array}{ll}\text { 7.2. Sugestões } & 112\end{array}$

$\begin{array}{ll}\text { Referências bibliográficas } & 114\end{array}$ 


\section{Lista de figuras}

Figura 1.1: Processo de fraturamento hidráulico (Mohammadnejad et al.,2013)

Figura 2.1: Abertura da fratura e o fluxo do fluido fraturante (Zielonka, 2014)

Figura 2.2: Modelo KGD (Yew, 1997)

Figura 2.3: Modelo PKN (Yew, 1997)

Figura 2.4: Fratura radial (Savitski \& Detournay, 2002.)

Figura 2.5: Superposição de carregamentos (modificado de Simonson, 1978)

Figura 2.6: Modelo de Simonson (modificado do Simonson, 1978) 36

Figura 2.7: Modelo de Fung et al. (modificado de Fung et al, 1987) 37

Figura 2.8: Regimes de propagação de fratura (Carrier, 2012) 40

Tabela 2.1 Comparação dos modelos analíticos

Figura 3.1: Zona coesiva introduzida numa fratura hidráulica (modificado Cheng, 2009, 2012)

Figura 3.2: Modelo coesivo para fraturamento hidráulico (modificado de Zielonka, 2013)

Figura 3.3: Elementos coesivos acoplados para o fraturamento hidráulico (Zielonka, 2014)

Figura 3.4: Fluxo nos elementos coesivos (Shen 2012)

Figura 3.5: Pressões no elemento coesivo (Abaqus 2014)

Figura 4.1: Modelo sintético de uma camada

Tabela 4.1: Propriedades da rocha, do fluido e da fratura

Figura 4.2: Lei de tensão de tração-separação do modelo coesivo

Figura 4.3: Variação do modelo coesivo com o parâmetro $\alpha$.

Figura 4.4: Efeito da variação do $\alpha$ no cálculo do dano

Figura 4.5: Efeito do parâmetro $\alpha$ na pressão de injeção. 
Figura 4.6: Efeito do Efeito do parâmetro $\alpha$ na abertura máxima da fratura.

Figura 4.7: Efeito do Efeito do parâmetro $\alpha$ no perfil de pressão ao longo da fratura.

Figura 4.8: Efeito do parâmetro $\alpha$ na geometria da fratura 61

Figura 4.9: Efeito da regularização viscosa na pressão de injeção. $\quad 63$

Figura 4.10: Efeito da regularização viscosa na abertura da fratura. 63

Figura 4.11: Efeito da regularização viscosa no perfil de pressão na fratura.

Figura 4.12: Efeito da regularização viscosa na geometria da fratura. $\quad 64$

Figura 4.13: Cálculo da vazão total por unidade de comprimento

Figura 4.14: Efeito do comprimento do intervalo injetado na pressão de injeção.

Figura 4.15: Efeito do comprimento do intervalo injetado na abertura máxima.

Figura 4.16: Efeito do comprimento do intervalo injetado na geometria da fratura.

Figura 4.17: Efeito do comprimento do intervalo injetado na geometria da fratura

Figura 4.18: Efeito do grau de poro na pressão de injeção.

Figura 4.19: Efeito do grau de poro na abertura máxima da fratura.

Figura 4.20: Perfil de distribuição de pressões nas situações de regime de fluxo transiente (traço descontínuo) e permanente (traço contínuo).

Figura 4.21: Geometria da fratura nas análises em regime de fluxo transiente (traço descontínuo) e permanente (traço contínuo).

Figura 4.22: Poropressões na fratura em regime de fluxo permanente.

Figura 4.23: Poropressões na fratura em regime de fluxo transiente 72 Figura 4.24: Nós selecionados para estudar os excessos de poropressão

Figura 4.25: Tensões horizontais para situações de regime transiente (traço descontínuo) e permanente (traço contínuo). 
Figura 4.26: Perfil de poropressões nas situações de fluxo transiente (traço descontínuo) e fluxo permanente (traço contínuo) ao longo do comprimento $A B$

Figura 4.27: Perfil de poropressões (traço descontínuo) e de tensões horizontais (traço contínuo) ao longo do comprimento $A B$ para a situação de fluxo em regime transiente.

Figura 4.28: Efeito da permeabilidade na pressão de injeção

Figura 4.29: Pressão de injeção em controle de pressão

Figura 4.30: Abertura máxima da fratura em controle de pressão

Figura 4.31: Perfil de pressão para análise transiente e permanente. $\quad 77$

Figura 4.32: Geometria da fratura em situações de regime de fluxo transiente (traço descontínuo) e permanente (traço contínuo).

Figura 4.33: Migração da poropressão no passo geostático

Figura 4.34: Modelo de três camadas com barreiras impermeáveis.

Tabela 4.3: Condições iniciais do modelo de três camadas

Figura 4.35: Seções A-B e C-D, pontos 1, 2 e 3, para verificação das poropressões.

Figura 4.36: Distribuição de poropressões ao longo da seção A-B

Figura 4.37: Distirbuição das poropressões ao longo da seção C-D. $\quad 81$

Figura 4.38: Pressão de injeção com e sem barreira impermeável

Figura 4.39: Abertura máxima da fratura com e sem barreira impermeável

Figura 4.40: Distribuição de poropressões ao longo da seção A-B.

Figura 4.41: Poropressão ao longo da trajetória C-D

Figura 4.42: Pressão de injeção com e sem barreira impermeável

Figura 4.43: Abertura máxima da fratura com e sem barreira impermeável.

Figura 4.44: Geometria da fratura para o caso 1.

Figura 4.45: Geometria da fratura para o caso 2.

Figura 4.46: Geometria da fratura para o caso 3.

Tabela 4.4 Anánlisis de fatores atuantes na modelagem numérica

Figura 5.1: Modelo sintético de uma camada

Figura 5.2: Abertura máxima da fratura ao longo do tempo 
Figura 5.3: Pressão no ponto de injeção ao longo do tempo 90

Figura 5.4: Comprimento da fratura ao longo do tempo 91

Figura 5.5: Abertura máxima da fratura no regime dominado pela rigidez. $\quad 92$

Figura 5.6: Pressão de injeção no regime dominado pela rigidez. $\quad 92$

Figura 5.7: Modelo de três camadas contraste simétrico de tensões 93

Figura 5.8: Comparação de resultados analíticos pela formulação de Simonson e valores numéricos obtidos pelo método dos elementos finitos.

Figura 5.9: Modelo de três camadas com contraste assimétrico de tensões

Figura 5.10: Comparação entre solução analítica de Fung e solução numérica do MEF

Figura 6.1: Efeito da viscosidade na pressão de injeção ao longo do tempo

Figura 6.2: Efeito da viscosidade na abertura máxima da fratura ao longo do tempo

Figura 6.3: Efeito da viscosidade no perfil de pressão ao longo da fratura

Figura 6.4: Efeito da viscosidade na geometria da fratura.

Figura 6.5: Efeito da vazão na resposta da pressão de injeção ao longo do tempo

Figura 6.6: Efeito da vazão sobre a abertura máxima da fratura ao longo do tempo.

Figura 6.7: Efeito da vazão no perfil da pressão ao longo do comprimento da fratura.

Figura 6.8: Efeito da vazão na geometria da fratura.

Figura 6.9: Efeito do fator de intensidade de tensões na pressão de injeção.

Figura 6.10: Efeito do fator de intensidade de tensões na abertura máxima

Figura 6.11: Efeito do fator de intensidade de tensões no perfil da pressão 
Figura 6.12: Efeito do fator de intensidade de tensões na geometria da fratura

Figura 6.13: Efeito da condutividade hidráulica na pressão de injeção 104 Figura 6.14: Efeito da condutividade hidráulica na abertura máxima da fratura

Figura 6.15: Efeito da condutividade hidráulica no perfil de pressão ao longo da fratura

Figura 6.16: Efeito da condutividade hidráulica na geometria da fratura

Figura 6.17: Efeito do modulo de Young na pressão de injeção

Figura 6.18: Efeito do módulo de Young na abertura máxima da fratura

Figura 6.19: Efeitos do módulo de Young na geometria da fratura

Figura 6.20: Efeito do módulo de Young no perfil de pressão na fratura

Figura 6.21: Efeito do coeficiente de Poisson na pressão de injeção Figura 6.22: Efeito do coeficiente de Poisson no perfil de pressões na fratura

Figura 6.23: Efeito do coeficiente de Poisson na abertura máxima da fratura.

Figura 6.24: Efeito do coeficiente de Poisson na geometria da fratura 109 


\section{Lista de tabelas}

Tabela 2.1 Comparação dos modelos analíticos 42

Tabela 4.1: Propriedades da rocha, do fluido e da fratura 57

Tabela 4.2: Terminologia assignada para cada tipo de análise $\quad 67$

Tabela 4.3: Condições iniciais do modelo de três camadas 79

Tabela 4.4 Anánlisis de fatores atuantes na modelagem numérica $\quad 87$

Tabela 6.1 Análise paramétrica 110 


\section{Introdução}

\section{1.}

\section{Definição do problema}

O fraturamento hidráulico é uma técnica utilizada para aumentar a permeabilidade por meio da injeção de um fluido sob altas pressões, com a finalidade de atingir a resistência da rocha para criar fraturas e facilitar o fluxo de fluido do reservatório para o poço produtor, como mostrado na figura 1.1.

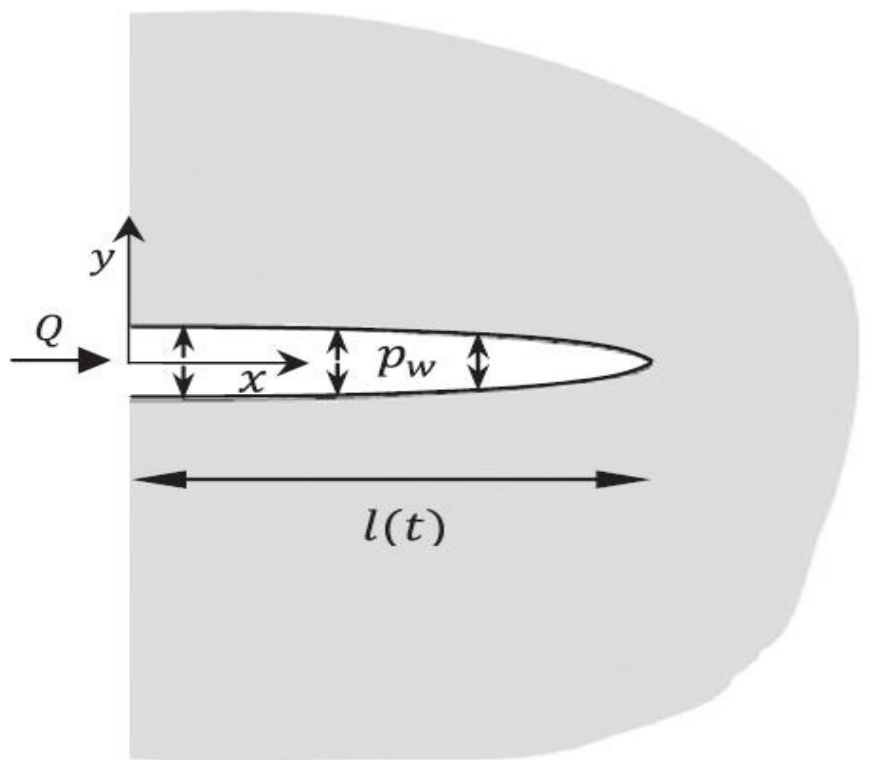

Figura 1.1: Processo de fraturamento hidráulico (Mohammadnejad et al.,2013)

O fraturamento hidráulico tem sido usado em reservatórios não convencionais como shale gás, os quais têm uma permeabilidade muito baixa e que é incrementada com o uso desta técnica; também é usado na injeção de recortes (cuttings) de perfuração, já que se faz necessário depositar os resíduos indesejados da perfuração em um local seguro sem risco de contaminação. Outra aplicação do faturamento hidráulico está no sequestro de dióxido de carbono $\mathrm{CO}_{2}$, pois após a captura do contaminante este necessita ser armazenado no subsolo por muitos anos sem risco de vazamento; além disso, a injeção de água para aumentar a recuperação de 
petróleo no reservatório pode ocasionar o fraturamento indesejável das camadas capeadoras, o que deve ser prevenido, pois romper os folhelhos capeadores comunica zonas indesejadas tornando a operação fora de controle e inviável economicamente.

No início da utilização da técnica do fraturamento hidráulico não havia ferramentas computacionais que permitissem sua modelagem, a qual resultava em problemas operacionais, geometrias de fraturas indesejadas e fraturas interceptando camadas adjacentes à zona de interesse. Por isso, foram desenvolvidas soluções analíticas para modelagem da propagação de fraturas considerando simplificações geométricas, balanço de massa e mecânica da fratura linear elástica. Os modelos analíticos mais usados são: i) o modelo de deformação plana ou KGD elaborado por Khristianovic e Zheltov (1955) e aperfeiçoado por Geertsma e de Klerk (1969), assumindo uma secção transversal retangular; ii) o modelo PKN, de Perkins e Kern (1961) e Nordgren (1972), que assume uma fratura de secção transversal elíptica de altura constante no estado plano de deformação; iii) penny shaped ou modelo radial, propagando a fratura perpendicular e simetricamente com respeito ao poço.

Com o desenvolvimento de ferramentas computacionais como o método de elementos finitos, a propagação de fraturas induzidas hidraulicamente pode ser modelada mais realisticamente, com a consideração de elementos de interface (elementos coesivos) para tratar do problema da singularidade na ponta da fratura, porém com a desvantagem de assim se predefinir a direção de propagação. Tem-se também o método dos elementos finitos estendido no qual a direção da propagação da fratura é parte da solução, pois os elementos são enriquecidos com graus de liberdade de funções especiais de deslocamento. Estas soluções numéricas permitem determinar as condições de maior efetividade da operação.

Neste trabalho será analisada a técnica de fraturamento hidráulico com a finalidade de melhor compreender a interação entre a rocha e o fluido injetado, mediante o uso do método dos elementos finitos, utilizando o modelo de zona coesiva para simulação da propagação da fratura. Resultados numéricos e analíticos assim obtidos podem auxiliar no planejamento de operações de fraturamento hidráulico, propiciando um melhor conhecimento das condições de propagação da fratura nas camadas capeadoras adjacentes à zona de interesse, e assim reduzindo as incertezas associadas ao processo de fraturamento hidráulico. 


\section{2. \\ Motivação e Objetivos}

Neste trabalho pretende-se compreender a influência dos fatores atuantes no fraturamento hidráulico por meio de uma modelagem hidromecânica acoplada, empregando o método dos elementos finitos com o modelo de zona coesiva.

Este tipo de análise permite representar de forma mais realista o comportamento da fratura, projetar adequadamente a operação de injeção e estudar a resposta da rocha, com a finalidade de obter o cenário de maior eficiência volumétrica para o fraturamento hidráulico.

Com a finalidade de atingir este objetivo é necessário considerar as seguintes etapas de trabalho:

- Realizar uma revisão bibliográfica, estudando as equações governantes que descrevem de forma matemática o processo de fraturamento hidráulico.

- Compreender os modelos analíticos de propagação de fraturas, suas hipóteses, vantagens e limitações.

- $\quad$ Estudar o método de elementos finitos com o modelo de zona coesiva;

- Entender e usar o software comercial Abaqus para modelar computacionalmente o fraturamento hidráulico.

- Validar e comparar os resultados numéricos com as soluções analíticas disponíveis na literatura.

\section{3.}

\section{Estrutura da dissertação}

Este trabalho está estruturado em 7 capítulos, incluindo esta introdução como capitulo 1. No capítulo 2 apresenta-se a revisão bibliográfica correspondente as equações governantes que descrevem matematicamente o processo de faturamento hidráulico. Sumarizam-se os modelos analíticos mais relevantes de propagação de fraturas bidimensionais, cujas hipóteses estabelecem as condições iniciais dos modelos numéricos, necessárias para fazer mais tarde a comparação entre resultados de soluções analítica e numérica. Apresenta-se também a formulação numérica dos regimes de propagação de fratura, especialmente o regime dominado pela rigidez (vértice-K).

No capítulo 3, descreve-se o método de elementos finitos com modelo de zona coesiva, informando como é feita a modelagem computacional do 
fraturamento hidráulico no software comercial Abaqus, apresentando as propriedades necessárias para modelar a rocha intacta, o fluido de fraturamento hidráulico e o modelo coesivo para caracterização da fratura.

No capítulo 4, ilustram-se alguns tópicos relacionados com a malha de elementos finitos, tipos e passos da análise, sub-rotinas programadas em linguagem Fortran e tipos de controle na injeção do fluido, logo são analisados aspectos da modelagem numérica como o modelo coesivo, regularização viscosa, analise transiente e permanente, e o modelo de três camadas com barreiras impermeáveis.

No capítulo 5, é feita a validação do modelo numérico comparando seus resultados com aqueles obtidos com o modelo analítico KGD. Apresenta-se a validação do modelo de uma camada com a solução analítica no regime de propagação de fratura dominado pela rigidez (vértice K), e por último, mostra-se a comparação dos modelos analíticos de Simonson (1978) e Fung (1987) com o numérico.

No capítulo 6, apresenta-se as análises paramétricas para investigação dos fatores influentes no processo de fraturamento hidráulico.

Finalmente, o capitulo 7 discute as principais conclusões desta dissertação e sugere alguns temas para pesquisas futuras nesta área. 


\section{2 Revisão bibliográfica}

Neste capitulo apresentam-se alguns conceitos básicos para o entendimento do tratamento do fraturamento hidráulico, tal como as equações governantes utilizadas para modelar a iniciação e propagação de fraturas, tensões e deformações desenvolvidas durante o processo e o fluxo de fluido no interior e fora da fratura. Também se descrevem os modelos analíticos mais relevantes que permitem determinar a geometria da fratura e poropressão nela gerada. Por último, apresentase o modelo analítico de acordo com o regime de propagação de fratura dominado pela rigidez (vértice $\mathrm{K}$ ).

\section{1. Equações governantes do fraturamento hidráulico}

Para a descrição matemática do fraturamento hidráulico como um processo hidromecânico acoplado são necessárias as equações da teoria da poroelasticidade de Biot para o material sólido, a lei de Darcy para o fluxo de fluido através do meio poroso, a teoria da lubrificação de Reynolds para o fluxo no interior da fratura e o modelo da zona coesiva para caracterizar a propagação da fratura (Zielonka 2014, Charlez 1997). Estas equações são resumidamente apresentadas a seguir.

\subsection{1. Deformação do meio poroso}

O meio poroso pode ser modelado como um material isotrópico e poroelástico, com a equação de equilíbrio, na ausência de forças de corpo, expressa por:

$\sigma_{i j, j}=0$

Onde $\sigma_{i j}$ representa o tensor das tensões na notação indicial. 
A relação constitutiva poroelástica, assumindo pequenas deformações, é dada por:

$$
\begin{aligned}
& \sigma_{i j}-\sigma_{i j}^{0}=2 G \varepsilon_{i j}+\varepsilon_{k k}\left(K-\frac{2}{3} G\right)-\alpha \delta_{i j}\left(p-p_{0}\right) \\
& G=\frac{E}{2(1+v)} \\
& K=\frac{E}{3(1-2 v)}
\end{aligned}
$$

Onde $\alpha$ é o coeficiente de Biot, G e K são os módulos de cisalhamento e de variação volumétrica, respectivamente, E o módulo de Young, $v$ é o coeficiente de Poisson, $p$ a poropressão atual e $p_{0}$ a poropressão inicial, $\sigma_{i j}$ a tensão total atual e $\sigma_{i j}^{0}$ a tensão total inicial. Tensões compressivas são consideradas negativas e tensões de tração positivas.

As tensões efetivas de Terzaghi definidas para um meio totalmente saturado são da forma,

$$
\sigma_{i j}^{\prime}=\sigma_{i j}+p \delta_{i j} \quad \text { e } \quad \sigma_{i j}^{\prime 0}=\sigma_{i j}^{0}+p_{0} \delta_{i j}
$$

Substituindo as equações (2.5) na (2.2) tem-se:

$$
\sigma_{i j}^{\prime}-\sigma_{i j}^{\prime 0}=2 G \varepsilon_{i j}+\varepsilon_{k k} \delta_{i j}\left(K-\frac{2}{3} G\right)-(\alpha-1) \delta_{i j}\left(p-p_{0}\right)
$$

As deformações efetivas são definidas como:

$$
\varepsilon_{i j}^{\prime}=\varepsilon-\frac{\alpha-1}{3 K} \delta_{i j}\left(p-p_{0}\right)
$$

A equação constitutiva fica como segue:

$$
\sigma_{i j}^{\prime}-\sigma_{i j}^{\prime 0}=2 G \varepsilon_{i j}^{\prime}+\varepsilon_{i j}^{\prime} \delta_{i j}\left(K-\frac{2}{3} G\right)
$$


Esta equação é idêntica à relação constitutiva para materiais linearmente elásticos (lei de Hooke generalizada), expressa em termos de tensões efetivas de Terzaghi e de deformações efetivas.

\subsection{2.}

\section{Fluxo de fluido no meio poroso}

A equação de continuidade para o fluido no meio poroso assumindo pequenas deformações volumétricas é dada por Zielonka et al, (2014):

$\frac{1}{M} \dot{p}+\alpha \dot{\varepsilon}_{k k}+v_{k, k}=0$

Onde $v_{k}$ é a velocidade de fluxo do fluido no meio poroso e $\mathrm{M}$ e $\alpha$ são o módulo de Biot e o coeficiente de Biot, respectivamente. Estas duas constantes poroelásticas são definidas por:

$\frac{1}{M}=\frac{\phi_{0}}{k_{f}}+\frac{\alpha-\phi_{0}}{k_{s}}$

$\frac{1}{k_{s}}=\frac{1-\alpha}{K}$

Onde $k_{f}$ é o módulo de variação volumétrica do fluido, $k_{s}$ é o módulo de variação volumétrica dos grãos sólidos e $\phi_{0}$ a porosidade inicial. O fluxo do fluido através de um meio com poros interconectados é governado pela lei de Darcy:

$v_{i}=-\bar{k} i$

Onde $\bar{k}$ é a condutividade hidráulica e $i$ é o gradiente hidráulico. Substituindo a equação (2.12) em (2.9) tem-se:

$\frac{1}{M} \dot{p}+\alpha \dot{\varepsilon}_{k k}=\bar{k} i$ 


\subsection{3.}

\section{Fluxo do fluido no interior da fratura}

O fluxo unidimensional do fluido no interior da fratura é governado pela teoria de lubrificação de Reynolds, conforme equação de continuidade Zielonka et al, (2014)

$$
\dot{W}+\frac{\partial Q}{\partial s}+v_{T}+v_{B}=0
$$

Onde $\dot{W}=\partial W / \partial t$ é a variação da abertura da fratura com o tempo, $Q$ a vazão do fluido de faturamento por unidade de comprimento e $v_{T}$ e $v_{B}$ as velocidades normais nas faces superior e inferior da fratura.

A equação de momentum para um fluido incompressível e Newtoniano através de placas estreitas paralelas (i.e., fluxo de Poiseuille) é descrita por Zielonka et al, (2014):

$$
Q=-\frac{W^{3}}{12 \mu} \frac{\partial p_{f}}{\partial s}
$$

Onde $Q$ é vazão, $\mu$ é a viscosidade dinâmica do fluido de fraturamento e $p_{f}$ é a pressão do fluido sobre a superfície da fratura, parametrizada com a coordenada curvilínea s, como mostra a figura 2.1.

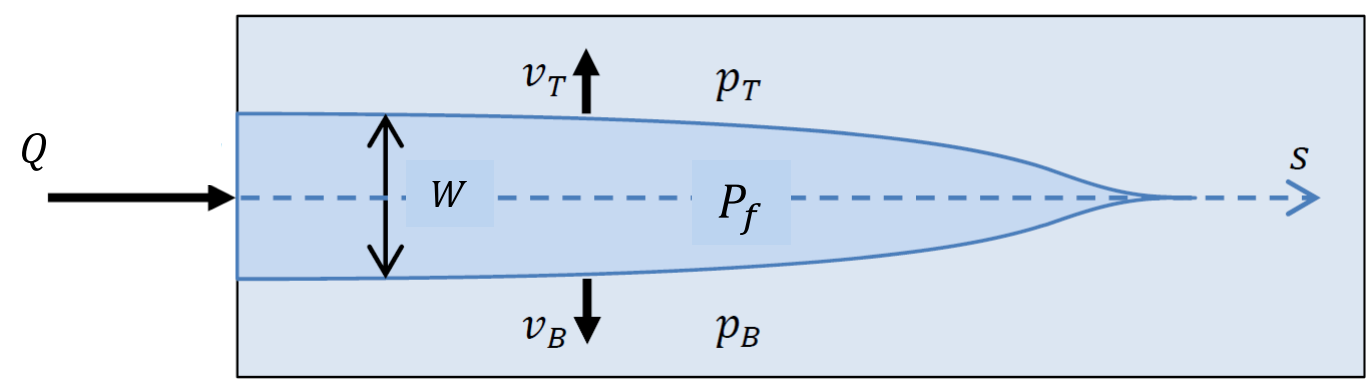

Figura 2.1: Abertura da fratura e o fluxo do fluido fraturante (Zielonka, 2014)

As velocidades normais do fluido podem ser calculadas pelas seguintes expressões Zielonka (2014):

$$
v_{T}=C_{T}\left(p_{f}-p_{T}\right)
$$


$v_{B}=C_{B}\left(p_{f}-p_{B}\right)$

Onde $p_{T}$ e $p_{B}$ são as pressões do fluido no meio poroso nas superfícies do topo e do fundo da fratura e $C_{T}$ e $C_{B}$ são coeficientes de filtração (dependendo da infiltração de fluido da fratura para o meio poroso circundante). Este modelo simples de filtração simula uma camada de material (cake) que poderia acumular e reduzir a permeabilidade efetiva normal às superfícies da fratura (Abaqus, 2014). Incluindo a equação de fluxo de Poiseuille e o modelo simplificado de filtração na equação de continuidade (2.14) para o fluido de faturamento, tem-se finalmente a equação diferencial do fluxo no interior da fratura:

$$
\dot{W}+C_{T}\left(p_{f}-p_{T}\right)+C_{B}\left(p_{f}-p_{B}\right)=\frac{\partial}{\partial s}\left(\frac{W^{3}}{12 \mu} \frac{\partial p_{f}}{\partial s}\right)
$$

\subsection{4.}

\section{Propagação da fratura}

O fraturamento hidráulico é a transição entre dois estados limites: o estado intacto com deslocamentos contínuos e tensões não nulas em todos os pontos e o estado totalmente danificado caracterizado pela presença de uma descontinuidade no campo de deslocamentos ao longo da interface do material, com tensões nulas na direção normal à interface. Este processo de transição é modelado como uma degradação progressiva da resistência coesiva do material ao longo de uma interface de espessura zero, cuja orientação e tamanho é predefinido no modelo de zona coesiva. A perda gradual da resistência na interface com o aumento da separação das superfícies da fratura é definida via uma relação tensão de tração versus separação da interface ou lei coesiva (Abaqus 2014, Ortiz 1999). A lei coesiva será discutida com mais detalhes no terceiro capitulo.

\section{2. Modelos analíticos de fraturas induzidas hidraulicamente}

As características de dimensão e propagação de uma fratura hidráulica são informações fundamentais para um projeto de fraturamento hidráulico. O conhecimento das propriedades da rocha, do fluido de fraturamento e da magnitude 
e direção das tensões in-situ é primordial para uma boa previsão das dimensões (abertura, comprimento e altura) da fratura produzida para uma dada vazão de injeção e tempo. Vários modelos analíticos de fratura foram desenvolvidos com este propósito, apresentados nas próximas seções.

\subsection{1.}

\section{Sneddon (1946) e Sneddon \& Elliot (1946)}

Os trabalhos de Sneddon (1946) apresentam soluções para o campo de tensões e pressão associadas com fraturas estáticas pressurizadas baseadas na teoria de elasticidade linear. Mostraram que a abertura de uma fratura estática pennyshaped (i.e., circular) de raio R sob pressão constante é dada por:

$$
W(r)=\frac{8 P_{e f e} R\left(1-v^{2}\right)}{\pi E} \sqrt{1-(r / R)^{2}}
$$

$\mathrm{O}$ volume da fratura $\mathrm{V}$, correspondente ao volume de um elipsoide, é descrito por:

$$
V=\frac{16 R^{3}\left(1-v^{2}\right)}{3 E} P_{l i q}
$$

Onde a pressão liquida $\mathrm{P}_{\text {liq }}$ (net pressure) é definida como a pressão na fratura menos a tensão de confinamento atuante nas faces das fraturas, E é o modulo de Young e $v$ é o coeficiente de Poisson.

Sack (1946) mostrou que a pressão requerida para estender uma fratura de raio $\mathrm{R}$ sob pressão constante é dada por:

$$
P_{\text {liq }}=\sqrt{\frac{\pi \gamma_{f} E}{2 R\left(1-v^{2}\right)}}
$$

Onde $\gamma_{f}$ é a energia específica da superfície da fratura. A equação (2.21) foi derivada usando a mecânica da fratura linear elástica, admitindo que a energia 
requerida para propagar a fratura deve igualar ao trabalho feito pela pressão sobre as superfícies da fratura para uma abertura adicional (Economides e Nolte, 2000). Com base nas equações (2.20) e (2.21), Perkins e Kern (1961) mostraram que a pressão para propagação de uma fratura radial é dada por:

$$
P_{\text {efe }}=\left(\frac{2 \pi^{3} \gamma_{f}^{3} E^{2}}{3 V\left(1-v^{2}\right)^{2}}\right)^{1 / 5}
$$

Assim, se o volume da fratura for conhecido $\mathrm{V}, P_{\text {efe }}$ pode ser calculado e a equação (2.20) usada para determinar R. Por exemplo, se a taxa de injeção $q_{i}$ for constante, o atrito do fluido na fratura for desprezível e não houver ocorrência de filtração (leakoff), então substituindo a equação (2.22) na equação (2.20) com o volume V substituído por $Q t$, obtém-se que:

$$
Q t=\frac{16 R^{3}\left(1-v^{2}\right)}{3 E}\left(\frac{2 \pi^{3} \gamma_{f}^{3} E^{2}}{3 Q t\left(1-v^{2}\right)^{2}}\right)^{\frac{1}{5}}
$$

Onde t é o tempo. Reorganizando em função de R,

$$
R=\left[\frac{9 E Q^{2} t^{2}}{128 \pi \gamma_{f}\left(1-v^{2}\right)}\right]^{\frac{1}{5}}
$$

Sneddon e Elliot (1946) também mostraram que para fraturas de altura fixa $h_{f}$ e extensão infinita (estado plano de deformação) a abertura máxima é:

$$
W=\frac{2 P_{n e t} h_{f}\left(1-v^{2}\right)}{E}
$$

A forma da fratura é elíptica, de tal modo que a abertura média é equivalente a $\bar{W}=(\pi / 4) W$. O termo $E /\left(1-v^{2}\right)$, que aparece comumente nas equações de fraturamento hidráulico, é convenientemente substituído pelo módulo de elasticidade no estado plano de deformação $E^{\prime}$ definido como: 
$E^{\prime}=\frac{E}{1-v^{2}}$

A hipótese de estado plano de deformação é geralmente adequada para fraturas nas quais uma dimensão (comprimento ou altura) é muito maior que a outra (Economides e Nolte, 2000).

\subsection{2.}

Modelo de Khristianovic-Geertsma-de Klerk (KGD)

Os primeiros trabalhos sobre modelagem de fraturamento hidráulico foram desenvolvidos por pesquisadores russos resumidos por Khristianovich et al, (1959). A primeira referência em inglês foi o artigo de Khristianovich e Zheltov (1955), com consideração de conceitos da mecânica da fratura e certas suposições a respeito do fluxo de fluido. Este trabalho foi desenvolvido para calcular a abertura da fratura para uma vazão e comprimento específico, porém o balanço de volume no interior da fratura não é satisfeito. Carter (1957) introduziu um modelo que satisfaz o balanço de volume, mas assume uma abertura constante e uniforme.

Estas hipóteses limitantes do modelo de modelo de Khristianovich e Zheltov (1955) foram retiradas por Geertsma e de Klerk (1969), dando origem ao modelo atualmente conhecido como KGD, com as seguintes características (Figura 2.2):

- Aplicável somente para fraturas totalmente confinadas;

- Altura da fratura constante;

- Seção transversal retangular;

- Estado plano de deformação (no plano horizontal);

- A extremidade da fratura é pontiaguda, conforme modelo de Barrenblatt (1962), para remoção da singularidade de tensões na extremidade da fratura;

- A altura da fratura é muito maior do que seu comprimento;

- Vazão considerada constante na fratura sob fluxo 1D;

- Fluido fraturante é newtoniano;

- Rocha continua, homogênea, linearmente elástica; 


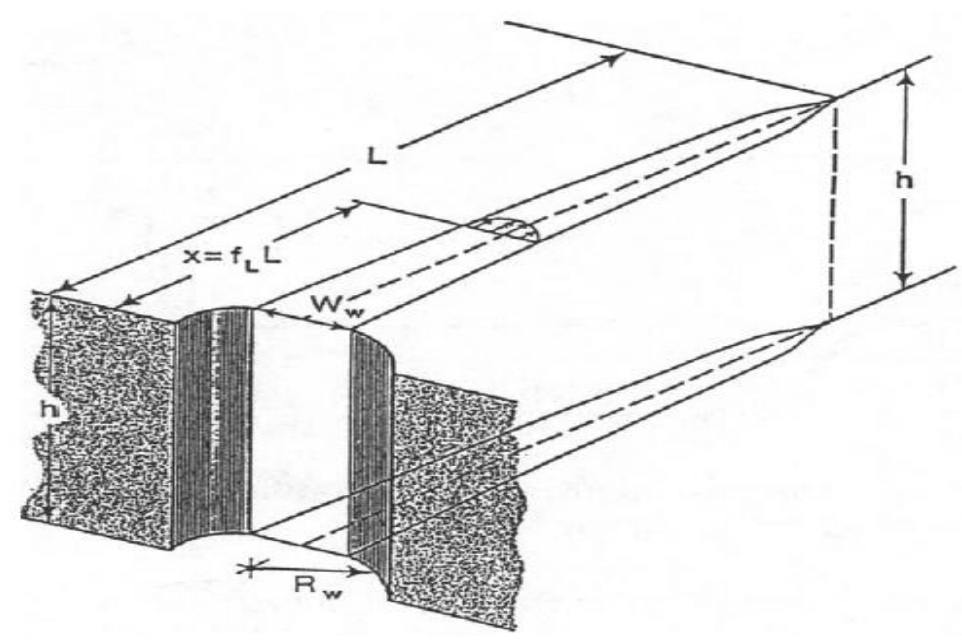

Figura 2.2: Modelo KGD (Yew, 1997)

Assumindo-se a existência de uma pequena área seca nas proximidades da ponta da fratura (fluid lag), e que o formato desta área possa ser aproximado por uma elipse, as seguintes soluções aproximadas (sem filtração ou leakoff) foram

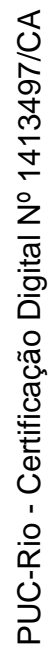
obtidas por Geertsma e de Klerk (1979):

- Comprimento da fratura:

$L=0.48\left[\frac{8 G Q^{3}}{\mu(1-v)}\right]^{1 / 6} t^{2 / 3}$

- Máxima abertura da fratura:

$W=1.32\left[\frac{8(1-v) \mu Q^{3}}{G}\right]^{1 / 6} t^{1 / 3}$

○ Pressão de injeção:

$P_{w}=\sigma_{\min }+0.96\left[\frac{2 Q \mu G^{3}}{(1-v)^{3} L^{2}}\right]^{1 / 4}$

Onde $Q$ é a vazão, $\mu$ é a viscosidade dinamica, $G$ módulo de cisalhamento, $v$ é o coeficiente de Poisson, $\sigma_{\min }$ é a tensão horizontal mínima, $L$ é o comprimento da fratura calculado com a equação (2.27), e $t$ é o tempo. 
Verifica-se que a máxima abertura de fratura aumenta proporcionalmente a $t^{1 / 3}$ e que a pressão no poço decresce com o aumento do comprimento da fratura, aproximando-se do valor insitu de $\sigma_{\min }$ para grandes valores de L. Por assumir a condição de deformação plana, o modelo KGD se adapta melhor a fraturas cuja altura é maior que o comprimento da fratura

\subsection{3. \\ Modelo Perkins-Kern-Nordgren (PKN)}

Perkins e Kern (1961) assumiram que a mecânica da fratura não era o fator mais importante e focalizaram na influência do fluxo de fluidos. Este trabalho foi desenvolvido para calcular a abertura para uma vazão e comprimento predeterminados sem satisfazer o balanço de volume no interior da fratura.

Essa última hipótese foi removida por Nordgren (1972) do modelo de Perkins e Kern (1969), dando origem ao modelo hoje conhecido como PKN. Os efeitos da ponta da fratura não são considerados pois, como já mencionado, o foco do modelo está no fluxo de fluido e os correspondentes gradientes de pressão. Suas principais características são (Figura 2.3):

- Aplicável somente para fraturas totalmente confinadas;

- Altura da fratura constante (h);

- Seção transversal elíptica;

- $\quad$ Estado plano de deformação (plano vertical);

- Altura da fratura muito menor comparado com seu comprimento;

- Vazão constante na fratura e fluxo 1D;

- Fluido fraturante é newtoniano;

- Rocha contínua, homogênea, linearmente elástica; 


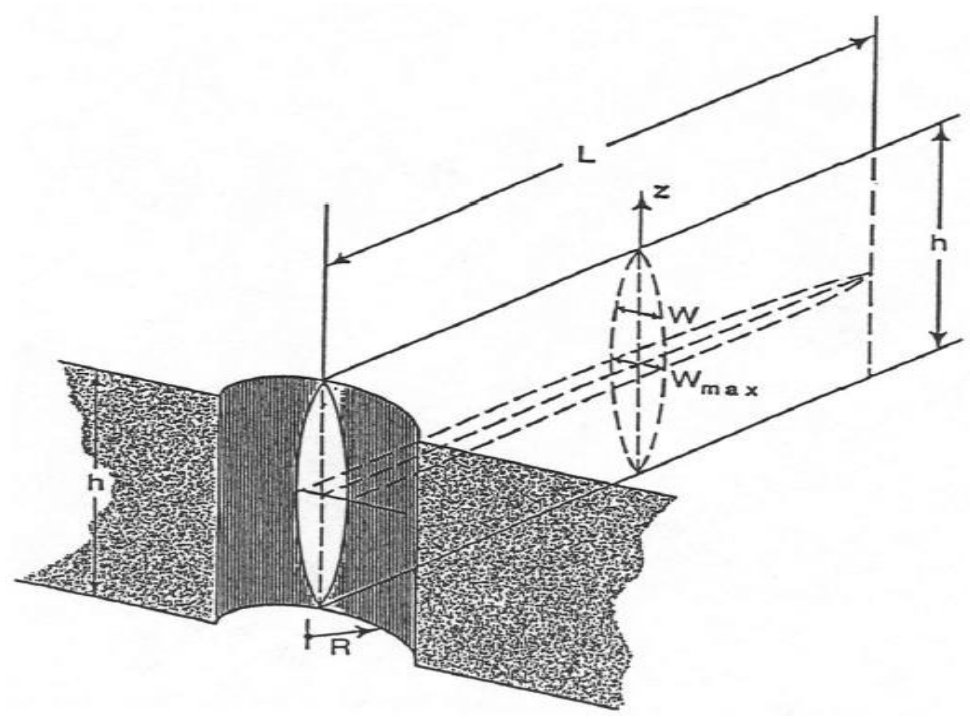

Figura 2.3: Modelo PKN (Yew, 1997)

Nordgren (1972) obteve soluções para dois casos limites considerando

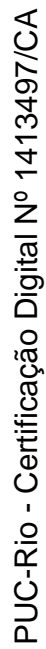
situações com eficiência volumétrica tendendo a zero ou tendendo a um.

○ Eficiência volumétrica tendendo a zero:

- Comprimento da fratura:

$L=\frac{Q}{\pi c_{l} h} t^{1 / 2}$

- Abertura da fratura:

$W=4\left[\frac{2(1-v) \mu Q^{2}}{\pi^{3} G c_{l} h}\right]^{1 / 4} t^{1 / 8}$

- Pressão de injeção:

$P_{w}=4\left[\frac{2 G^{3} \mu Q^{2}}{\pi^{3}(1-v)^{3} c_{l} h^{5}}\right]^{1 / 4} t^{1 / 8}$ 
○ Eficiência volumétrica alta tendendo a um:

- Comprimento da fratura:

$L=0.68\left[\frac{G Q^{3}}{(1-v) \mu h^{4}}\right]^{1 / 5} t^{4 / 5}$

- Abertura da fratura:

$W=2.5\left[\frac{(1-v) \mu Q^{2}}{G h}\right]^{1 / 5} t^{1 / 5}$

- Pressão de injeção:

$P_{w}=2.5\left[\frac{G^{4} \mu Q^{2}}{(1-v)^{4} h^{6}}\right]^{1 / 5} t^{1 / 5}$

Onde $Q$ é a vazão, $\mu$ é a viscosidade dinamica, $G$ módulo de cisalhamento, $v$ o coeficiente de Poisson, $t$ o tempo, e $c_{l}$ o coeficiente de filtração de Carter.

Devido à hipótese de estado plano deformação (plano vertical), o modelo PKN tem sido geralmente considerado adequado para fraturas com relação comprimento/altura $(\mathrm{L} / \mathrm{h})$ grande. É interessante notar que a pressão de poço prevista pelo modelo PKN, ao contrário do modelo KGD, cresce com o aumento do comprimento da fratura.

\subsection{4.}

\section{Penny-Shaped ou modelo radial}

Este modelo assume uma fratura propagando em dado plano, simetricamente em relação a um eixo (poço), como mostra a Figura 2.4, num meio elástico infinito e impermeável, caracterizado pelo modulo de Young E, coeficiente de Poisson v e fator de intensidade de tensão no modo $1 K_{1 c}$ 


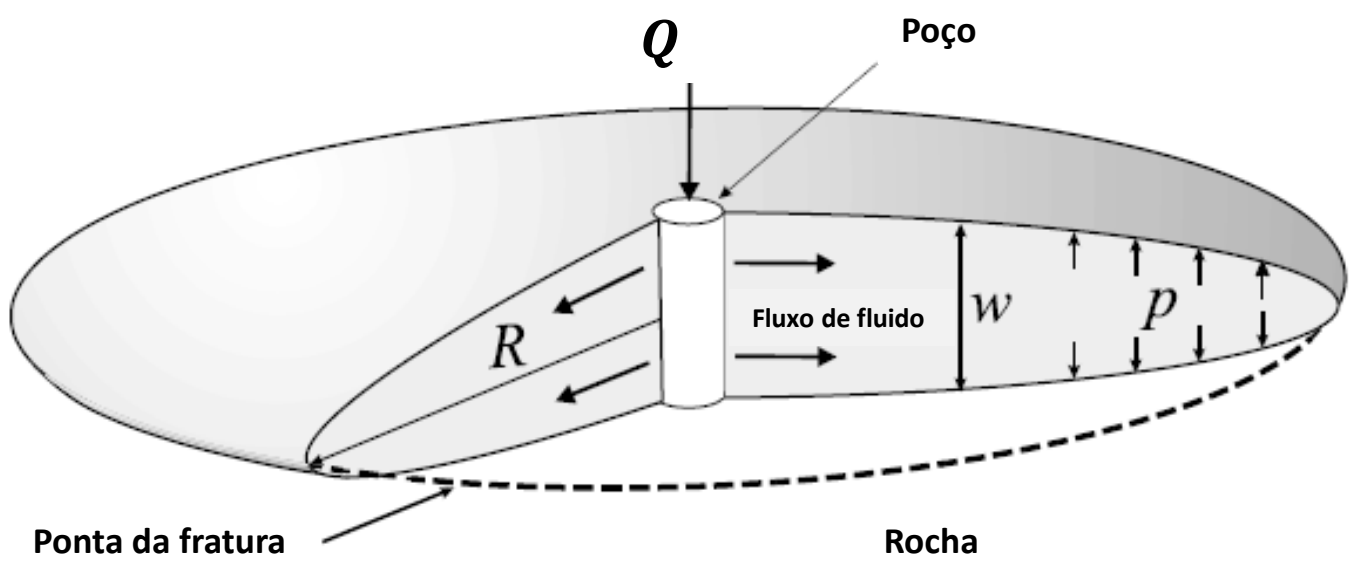

Figura 2.4: Fratura radial (Savitski \& Detournay, 2002.)

Neste modelo um fluido incompressível newtoniano com viscosidade dinâmica $\mu$ é injetado no centro da fratura sob vazão constante $Q$. Pretende-se determinar o raio da fratura $R(t)$ e a abertura da fratura $w(r, t)$ como função da coordenada radial $\mathrm{r}$ e do tempo $\mathrm{t}$.

As seguintes hipóteses são admitidas:

- O fluido é injetado a partir de uma fonte pontual (i.e., o raio do poço é desprezível comparado com o raio da fratura);

- A frente da fratura coincide com a ponta da fratura (i.e., o espaço entre a ponta da fratura e a frente do fluido é muito pequeno comparado com o raio da fratura);

- A fratura se propaga continuamente em equilíbrio quase estático $\left(K_{1 c}=K_{1}\right)$.

- A teoria da lubrificação de Reynolds é aplicável.

Tanto Perkins e Kern (1961) e Geertsma e de Klerk (1969) consideraram fratura radiais que crescem a partir de ponto inicial. Este modelo é aplicável em situações onde não há barreiras restringindo o crescimento da altura da fratura ou para fratura horizontal. Geertsma e de Klerk (1969) formularam o modelo radial com a abertura da fratura dada por:

$$
W=2.56\left[\frac{\mu Q R}{E^{\prime}}\right]^{1 / 4}
$$


E o comprimento radial dado por:

$$
R=\sqrt{\frac{Q_{0}\left(4 W+15 S_{p}\right)}{30 \pi^{2} C_{L}^{2}}\left(e^{s^{2}} \operatorname{erfc}(S)+\frac{2}{\sqrt{\pi}} S-1\right)}
$$

Onde $S_{p}$ é o coeficiente de perda de fluido antes da formação do material (cake), $C_{L}$ é o coeficiente de filtração de Carter, $\operatorname{erf} c$ é a função de erro complementar e a variável S expressa por:

$$
S=\frac{15 C_{L} \sqrt{\pi t}}{4 W+15 S_{p}}
$$

Uma relação explicita para a pressão pode ser derivada considerando que a pressão na fratura seja uma função de $\ln \left(r_{w} / R\right)$, onde $r_{w}$ é o raio do poço (Economides, 2000).

$$
P_{w}=S-\frac{5}{4 \pi} \frac{G W}{R} \ln \left(\frac{r_{w}}{R}\right)
$$

As aproximações para o modelo radial no caso sem perda de fluido (sem leakoff) são:

$$
\begin{aligned}
& W=2.17\left[\frac{\mu^{2} Q^{3}}{E^{\prime 2}}\right]^{1 / 9} t^{1 / 9} \\
& R=0.52\left[\frac{E^{\prime} Q^{3}}{\mu}\right]^{1 / 9} t^{4 / 9}
\end{aligned}
$$

Já para o modelo radial no caso com leakoff as aproximações são:

$$
R=\frac{1}{\pi}\left[\frac{Q^{2} t}{C_{L}^{2}}\right]^{1 / 4}
$$


Para cálculo da abertura pode-se substituir a equação (2.42) na equação (2.36).

\subsection{5.}

\section{Simonson (1978)}

Este autor considerou o caso de uma fratura hidráulica que pode estender-se por camadas adjacentes, com contraste de tensões simétricos (contraste com a camada superior igual ao contraste com a camada adjacente inferior). O fator de intensidade de tensão em cada extremo da fratura pode ser determinado pela superposição de dois problemas, como mostra a Figura 2.5.

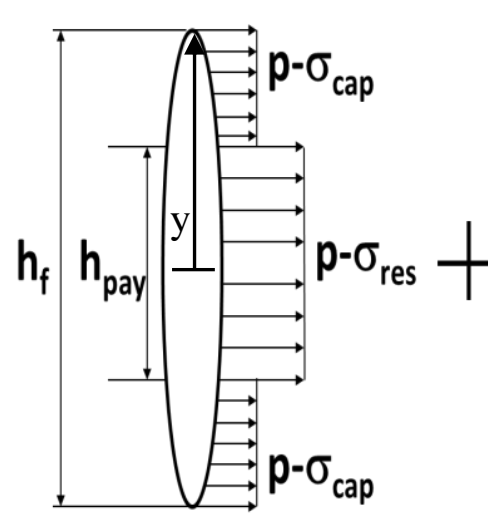

(A)

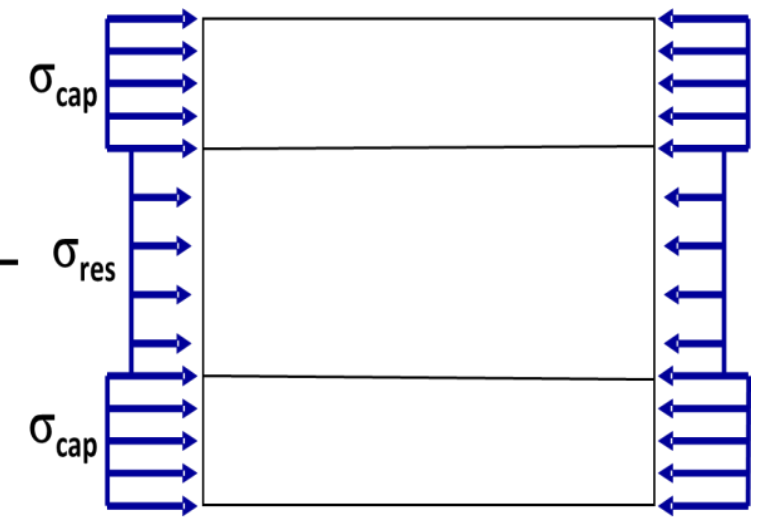

(B)

Figura 2.5: Superposição de carregamentos (modificado de Simonson, 1978)

O fator de intensidade de tensões $K_{I}$ é a soma das contribuições dos carregamentos (A) e (B) da Figura 2.5, porém a contribuição do carregamento (B) é nula. $\mathrm{O}$ valor de $K_{I}$ pode ser calculado então diretamente com a seguinte equação ( Rice, 1962):

$$
K_{I}=\frac{1}{\sqrt{\pi\left(\frac{h_{f}}{2}\right)}} \int_{-h_{f} / 2}^{h_{f} / 2} P(y) \sqrt{\frac{\left(h_{f} / 2\right)+y}{\left(h_{f} / 2\right)-y}} d y
$$

Onde 
$P(y)=\left\{\begin{array}{cc}P-\sigma_{\text {cap }} & h_{\text {pay }} / 2<y<h_{f} / 2 \\ P-\sigma_{\text {res }} & -h_{\text {pay }} / 2<y<h_{\text {pay }} / 2 \\ P-\sigma_{\text {cap }} & -h_{\text {pay }} / 2<y<-h_{f} / 2\end{array}\right.$

Substituindo a equação (2.44) na equação (2.43) e resolvendo a integração, obtem-se para $K_{I}$ :

$$
K_{I}=\left(\sigma_{\text {cap }}-\sigma_{\text {res }}\right) \sqrt{\frac{h_{f} / 2}{\pi}}\left\{2 \sin ^{-1}\left(\frac{h_{p a y} / 2}{h_{f} / 2}\right)\right\}+\left(P-\sigma_{\text {cap }}\right) \sqrt{\pi h_{f} / 2}
$$

Se considerarmos a relação $h_{f}=h_{\text {pay }}+\varepsilon h_{\text {pay }}$, onde $\varepsilon$ é a fração de distância que a fratura se propaga no interior de camadas adjacentes, é possível obter da equação (2.45) que:

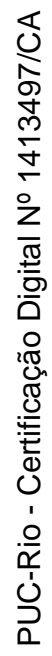

$$
\frac{1}{1+\varepsilon}=\cos \left[\frac{K_{I}-\left(P-\sigma_{\text {res }}\right) \sqrt{\pi\left(h_{\text {pay }} / 2\right)(1+\varepsilon)}}{2\left(\sigma_{\text {cap }}-\sigma_{\text {res }}\right) \sqrt{\left(h_{\text {pay }} / 2\right)(1+\varepsilon)}}\right]
$$

Se $\mathrm{P}$ for a pressão requerida para propagar a fratura quando $\varepsilon=0$ e $K_{I}=K_{I C}$ (valor critico de $K_{I}$ na ponta da fratura pelo qual a propagação da fratura começa), então:

$$
P=\sigma_{r e s}+\frac{K_{1 c}}{\sqrt{\pi\left(\frac{h_{f}}{2}\right)}}
$$

Considere o cenário de um conjunto simétrico de três camadas horizontais e homogêneas, submetidas a um contraste de tensões horizontais $\left(\Delta \sigma=\sigma_{\text {cap }}-\sigma_{\text {res }}\right)$ conforme mostra a Figura 2.6. Se a força gravitacional for desconsiderada, então a penetração da fratura nas duas camadas (superior e inferior) é a mesma. 


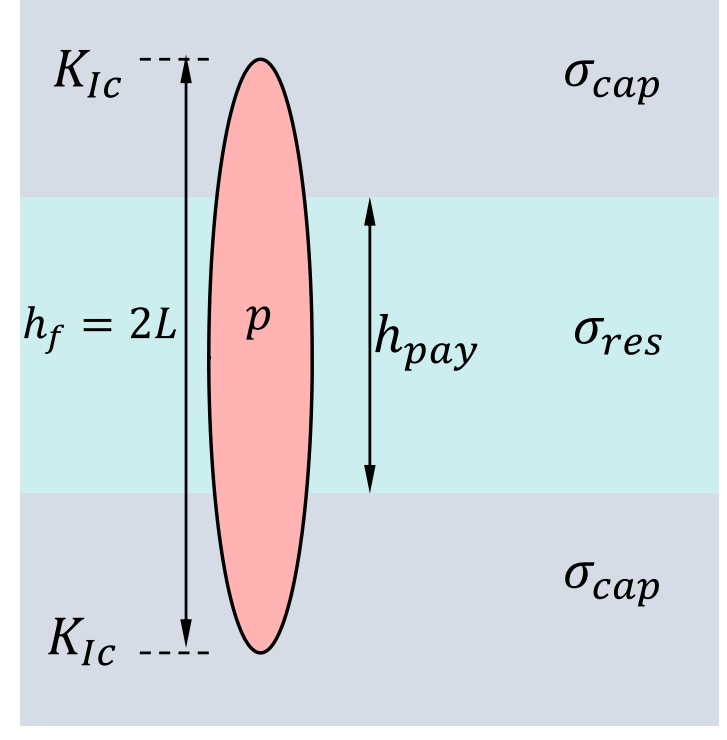

Figura 2.6: Modelo de Simonson (modificado do Simonson, 1978)

Para esse caso, Simonson et al. (1978) derivaram uma solução em função da pressão, das tensões in-situ, do fator de intensidade de tensão e da altura da fratura, pela substituição da equação (2.47) na equação (2.46), para obter:

$$
P=\sigma_{r e s}+\frac{K_{1 c}}{\sqrt{\pi L}}+\frac{2\left(\sigma_{c a p}-\sigma_{r e s}\right)}{\pi} \cos ^{-1}\left(\frac{h_{p a y}}{2 L}\right)
$$

\subsection{6.}

\section{Fung et al (1987)}

A partir do trabalho de Simonson (1978), Fung et al. (1987) generalizaram uma solução de propagação da fratura com um procedimento semi-analítico, que permite calcular a extensão de uma fratura vertical em um reservatório homogêneo com distribuição de tensões horizontais arbitrárias (contraste assimétrico de tensões). Geralmente, as propriedades de um reservatório e a distribuição das tensões in-situ horizontais não são simétricas, o que torna o problema muito mais complexo do que o caso simétrico devido à necessidade de se incluir um grau de liberdade extra nas análises. No caso simétrico, a altura da fratura é um eixo de simetria vertical, enquanto no caso assimétrico esta não é conhecida e varia à medida que a fratura cresce, como mostra a Figura 2.7. 


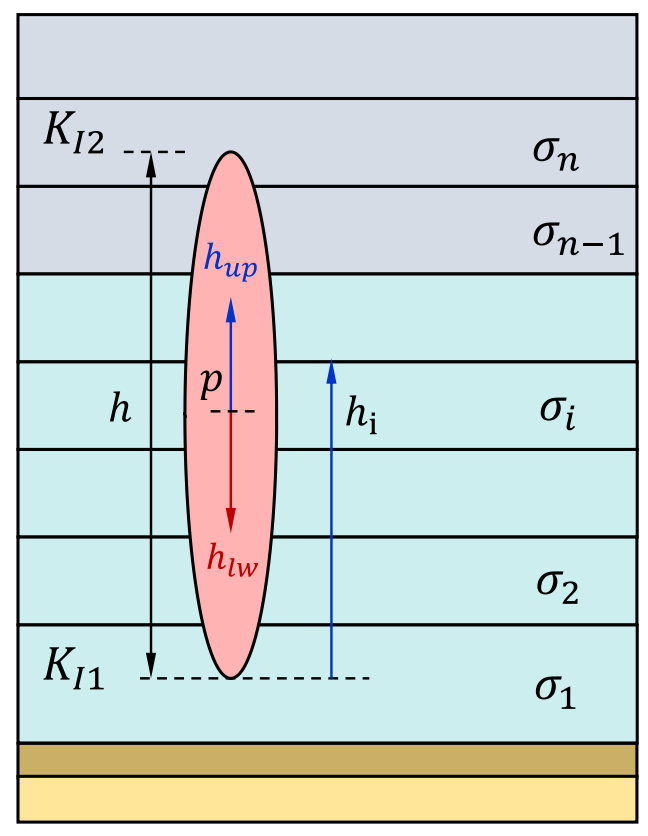

Figura 2.7: Modelo de Fung et al. (modificado de Fung et al, 1987)

As hipóteses do modelo são: fratura vertical, estado plano de deformação, o modelo é válido para fraturas com comprimento muito maior comparado com sua altura, o perfil vertical da distribuição de pressão no interior da fratura é aproximadamente hidrostático, a fratura está em equilíbrio com respeito a movimentos verticais da ponta da fratura, o campo de tensões tectônicas está composto de muitas camadas de tensões uniformes verticalmente (Fung et al, 1987).

$\mathrm{Na}$ mecânica da fratura linear, uma fratura se propaga quando o fator de intensidade de tensão em sua ponta $\left(K_{I}\right)$ excede ao fator crítico de intensidade de tensão $\left(K_{I C}\right)$ do material. Numa fratura equilibrada, os fatores de intensidades de tensão de ambas pontas são iguais aos seus valores críticos. À medida que o fraturamento acontece e a pressão do fluido fraturante aumenta, a ponta da fratura ajusta sua posição continuamente para manter o equilíbrio do sistema. O problema de calcular o comprimento da fratura consiste em determinar as posições das pontas superior e inferior que correspondam à condição de equilíbrio para uma pressão do fluido fraturante específica.

Fung et al. (1987), derivaram uma expressão geral para casos com multicamadas não simétricas. Os fatores de intensidades de tensão no topo e na base da fratura são escritos em função da pressão no centro da perfuração P e as tensões in-situ, como descreve a equação (2.49). 


$$
\begin{aligned}
K_{I m}=\sqrt{\frac{h}{2 \pi}}\{( & \left(P-\sigma_{n}\right) \pi \\
& +\sum_{i=1}^{n}\left(\sigma_{i+1}-\sigma_{i}\right)\left[2 \sin ^{-1} \sqrt{\frac{h_{i}}{h}}\right. \\
& \left.\left.-\left(-1^{m}\right) \sqrt{1-\left(\frac{2 h_{i}-h}{h}\right)^{2}}\right]\right\}
\end{aligned}
$$

Onde m é 1 ou 2 para a base ou topo da fratura, respectivamente, h é altura total da fratura, $h_{i}$ sua distância medida da ponta inferior até o topo da camada i, $\sigma_{n}$ é a tensão agindo na ponta da fratura, $\sigma_{i+1}$ tensão da camada adjacente à camada i onde age a tensão $\sigma_{i}$.

Para uma fratura em equilíbrio, os fatores de intensidade de tensão deveriam ser iguais aos seus valores críticos, como já mencionado. Da equação (2.49), a diferença entre os fatores de intensidade de tensão das pontas superior e inferior na condição de equilíbrio é calculado então:

$$
K_{I c 1}-K_{I c 2}=\sqrt{\frac{h}{2 \pi}} \sum_{i=1}^{n}\left(\sigma_{i+1}-\sigma_{i}\right) \sqrt{1-\left(\frac{2 h_{i}-h}{h}\right)^{2}}
$$

Desta maneira, a pressão no interior da fratura (P) é eliminada. Então, para uma posição específica da ponta inferior da fratura, a altura da fratura e a correspondente posição da ponta superior podem ser calculadas mediante um esquema iterativo. Uma vez que a altura da fratura (h) é determinada, a equação (2.49) é usada para estimar a pressão (P) que produz a altura da fratura h. A solução da equação (2.50) pode ser encontrada combinando o método iterativo de Newton e de bisseção.

\section{3.}

\section{Regimes de propagação de fraturas}

Apesar da simplicidade da geometria de fratura e a simetria adotada em vários modelos, não há soluções analíticas gerais para simular o fraturamento hidráulico 
quando o acoplamento hidromecânico é incorporado no problema, i.e., quando a formação é assumida como porosa e permeável, com fluxo de fluido fraturante através dos poros e provocando o movimento do fluido originalmente contido neles.

Com a normalização das equações governantes feitas por Adachi (2001), podem-se notar as condições nas quais a solução torna-se independente da rigidez da rocha, da viscosidade, do leakoff ou uma combinação destes parâmetros, o qual nas soluções analíticas anteriores não era levado em conta.

Essas condições estão dadas pelas hipóteses simplificadoras como: a) domínio infinito; b) material totalmente impermeável, c) material linearmente elástico, c) mecânica da fratura linear elástica, d) modelo de filtração (leakoff) de Carter (Howard 1957, Charlez 1997) existem soluções analíticas aproximadas na forma de expansões assintóticas regulares (Bunger 2005, Detournay 2006, Garagash 2006, Hu 2010, Garagash 2011, Pierce 2008, Savitski 2002). As equações governantes então envolvem: a) equação de equilíbrio para um material linearmente elástico, que para um domínio infinito pode ser representado como uma equação integral singular relacionando a abertura da fratura com a pressão do fluido, b) as equações de balanço de massa locais e globais para o fluido fraturante, c) o critério de propagação de fratura, também expresso como uma equação integral singular relacionando a pressão fraturante e a rigidez da fratura. Uma análise adimensional deste sistema reduzido de equações detecta a presença de dois pares de processos físicos concorrentes. O primeiro par consiste nos mecanismos concorrentes dissipadores: a) energia dissipada pela viscosidade do fluido; b) energia dissipada pela propagação da fratura; o segundo par consiste de componentes concorrentes do balanço do fluido: a) armazenamento do fluido no interior da fratura, b) filtração do fluido da fratura para o material circundante. Dependendo de qual dos mecanismos dissipadores e mecanismos de armazenamento sejam dominantes temse então quatro regimes limitantes de propagação da fratura:

$\checkmark$ Regime de propagação dominado pela viscosidade e pelo armazenamento (M);

$\checkmark$ Regime de propagação dominado pela rigidez e pelo armazenamento (K);

$\checkmark$ Regime de propagação dominado pela viscosidade e pelo leakoff $(\widetilde{M})$;

$\checkmark$ Regime de propagação dominado pela rigidez e pelo leakoff $(\widetilde{K})$. 
Estes quatro regimes de propagação de fratura podem ser descritos num espaço paramétrico, onde cada regime limite corresponde a um dos vértices do retângulo com um dos mecanismos de dissipação dominando e o outro sendo desprezado, e uma componente do balanço global de fluido dominando e a outra ignorada, como mostra a Figura 2.8.

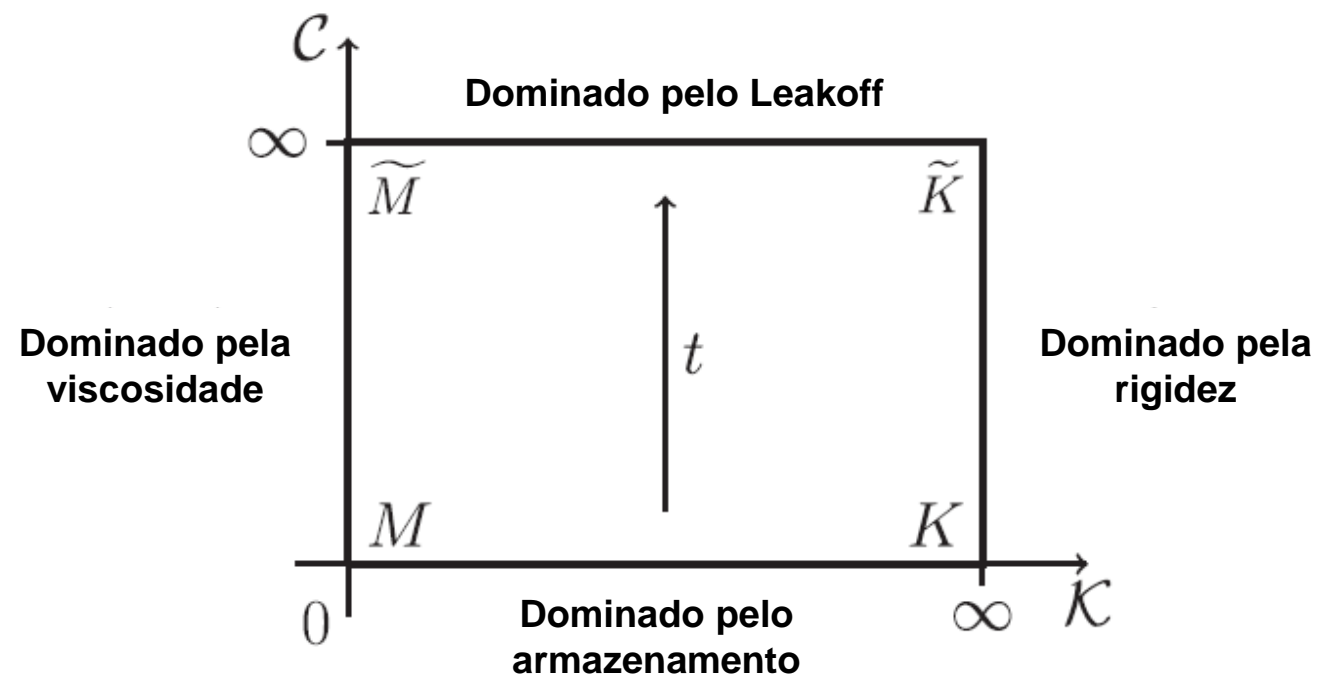

Figura 2.8: Regimes de propagação de fratura (Carrier, 2012)

Na dissertação de Adachi (2001), tem-se a descrição completa da análise adimensional das equações governantes para obter as soluções analíticas aproximadas na forma de expansões assintóticas regulares. No presente trabalho procurou-se comparar a solução analítica para o regime de fratura do vértice $\mathrm{K}$ com um modelo numérico por elementos finitos.

A magnitude relativa dos processos de dissipação e dos processos de armazenamento pode ser descrita pela rigidez adimensional e pelo coeficiente de leakoff adimensional (Adachi e Detournay, 2008), como segue:

$$
K=\frac{4 K_{1 c}}{\sqrt{\pi}}\left(\frac{1}{3 Q_{0} E^{\prime 3} \mu}\right)^{1 / 4} \quad \mathrm{C}=2 C_{L}\left(\frac{E^{\prime} t}{12 \mu Q_{0}^{3}}\right)^{1 / 6}
$$

Cada vértice do espaço paramétrico da Figura 2.8 representa um regime assimptótico durante a injeção de fluido numa fratura no estado plano de deformação. O regime de propagação pode começar no vértice dominado pela 
viscosidade $(K \ll 1)$ ou pelo vértice dominado pela rigidez $(K \gg 1)$; além disso, o regime de propagação pode evoluir do vértice dominado pelo armazenamento $(\mathrm{C} \ll$ 1), para o vértice dominado pelo leakoff $(\mathrm{C} \gg 1)$.

As soluções analíticas correspondentes ao modelo do vértice $\mathrm{K}$ são apresentadas a seguir (Adachi, 2001):

- Abertura da fratura:

$W(x, t)=\epsilon_{k} * L_{k} * \Omega(\xi ; K ; C)$

Onde

$\epsilon_{k}=\left(\frac{K^{\prime}}{E^{\prime 4} Q_{0} t}\right)^{1 / 3} \quad L_{k}=\left(\frac{E^{\prime} Q_{0} t}{K^{\prime}}\right)^{2 / 3} \quad \Omega=\frac{1}{\pi^{1 / 3}} \sqrt{1-\xi^{2}}$

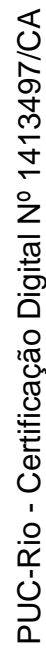

$\xi=\frac{x}{L} \operatorname{com} \xi=0$, no ponto de injeção e $\xi=1$, na ponta da fratura

- Pressão na fratura:

$P(x, t)=\epsilon_{k} * E^{\prime} * \Pi(\xi ; K ; C)$

Onde

$\Pi=\frac{\pi^{1 / 3}}{8} \quad E^{\prime}=\frac{E}{1-v^{2}}$ 
Tabela 2.1 Comparação dos modelos analíticos

\begin{tabular}{|c|c|c|}
\hline Dimensão & Modelo & Descrição \\
\hline \multirow{3}{*}{$\begin{array}{l}\text { 2D } \\
\text { Deformação } \\
\text { Plana }\end{array}$} & KGD & $\begin{array}{l}\text { Fraturas totalmente confinadas, altura da } \\
\text { fratura constante, estado de deformação plana } \\
\text { horizontal, ponta de fratura segundo } \\
\text { Barrenblatt, seção transversal retangular, vazão } \\
\text { constante em fluxo 1D, fluido fraturante } \\
\text { newtoniano, rocha continua, homogênea, } \\
\text { linearmente elástica. }\end{array}$ \\
\hline & $\begin{array}{l}\text { KGD no } \\
\text { Vértice K }\end{array}$ & $\begin{array}{l}\text { Propagação de fratura dominada pela rigidez da } \\
\text { rocha, meio elástico infinito e impermeável, } \\
\text { mecânica da fratura linear elástica, as } \\
\text { suposições geométricas do KGD clássico são } \\
\text { aplicáveis }\end{array}$ \\
\hline & PKN & $\begin{array}{l}\text { Fraturas totalmente confinadas, altura da } \\
\text { fratura constante, estado de deformação plana } \\
\text { vertical, seção transversal elítptica, vazão } \\
\text { constante em fluxo 1D, fluido fraturante } \\
\text { newtoniano, rocha continua, homogênea, } \\
\text { linearmente elástica. }\end{array}$ \\
\hline $\begin{array}{c}2 \mathrm{D} \\
\text { Axissimétrico }\end{array}$ & Penny shaped & $\begin{array}{l}\text { Meio elástico infinito e impermeável, fluido } \\
\text { incompressível newtoniano, vazão constante, a } \\
\text { frente da fratura coincide com a ponta da } \\
\text { fratura, a teoria da lubrificação de Reynolds é } \\
\text { aplicável. }\end{array}$ \\
\hline \multirow[b]{2}{*}{ Pseudo 3D } & Simonson & $\begin{array}{l}\text { Contraste de tensões simétricos, mecânica da } \\
\text { fratura linear elástica, três camadas horizontais } \\
\text { e homogêneas, força gravitacional nula. }\end{array}$ \\
\hline & Fung & $\begin{array}{l}\text { Contraste de tensões asimétricos, mecânica da } \\
\text { fratura linear elástica, multi camadas } \\
\text { horizontais e homogêneas, força gravitacional } \\
\text { nula. }\end{array}$ \\
\hline
\end{tabular}




\section{3 \\ Métodos dos elementos finitos com modelo de zona coesiva}

Neste capitulo apresenta-se o modelo de zona coesiva para a simulação do fraturamento hidráulico com o método dos elementos finitos. Discute-se também as propriedades necessárias para a definição do modelo constitutivo do elemento coesivo e do fluido injetado.

\subsection{Modelo da zona coesiva}

O modelo da zona coesiva (MZC) para fraturas, originalmente proposto por Barrenblatt (1962) e Dugdale (1960), tem sido amplamente usado com sucesso para simular processos de fraturamento em rochas (Cheng 2009,2012, Zielonka 2013, Carrier 2012, Shen 2012). Este modelo postula a existência de uma zona de processo de fratura caracterizada por uma lei coesiva de tensão de tração vs separação na ponta da fratura. Desta forma, o modelo da zona coesiva previne a singularidade do campo de tensões na ponta da fratura que ocorre na mecânica da fratura clássica. Mais ainda, uma vez que a abertura na ponta da fratura coesiva não é nula, mas assume um valor finito, o problema de degeneração não linear associada com a singularidade da pressão do fluido na ponta da fratura é também evitado. No MZC a posição da ponta da fratura não é um parâmetro de entrada, e sim um resultado natural e direto da solução. Além disso, o modelo da zona coesiva se ajusta naturalmente na formulação do método de elementos finitos convencional e pode ser facilmente implementado em programas computacionais (Cheng, 2009, 2012). Portanto o método dos elementos finitos com zona coesiva fornece um enfoque alternativo para análises quantitativas do comportamento da fratura na simulação dos processos de fraturamento hidráulico.

Como mostrado na figura 3.1, uma fratura é induzida hidraulicamente com a injeção de um fluido no poço que se conecta a uma fratura. No modelo numérico, uma superfície predefinida de elementos coesivos que obedecem à lei coesiva tensão de tração vs separação é introduzida e a fratura hidráulica tende a crescer ao 
longo desta superfície. A zona de processo de fratura (zona coesiva intacta) é definida entre essas superfícies, que se separam quando as tensões de tração são diferentes de zero. A fratura é totalmente preenchida com fluido na zona coesiva fraturada e a pressão do fluido passa a atuar sobre as superfícies da fratura recém aberta.

$\mathrm{Na}$ zona de processo da fratura (Figura 3.1) a ponta matemática da fratura refere-se ao ponto que está ainda por se separar (Shet e Chandra, 2002), a ponta coesiva da fratura corresponde ao ponto de iniciação do dano, onde a tração atinge a resistência coesiva e a separação atinge o valor critico $g_{0}=\delta_{0}$, enquanto que a ponta material da fratura é o ponto completamente fraturado onde a separação atinge o valor crítico $g_{1}=\delta_{f}$ e a tensão de tração e resistência coesiva tornam-se nulas. $\mathrm{O}$ fluido fraturante penetra a zona coesiva danificada, i.e. até a ponta coesiva da fratura (Cheng, 2009, 2012).

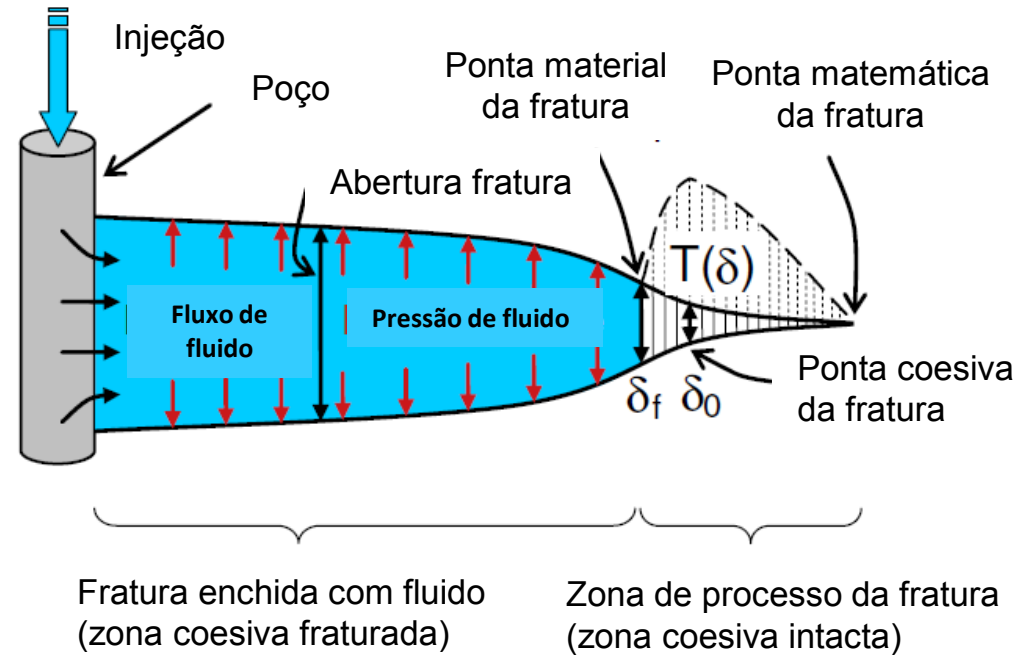

Figura 3.1: Zona coesiva introduzida numa fratura hidráulica (modificado Cheng, 2009, 2012)

\section{2.}

\section{Resposta constitutiva dos elementos coesivos}

O comportamento da interface antes do início do dano é descrito por uma relação linear elástica em termos de uma penalidade na rigidez, que se degrada sob carregamento de tração ou cisalhamento, mas não é afetada pela compressão.

Os elementos coesivos são usados em áreas da discretização onde se espera que fraturas se propaguem. A fratura não precisa ser iniciada: a localização onde 
surgirá, bem como as características de sua evolução, são determinadas como parte da solução (Cheng, 2009, 2012). No entanto, o fraturamento é restringido ao longo de linhas de elementos coesivos dispostos na malha de elementos finitos.

\subsection{1.}

\section{Comportamento antes do dano}

O modelo constitutivo tensão de tração vs. separação utilizado neste trabalho assume inicialmente um comportamento linear elástico seguido pela iniciação e evolução do dano. O comportamento elástico é descrito em termos de uma matriz constitutiva elástica que relaciona as tensões com as deformações através da interface.

$\mathrm{O}$ vetor de tensões, $\mathrm{t}$, consiste de três componentes: $t_{n}, t_{s}$ e $t_{t}$, que representam as componentes normal e cisalhante do vetor atuando nas paredes da fratura e $\delta_{n}, \delta_{s}, \delta_{t}$ representam as correspondentes separações. Denotando a espessura original do elemento coesivo $H$, as deformações nominais são:

$$
\varepsilon_{n}=\frac{\delta_{n}}{H}, \quad \varepsilon_{s}=\frac{\delta_{s}}{H}, \quad \varepsilon_{t}=\frac{\delta_{t}}{H}
$$

O comportamento elástico pode ser escrito como:

$$
t=\left\{\begin{array}{l}
t_{n} \\
t_{s} \\
t_{t}
\end{array}\right\}=\left[\begin{array}{lll}
E_{n n} & E_{n s} & E_{n t} \\
E_{n s} & E_{s s} & E_{s t} \\
E_{n t} & E_{s t} & E_{t t}
\end{array}\right]\left\{\begin{array}{l}
\varepsilon_{n} \\
\varepsilon_{s} \\
\varepsilon_{t}
\end{array}\right\}=E \varepsilon
$$

A matriz de elasticidade proporciona comportamento totalmente acoplado entre todas as componentes do vetor de tensões de tração e de deformação. Considerar os termos fora da diagonal como zero na matriz de elasticidade se desejar comportamento desacoplado entre as componentes normal e cisalhante. 


\subsection{2.}

\section{Iniciação do dano}

Como seu nome implica, a iniciação do dano refere-se ao começo da degradação da resposta de um ponto do material. O processo de degradação começa quando as tensões e/ou deformações satisfazem o critério de iniciação do dano especificado. O critério da tensão máxima é utilizado por grande número de autores (Zielonka. 2013; Cheng 2009, 2012; Shen, 2012), sendo representado pela equação 3.3. Quando a tensão atuante atinge o valor da tensão máxima (valor da resistência à tração da rocha), considera-se que o material inicia o processo de dano.

$$
f=\operatorname{MAX}\left\{\frac{\left\langle t_{n}\right\rangle}{t_{n}^{0}}, \frac{t_{s}}{t_{s}^{0}}, \frac{t_{t}}{t_{t}^{0}}\right\}=1
$$

$\mathrm{Na}$ equação (3.3) as componentes $t_{n}, t_{s}$ e $t_{t}$ representam os valores de pico das tensões de tração e $t_{n}^{0}, t_{s}^{0}, t_{t}^{0}$ representam os valores de pico das tensões quando a deformação é puramente normal à interface. O critério "Max" é baseado no valor máximo dos três coeficientes. Os colchetes de Macaulay $\left\langle t_{n}\right\rangle$, são usados para significar que um estado de tensões puramente compressivo não inicia o dano.

\subsection{3. \\ Evolução do dano}

A lei de evolução do dano define como o material se degrada após atingir um ou mais critérios de dano, ou seja, descreve a taxa na qual a rigidez coesiva é degradada. Múltiplas formas de evolução do dano podem atuar sobre o material ao mesmo tempo, um para cada critério de iniciação de dano definido.

Uma variável de dano escalar D representa o dano médio global na interseção entre a superfície da fratura e as bordas dos elementos fraturados. Inicialmente a variável de dano tem um valor nulo e evolui monotonicamente de 0 a 1. As componentes de tensões de tração e cisalhantes são afetadas pelo dano de acordo com:

$$
t_{n}=\left\{\begin{array}{ll}
(1-D) t_{n}, & t_{n} \geq 0 \\
t_{n} & t_{n}<0
\end{array}\right\}
$$


$t_{s}=(1-D) t_{s}$

$t_{t}=(1-D) t_{t}$

Onde $t_{n}, t_{s} e t_{t}$ são as componentes da tensão de tração normal e cisalhante previstas pelo comportamento elástico para as separações atuais sem dano.

A definição do dano tem duas componentes: a primeira envolve a especificação dos parâmetros do modelo coesivo e a segunda é a especificação da natureza da variável de evolução do dano D entre a iniciação do dano e o dano final (tipo de amolecimento).

\subsubsection{1. \\ Modelo coesivo}

O modelo coesivo de tração-separação com amolecimento linear é definido pela energia coesiva $G_{c}$ (área sob a parte de amolecimento na curva de traçãoseparação) e a resistência coesiva $N_{0}$. O comportamento tração-separação antes do dano deve ser especificado, assumindo-se linearmente elástico com rigidez inicial $K_{0}$. A tração coesiva da interface evolui desde a máxima resistência à tração $N_{0}$ no inicio do dano, diminuindo até zero quando a interface é totalmente danificada e livre para abrir-se além da separação $g_{1}$. Se a interface for descarregada antes do dano completo, a tração diminuirá linearmente com uma rigidez danificada $K_{p}$, como mostra a figura 3.3. As trações efetivas na interface são dadas por:

$T=K_{p} g \quad 0 \leq g \leq g_{p}$ 


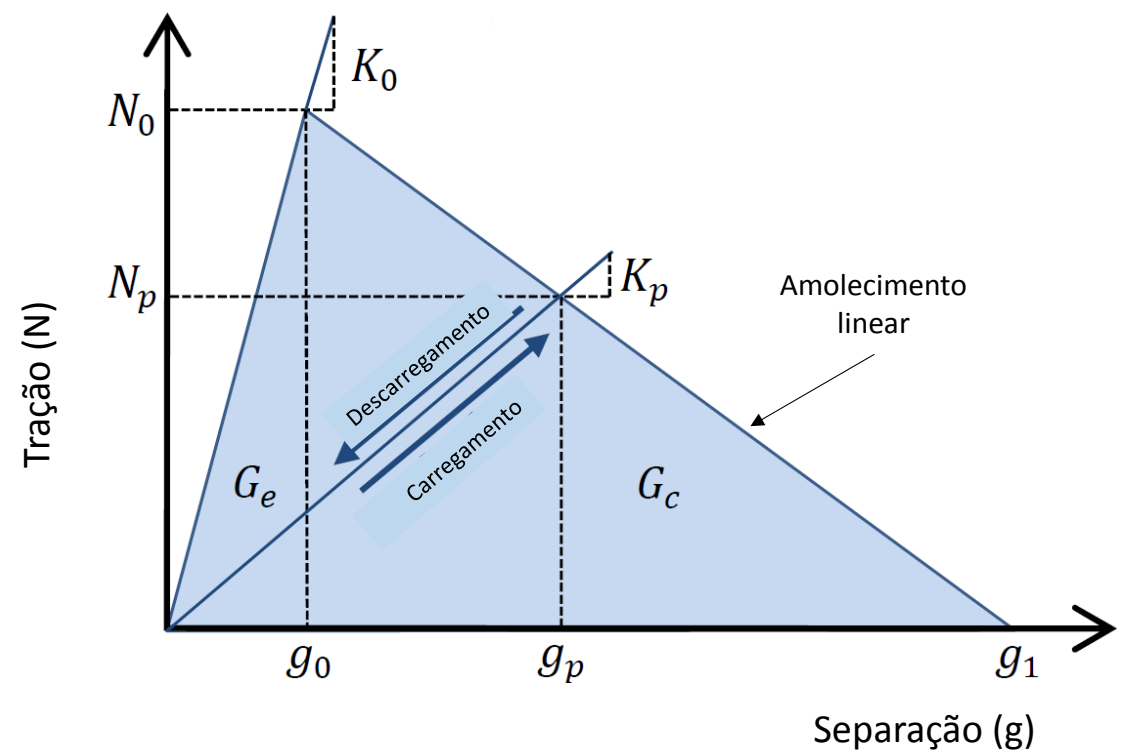

Figura 3.2: Modelo coesivo para fraturamento hidráulico (modificado de Zielonka, 2013)

A evolução da fratura é modelada através de elementos de interface de espessura nula com a separação resistida pelas trações que diminuem gradualmente. Estes elementos de interface são predefinidos entre elementos finitos contínuos, possuem acoplamento pressão/deformação, são elementos lineares isoparamétricos com graus de liberdade de poropressão e deslocamentos em seus nós dos cantos (nós 1,2,3,4), para estado plano de deformação, como mostra a figura 3.3. Os elementos contínuos adjacentes possuem acoplamento poropressão / tensões. Para permitir o acoplamento das equações de fluxo do fluido fraturante, os elementos coesivos contêm graus de poropressão adicionais (nós 5 e 6 no centro das bordas do elemento, perpendicularmente à fratura), estes são nós específicos para cálculo da pressão do fluido fraturante, quando da iniciação do dano.

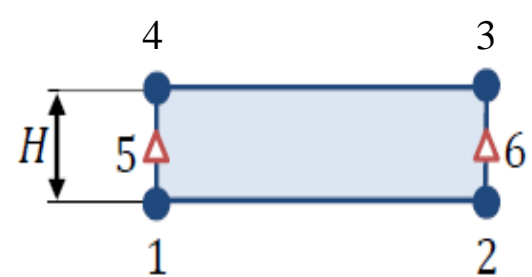

Configuração

Inicial

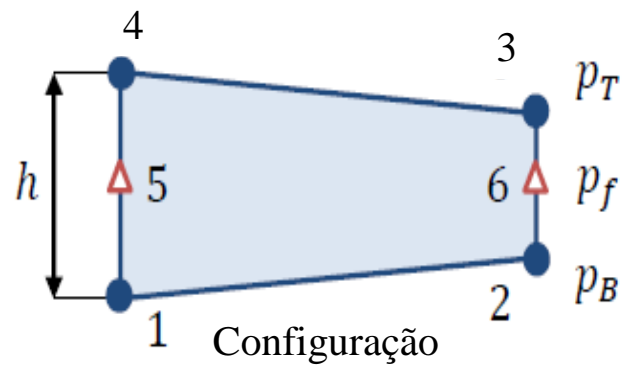

Deformada

Figura 3.3: Elementos coesivos acoplados para o fraturamento hidráulico (Zielonka, 2014) 
Os elementos coesivos podem ter uma espessura geométrica não deformada arbitraria $\mathrm{H}$, e a abertura instantânea $\mathrm{W}=\mathrm{g}$ acoplada na equação de fluxo de fluido fraturante (equação 2.18) é definida como a diferença entre a espessura deformada e a não deformada, i.e., $\mathrm{W}=\mathrm{g}=\mathrm{h}-\mathrm{H}$. Antes do dano, as faces do topo e fundo da fratura fechada estão submetidas à pressão do fluido no meio poroso $p$ e as trações efetivas coesivas resistindo à separação são:

$T=K_{0} g-p$

Onde $K_{0}$ é a rigidez do elemento coesivo antes da falha. Na iniciação do dano, o fluido no meio poroso é deslocado pelo fluido fraturante, pressurizando a interface $\left(p_{f}\right)$. As tensões de tração atuando sobre as faces do topo e fundo da fratura recémaberta são então substituídas por:

$T=K_{p} g-p_{f}$

Onde $K_{p}$ é a rigidez danificada, como mostra a figura 3.2.

\subsubsection{2.}

\section{Amolecimento do modelo coesivo}

Para o amolecimento linear, como ilustrado na figura 3.2, é utilizada uma variável de evolução de dano D definida por Camanho e Davila (2002) como:

$D=\frac{\delta_{m}^{f}\left(\delta_{m}^{\max }-\delta_{m}^{0}\right)}{\delta_{m}^{\max }\left(\delta_{m}^{f}-\delta_{m}^{0}\right)}$

Onde

$\delta_{m}^{f}=g_{1}$ É a separação crítica no dano total

$\delta_{m}^{0}=g_{0}$ É a separação crítica no início do dano

$\delta_{m}^{\max }=g_{\max }$ refere-se ao máximo valor da separação efetiva atingido durante a história de carregamento, como calculado pela equação (3.11). 
Para descrever a evolução do dano sob uma combinação de separações normal e cisalhante a separação efetiva é definida como:

$g_{\max }=\delta_{m}^{\max }=\sqrt{\left\langle\delta_{n}\right\rangle^{2}+\delta_{s}^{2}+\delta_{t}^{2}}$

\section{3.}

\section{Resposta constitutiva do fluido no elemento coesivo}

O modelo de fluxo de fluido no elemento coesivo é tipicamente para aplicações geotécnicas, onde a continuidade do fluxo deve ser mantida. A pressão normal do fluido sobre as superfícies do elemento coesivo contribui no seu comportamento mecânico, permitindo então o acoplamento hidráulico com a resposta mecânica governada pela lei constitutiva tensão de tração vs. separação

O fluxo do fluido tem duas componentes (figura 3.4):

- Fluxo tangencial no interior da separação (gap), o qual pode ser representado como um modelo newtoniano ou baseado em lei de potência;

- Fluxo normal que pode refletir a resistência devido aos efeitos da formação da retorta (caking)

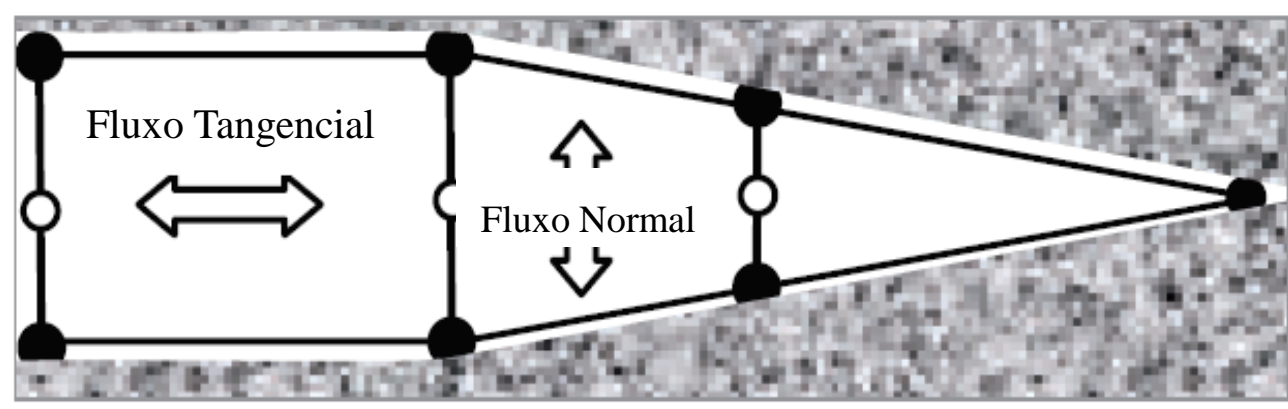

Figura 3.4: Fluxo nos elementos coesivos (Shen 2012)

Na modelagem numérica o fluido é considerado incompressível, e a formulação está baseada na continuidade do fluxo que considera os fluxos tangencial e normal e a taxa de abertura do elemento coesivo. 


\subsection{1.}

\section{Fluxo Tangencial}

Há dois tipos de representação do fluido que podem ser considerados na modelagem: (1) fluido Newtoniano; (2) fluido definido com base em uma lei de potência. Nas aplicações deste trabalho escolheu-se um fluido Newtoniano para comparação com as soluções analíticas de propagação de fraturas.

O vetor de densidade da taxa de fluxo de volume de fluido newtoniano é dado por:

$Q W=-K_{t} \nabla P$

Onde $k_{t}$ é permeabilidade tangencial (a resistência do fluxo de fluido); $\nabla p$ é o gradiente de pressão ao longo do elemento coesivo e W é a abertura do espaço (gap):

\footnotetext{
Abertura W é dada por:

$W=h-H+W_{\text {init }}$
}

Onde $h$ e $H$ são as espessuras geométricas atual (deformada) e original dos elementos coesivos, respectivamente, e $W_{\text {init }}$ é a abertura inicial do elemento coesivo, a qual tem um valor predefinido de 0,002 $\mathrm{m}$.

A permeabilidade tangencial, ou a resistência ao fluxo, é definida de acordo com a equação de Reynolds:

$$
k_{t}=\frac{W^{3}}{12 \mu}
$$

Onde $\mu$ é a viscosidade dinâmica do fluido e $\mathrm{W}$ é a abertura da fratura. 


\subsection{2.}

\section{Fluxo normal}

Defina-se o fluxo normal através de um coeficiente de filtração (leakoff) para o fluido no meio poroso do material. Este coeficiente define a relação pressão vs. fluxo entre os nós intermediários do elemento coesivo e os nós superficiais adjacentes. Os coeficientes de leakoff do fluido podem ser interpretados como coeficientes de permeabilidade de uma camada finita de material sobre a superfície dos elementos coesivos (Abaqus, 2014), como mostra a figura 3.5:

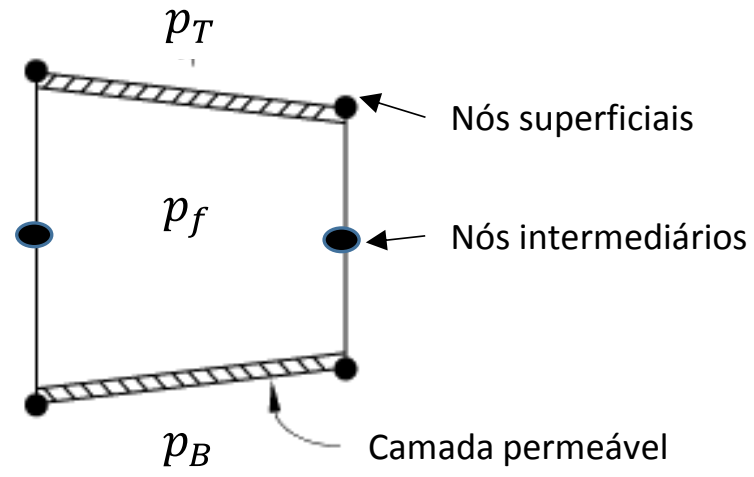

Figura 3.5: Pressões no elemento coesivo (Abaqus 2014)

O fluxo normal é definido como:

$v_{T}=C_{T}\left(p_{f}-p_{T}\right)$

$v_{B}=C_{B}\left(p_{f}-p_{B}\right)$

Onde $p_{T}$ e $p_{B}$ são as pressões do fluido no meio poroso nas superfícies do topo e da base da fratura, respectivamente, $C_{T}$ e $C_{B}$ são os correspondentes coeficientes de leakoff, $v_{T}$ e $v_{B}$ as velocidades do fluido no topo e na base, respectivamente, e $p_{f}$ é pressão de fluido na fratura. Este modelo simples de leakoff simula a existência de uma camada permeável que se pode acumular e reduzir a permeabilidade efetiva normal das superfícies da fraturas. 


\subsection{Tamanho do elemento coesivo}

Com a finalidade de garantir a convergência da solução e capturar apropriadamente os detalhes do campo de deformação nas vizinhanças da ponta da fratura, bem como a distribuição da tensão normal na zona coesiva, o tamanho do elemento coesivo deve ser menor que o comprimento da zona coesiva (Cheng, 2009, 2012).

O comprimento da zona coesiva é um comprimento determinado pelas propriedades do material. Para o modo I de fratura sob condições do estado plano de deformação o comprimento $d_{z}$ da zona coesiva é determinado por Rice (1980):

$d_{z}=\frac{9 \pi}{32} \frac{K_{1 c}^{2}}{N_{0}^{2}}=\frac{9 \pi}{32} \frac{E}{\left(1-v^{2}\right)} \frac{G_{c}}{N_{0}^{2}}$

Onde:

$K_{1 c}=$ Fator de intensidade de tensão no modo I

$E=$ Módulo de Young

$v=$ Coeficiente de Poisson

$G_{c}=\frac{1}{2} N_{0} g_{1}=\frac{1}{2 \alpha} N_{0} g_{0}=\frac{N_{0}^{2}}{2 \alpha K_{0}}=$ Energia de fraturamento coesivo

$\alpha=\frac{g_{0}}{g_{1}}=\frac{\delta_{0}}{\delta_{f}}=$ Coeficiente de separação critica

$K_{0}=$ Rigidez inicial do modelo coesivo

A equação (3.17) é usada neste trabalho como um critério para a determinação do tamanho do elemento coesivo na modelagem de fraturamento hidráulico por meio do método dos elementos finitos associado com modelo de zona coesiva. 


\section{4 \\ Metodologia numérica do fraturamento hidráulico}

Neste capítulo apresenta-se a metodologia utilizada para a simulação do fraturamento hidráulico usando o método dos elementos finitos associado ao modelo de zona coesiva, mostra-se também um estudo sobre tópicos da modelagem numérica como modelo coesivo, regularização viscosa, análise permanente e transiente e o modelo de três camadas com barreiras impermeáveis.

Com a finalidade de simular o fraturamento hidráulico utilizou-se o software comercial Abaqus 6.14 que tem como vantagens: a capacidade de acoplamento total hidro-mecânico na análise de fraturamento hidráulico, dispor de modelo não linear de análise de adensamento de solos e elementos coesivos com pressão/deformação acoplada que modelam o dano progressivo da resistência mecânica e a condutividade hidráulica. Descrevem-se também nesse capítulo as sub-rotinas fornecidas para o Abaqus as quais foram desenvolvidas pelo autor desta tese para complementar as funcionalidades do software.

\section{1. Passos da simulação do fraturamento hidráulico \\ O fraturamento hidráulico foi aqui simulado nos seguintes três passos:}

\subsection{1.}

\section{Passo inicial}

Neste passo, as condições iniciais (tensões e poropressões), condições de contorno (em termos de deslocamento e poropressões) são definidas e aplicadas ao modelo.

As condições iniciais são definidas através das seguintes sub-rotinas, programadas em linguagem Fortran pelo autor desta dissertação.

- Subrotina SIGINI: Esta sub-rotina define o estado inicial de tensões efetivas para os elementos sólidos e coesivos.

- Subrotina UPOREP: Esta define as poropressões do modelo 
- Subrotina DISP: É utilizada para definir a distribuição de poropressões no contorno do modelo.

\subsection{2.}

\section{Geostático}

Neste passo geostático restringem-se os deslocamentos em todas as direções, para todos os nós, com a finalidade de obter as forças reativas em cada nó.

Após da primeira etapa, são aplicadas as reações nodais obtidas anteriormente. As restrições de deslocamento são impostas somente ao longo do contorno. Aplicam-se novamente as condições iniciais dadas pelas sub-rotinas, de forma que o sistema atinja o equilíbrio com deformações nulas.

\subsection{3.}

\section{Passo de injeção}

Este passo é realizado utilizando a palavra-chave SOILS, acompanhada da palavra-chave CONSOLIDATION para fazer uma análise transiente do fraturamento hidráulico ou, sem esta última, para executar uma análise em regime permanente. As diferenças nos resultados para estes dois tipos de análise serão exibidas na seção 4.5.

A injeção pode ser controlada por fluxo (vazão) ou por pressão.

- Injeção controlada por fluxo:

Neste caso define-se a vazão de injeção que controlará o processo de fraturamento hidráulico por meio da palavra chave CFLOW, seguida do valor da vazão, considerada constante.

- Injeção controlada por pressão:

Neste caso defina-se a pressão final de injeção (vazão não é constante), onde os incrementos de tempo passam a ser um fator multiplicador da pressão. A injeção aqui é efetuada através da palavra-chave BOUNDARY seguido do valor final da pressão de injeção. Este tipo de injeção não é comum nas operações de fraturamento hidráulico, mas é estudada para fins acadêmicos. 
Nas seguintes seções se fará um estudo sobre tópicos relacionados com a modelagem numérica, tais como: estudo do modelo coesivo, efeito da regularização viscosa na convergência e precisão dos resultados, influência do comprimento do intervalo injetado, a ingerência do tipo de análise permanente ou transiente na propagação de fraturas, e por último um estudo sobre a contenção de fraturas com contraste de tensões e poropressões entre suas camadas.

Na figura 4.1 mostra-se o modelo de uma camada utilizado na simulação do fraturamento hidráulico, as tensões e poropressão iniciais foram admitidas nulas pois as soluções analíticas utilizadas não levam em conta estes valores. Apresentase também, um detalhe da malha de transição entre uma região mais densa, junto à fratura, e outra de menor discretização, mais distante. A malha esta composta por elementos contínuos bidimensionais de quatro nós só com grau de liberdade de deslocamento ativo (CPE4) e para representar a fratura temos elementos coesivos bidimensionais de quatro nós de deslocamento e dois nós de poropressão (COH2D4) onde será injetada a vazão para induzir o fraturamento hidráulico. As condições de contorno do modelo são: restrições de deslocamento na direção vertical para a base e topo do modelo e na direção horizontal para as bordas direitas e izquerda do modelo.

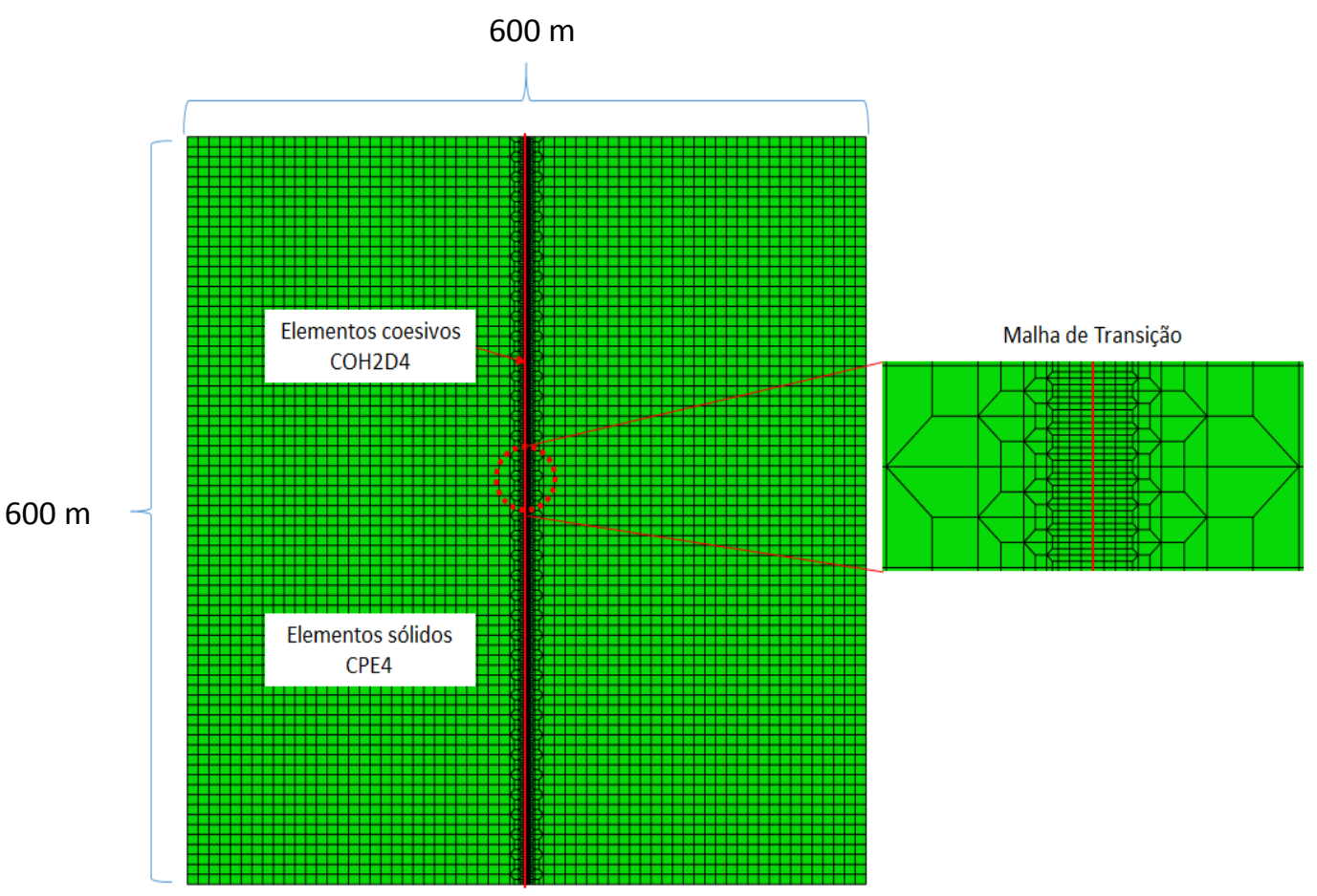

Figura 4.1: Modelo sintético de uma camada 
Na tabela 4.1 apresentam-se as propriedades utilizadas para todos os modelos desta dissertação, retiradas do artigo Zielonka (2014).

Tabela 4.1: Propriedades da rocha, do fluido e da fratura

\begin{tabular}{|l|c|}
\hline \multicolumn{1}{|c|}{ Propriedades } & Valor \\
\hline Rocha Intacta & 17 \\
\hline Módulo de Young [Gpa] & 0.2 \\
\hline Coeficiente de Poisson & 0.2 \\
\hline Porosidade & $9.8 \times 10^{-9}$ \\
\hline Condutividade Hidráulica [m/s] & 9.8 \\
\hline Fluido Fraturante & $1 \times 10^{-7}$ \\
\hline Pesso especifico do fluido [kPa/m] & 120 \\
\hline Viscosidade [kPa.s] & 1.46 \\
\hline Fratura & 1.25 \\
\hline Energia da fratura [Pa.m] & \\
\hline Fator de intensidade de tensões crítico [Mpa.m $\left.{ }^{1 / 2}\right]$ & \\
\hline Resistência à tração da rocha [Mpa] & \\
\hline
\end{tabular}

\subsection{Modelo coesivo}

Nesta secção, pesquisa-se o efeito da mudança nos parâmetros do modelo coesivo na geometria da fratura e no perfil de distribuição da pressão ao longo da fratura.

O modelo coesivo é brevemente relembrado na Figura 4.2:

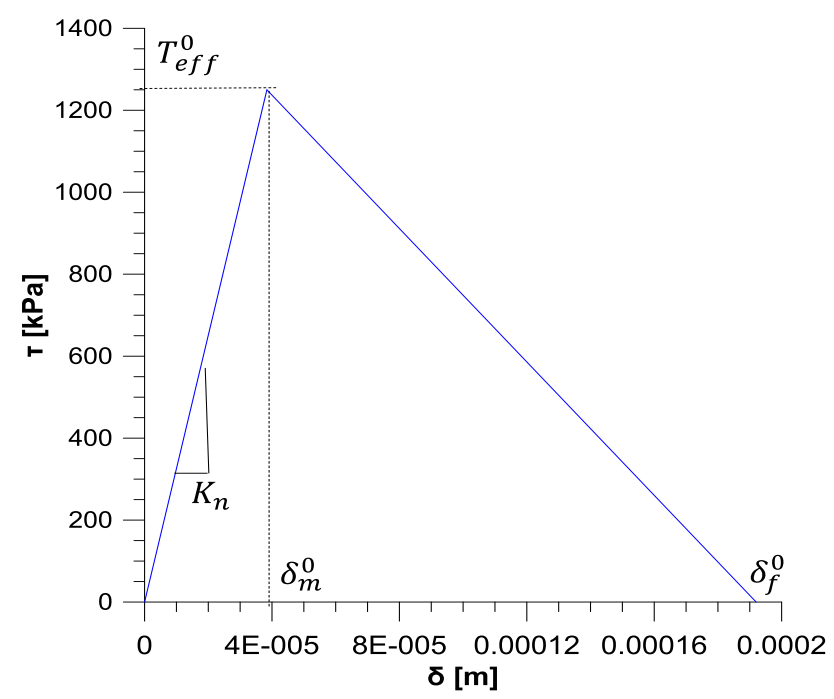

Figura 4.2: Lei de tensão de tração-separação do modelo coesivo 
Onde:

$$
\begin{aligned}
& \alpha=\frac{\delta_{m}^{0}}{\delta_{m}^{f}}=\frac{g_{0}}{g_{1}} \\
& \delta_{m}^{0}=\frac{T_{e f f}^{0}}{K_{n}}=\frac{N_{0}}{K_{0}}
\end{aligned}
$$

Fixando-se o valor de $\delta_{m}^{f}$ o parâmetro $\alpha$ varia conforme indicado na Figura 4.3. Para baixos valores de $\alpha$ o modelo constitutivo torna-se mais rígido, com grandes valores da constante elástica $K_{n}$, e baixo valor de $\delta_{m}^{0}$, causando tensões de tração no elemento coesivo que tendem a atingir rapidamente a resistência à tração da rocha. Por outro lado, quando o parâmetro $\alpha$ é grande, o modelo coesivo reflete um comportamento dúctil do material, com rigidez elástica $K_{n}$ pequena, tornando $\delta_{m}^{0}$ maior, indicando que a rocha suporta maiores deslocamentos antes de atingir sua resistência à tração.

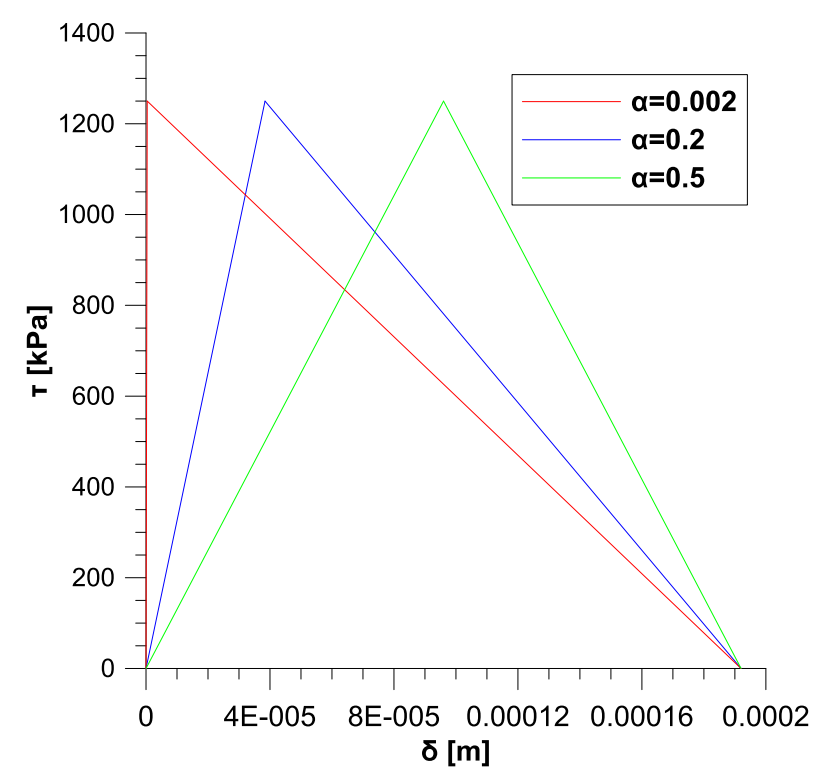

Figura 4.3: Variação do modelo coesivo com o parâmetro $\alpha$.

Lembrando que o dano D é calculado como (seção 3.2.3.2.):

$$
D=\frac{\delta_{m}^{f}\left(\delta_{m}^{\max }-\delta_{m}^{0}\right)}{\delta_{m}^{\max }\left(\delta_{m}^{f}-\delta_{m}^{0}\right)}
$$


Analisando a equação anterior, para um $\alpha$ muito pequeno $\delta_{m}^{0} \rightarrow 0$, isto faz que o dano aproxima-se a 1 :

$$
D=\frac{\delta_{m}^{f}\left(\delta_{m}^{\max }\right)}{\delta_{m}^{\max }\left(\delta_{m}^{f}\right)} \approx 1
$$

$\mathrm{Na}$ figura 4.4, mostra-se que para um $\alpha$ muito pequeno, o primeiro valor de dano calculado ao atingir a resistência a tração da rocha é praticamente 1 (estado totalmente danificado), pois o modelo coesivo é muito rígido tornando o material muito frágil. Enquanto que para um $\alpha$ maior, o primeiro valor de dano calculado ao atingir a resistência a tração da rocha é muito baixo, tornando o material dúctil e pouco rígido.

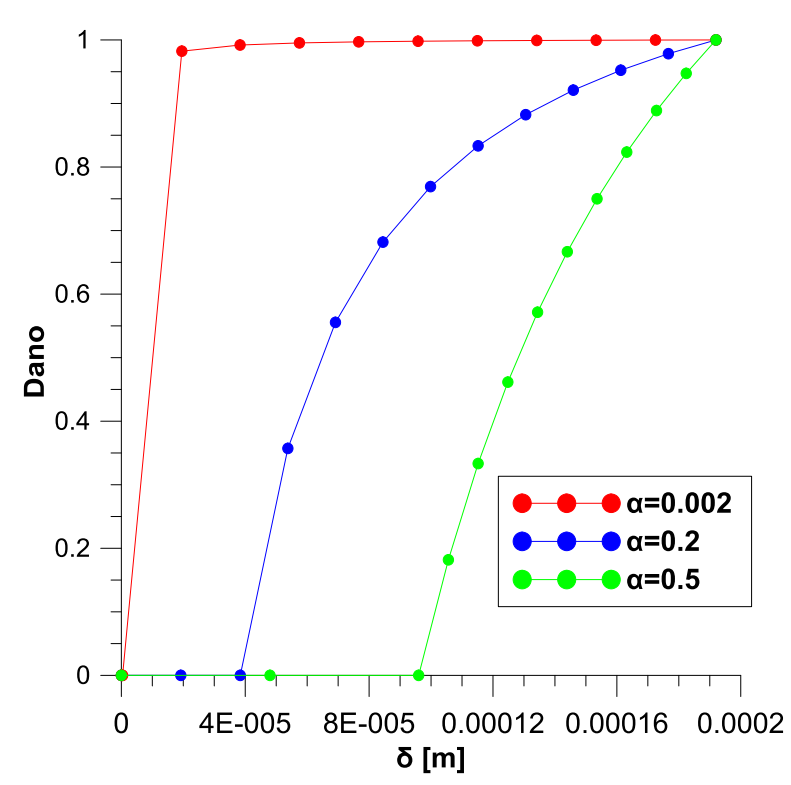

Figura 4.4: Efeito da variação do $\alpha$ no cálculo do dano

$\mathrm{Na}$ figura 4.5, observa-se que à medida que $\alpha$ aumenta, o pico da curva de pressão de injeção diminui (diminui a rigidez do material), mas o comportamento post-pico é igual. 


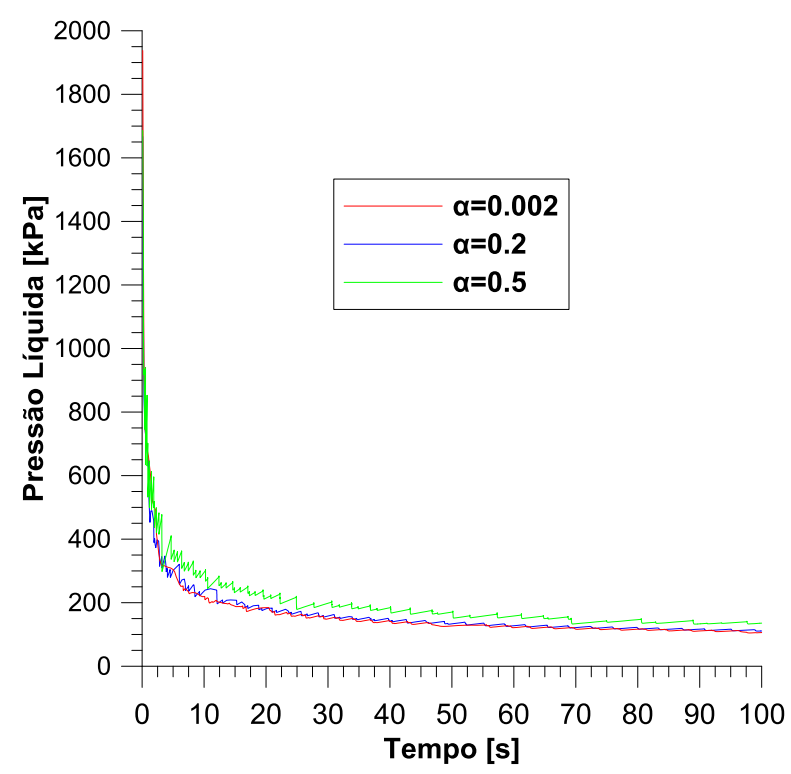

Figura 4.5: Efeito do parâmetro $\alpha$ na pressão de injeção.

À medida que o parâmetro $\alpha$ aumenta, também cresce a abertura máxima da fratura (Figura 4.6), e a distribuição da pressão no interior da fratura (Figura 4.7), pois o elemento coesivo tende a aumentar os valores de pressão para fraturar e propagar, porém com menor comprimento da fratura, como ilustra a Figura 4.8.

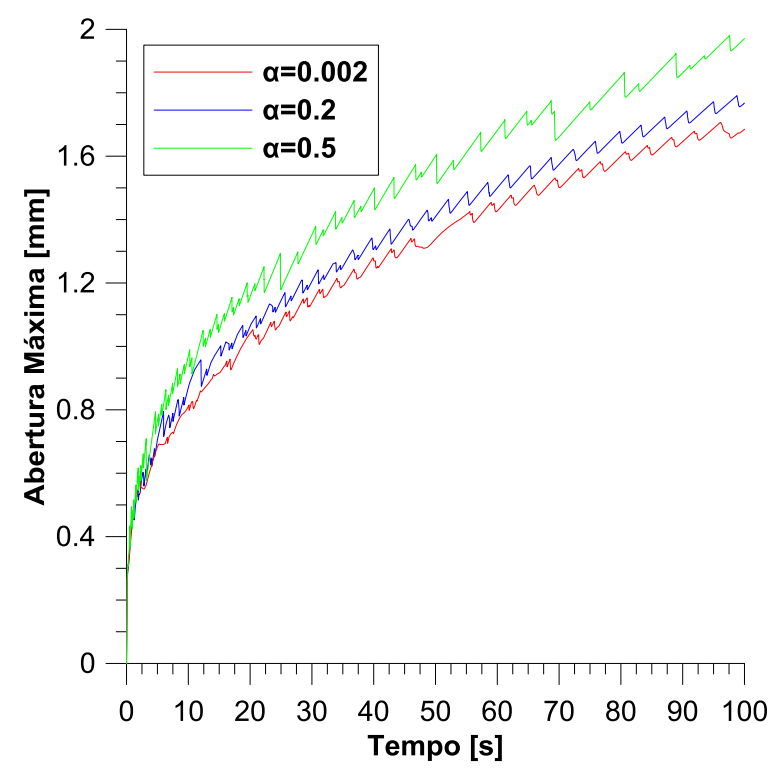

Figura 4.6: Efeito do Efeito do parâmetro $\alpha$ na abertura máxima da fratura. 


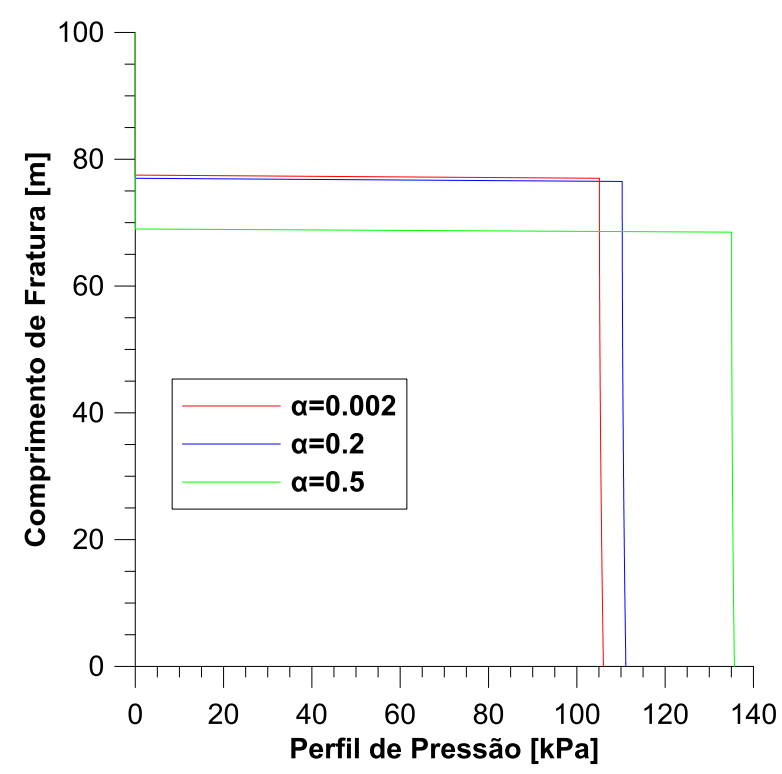

Figura 4.7: Efeito do Efeito do parâmetro $\alpha$ no perfil de pressão ao longo da fratura.

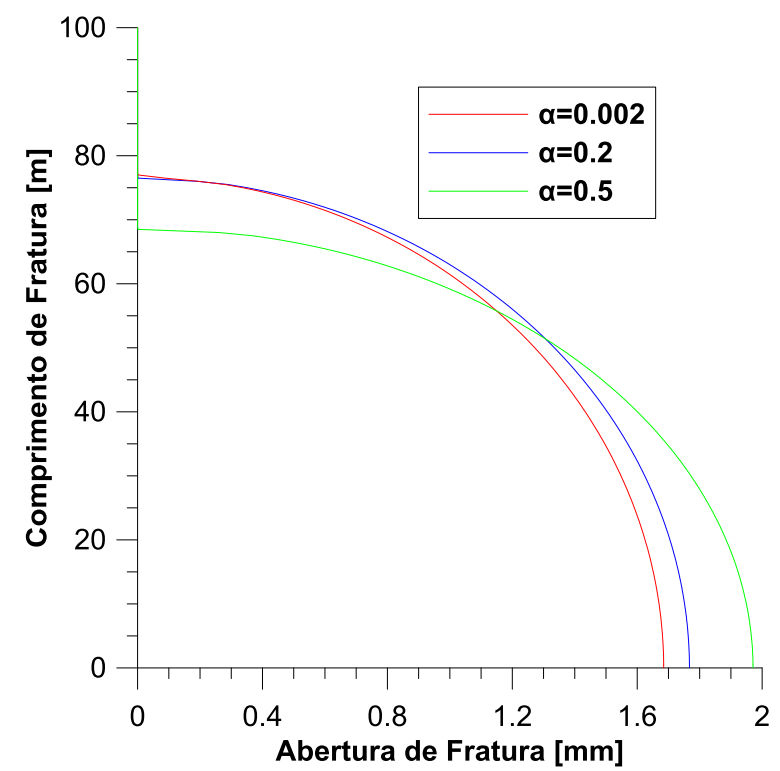

Figura 4.8: Efeito do parâmetro $\alpha$ na geometria da fratura

\subsection{Regularização viscosa}

Os modelos que exibem comportamento de amolecimento e degradação da rigidez frequentemente levam a severas dificuldades de convergência. Uma técnica comum para superar algumas destas dificuldades é o uso da regularização viscosa das equações constitutivas, que impõe que a matriz de rigidez tangente do material durante o amolecimento seja positiva para incrementos de tempo suficientemente pequenos (Abaqus, 2014). 
As leis constitutivas de tensão de tração vs. separação podem ser regularizadas por meio do parâmetro de viscosidade, permitindo que as tensões estejam fora dos limites fixados pela lei tensão de tração vs separação, esta regularização envolve o uso de uma variável de degradação viscosa da rigidez $D_{v}$, a qual tem um valor predeterminado, e cuja variação no tempo é definida pela seguinte equação da evolução:

$\dot{D}_{v}=\frac{1}{\rho}\left(D-D_{v}\right)=\frac{d D_{v}}{d t}$

Onde $\rho$ é o parâmetro de viscosidade que representa o relaxamento de tempo do sistema viscoso e D é a variável de degradação avaliada no modelo sem parâmetro de viscosidade.

Usando a regularização viscosa com um valor pequeno do parâmetro de viscosidade $\rho$ (pequeno comparado com o incremento de tempo característico), usualmente ajuda a melhorar a taxa de convergência do modelo no regime de amolecimento, sem alterar os resultados (Abaqus, 2014). A ideia básica é que a solução do sistema viscoso se relaxe ao caso invíscido (sem viscosidade) à medida que $t / \rho \rightarrow \infty$, onde t representa o tempo.

Para cálculos incrementais de elementos finitos, a variável de degradação de rigidez viscosa atual é calculada como, Jiang (2010):

$D_{v}(t+d t)=\frac{\left(D_{v}(t)+\frac{d t}{\rho} D(t+d t)\right)}{\left(1+\frac{d t}{\rho}\right)}$

Com $D \in[0,1], D_{v} \in[0,1]$, e $D_{v}<D$.

Quando esta técnica de regularização viscosa é usada, o termo do dano nas equações (3.4), (3.5), e (3.6) é substituído com a variável de degradação de rigidez viscosa atual $D_{v}$ e as equações constittivas são atualizadas com a variável $D_{v}$.

As Figuras 4.9 e 4.10 comparam a solução analítica KGD (seção 2.2.2) com resultados numéricos por elementos finitos, variando-se o parâmetro de regularização viscosa. As melhores concordâncias entre ambas as soluções foram 
obtidas para baixos valores deste parâmetro em termos da pressão de injeção (Figura 4.9) e da abertura máxima da fratura (Figura 4.10).

A Figura 4.11 ilustra a distribuição da pressão no interior da fratura enquanto que a Figura 4.12 mostra que para um valor mais alto do parâmetro de regularização viscosa $\left(\mathrm{v}=10^{-2}\right)$ a geometria da fratura tende a ser incorretamente prevista.

As soluções numéricas tendem a ser mais precisas quanto menor o valor do parâmetro de regularização viscosa, pois o número de intervalos de tempo aumenta contribuindo para uma melhor acurácia das respostas.

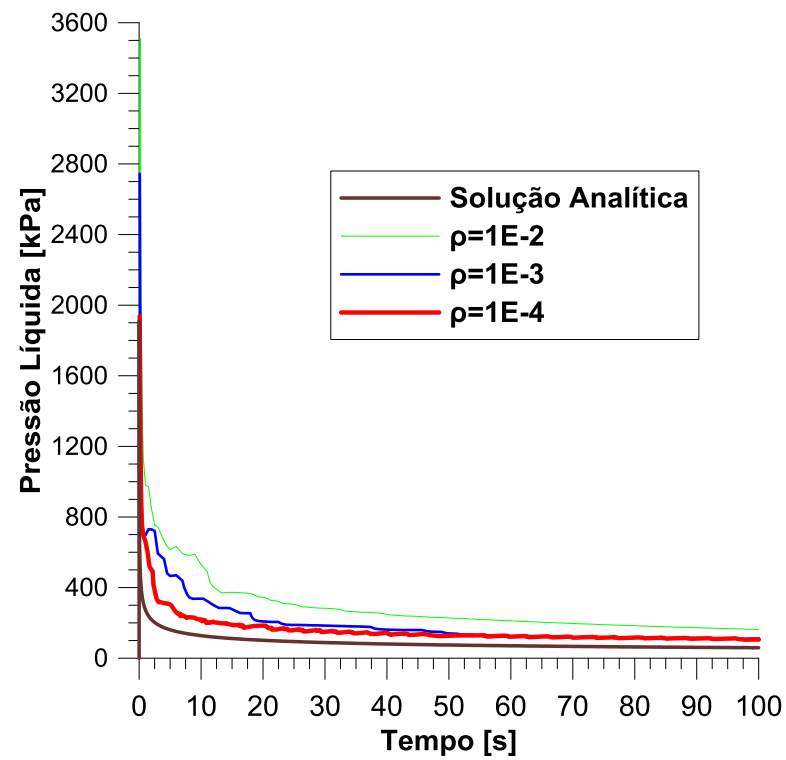

Figura 4.9: Efeito da regularização viscosa na pressão de injeção.

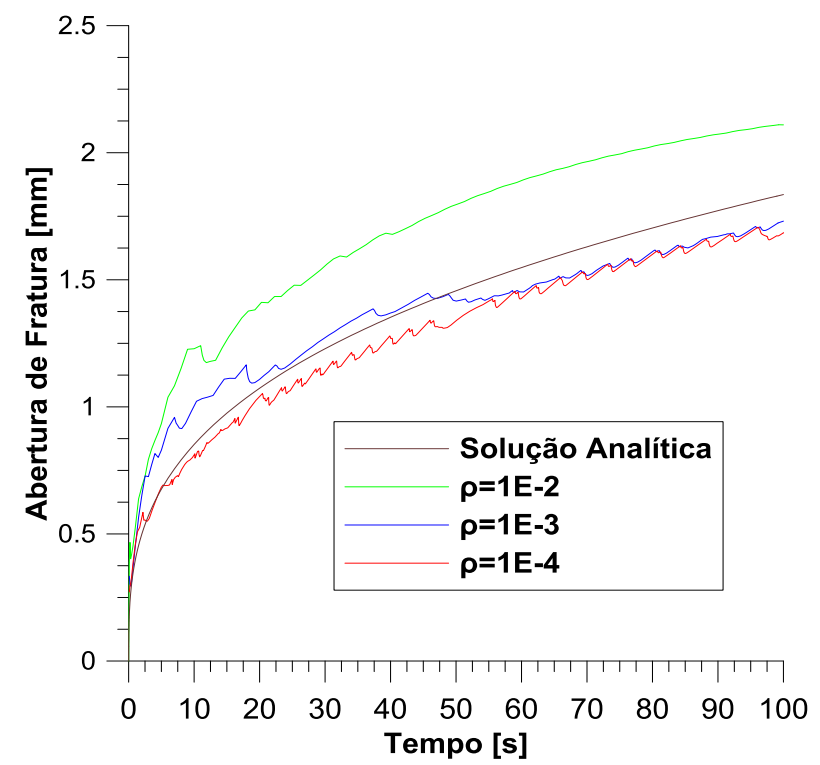

Figura 4.10: Efeito da regularização viscosa na abertura da fratura. 


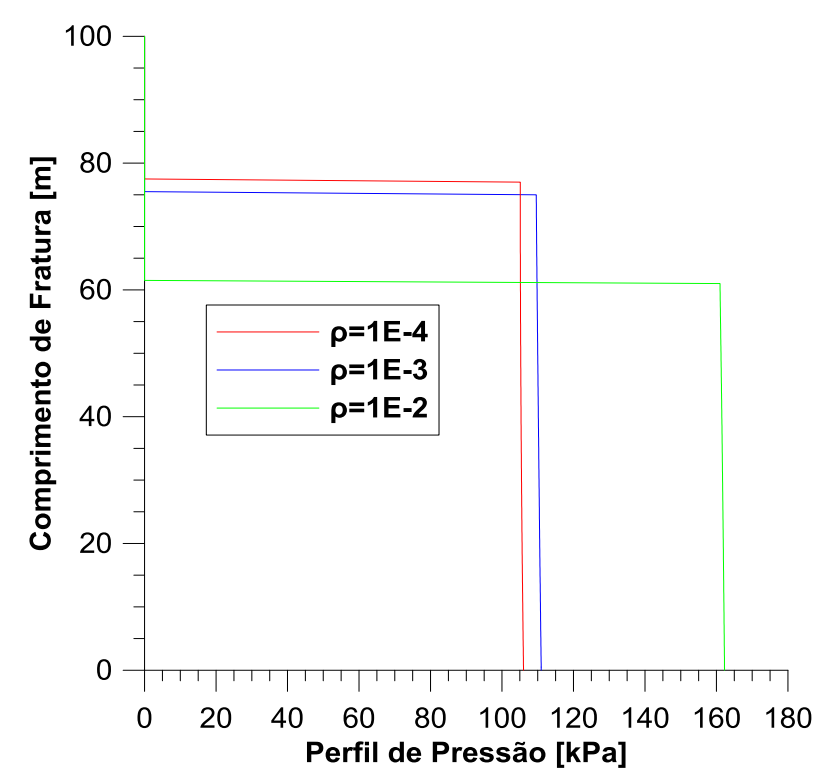

Figura 4.11: Efeito da regularização viscosa no perfil de pressão na fratura.

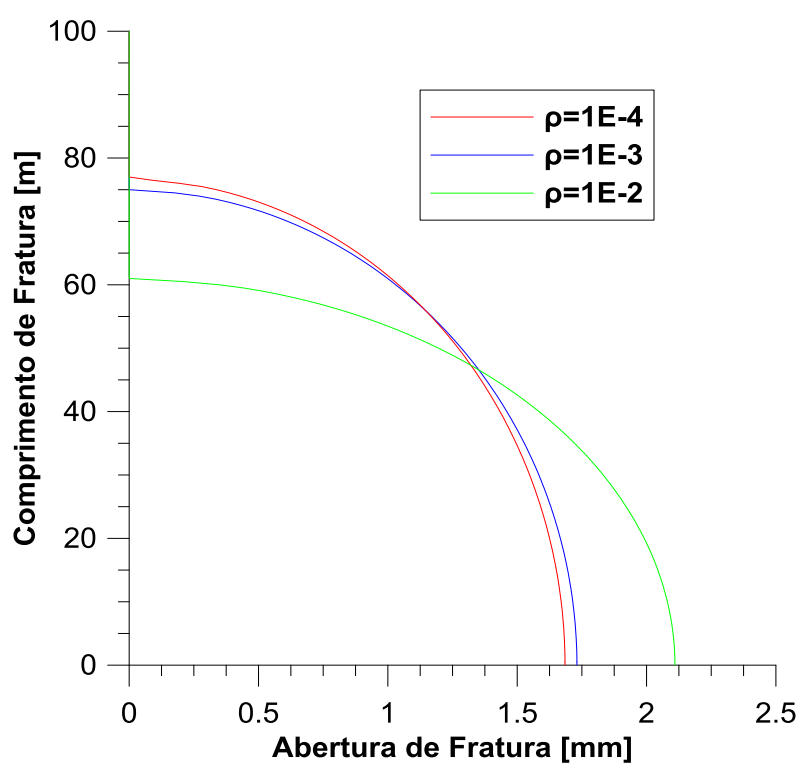

Figura 4.12: Efeito da regularização viscosa na geometria da fratura.

\subsection{Comprimento do intervalo injetado}

Nesta secção, pesquisa-se o efeito do comprimento de injeção mantendo-se constante o volume injetado por unidade de comprimento da fratura. Da figura 4.13, o valor da vazão total $\mathrm{Q}_{\text {total }}$ por unidade de comprimento, é determinado por,

$Q_{\text {total }}=Q_{\text {int }}+Q_{\text {ext }}$ 


$$
Q_{\text {int }}=\sum_{i=1}^{n-1}\left(\frac{Q_{\text {total }}}{n}\right)_{i}, \quad Q_{\text {ext }}=\sum_{j=1}^{j=2}\left(\frac{Q_{\text {total }}}{2 n}\right)_{j}
$$

Onde $\mathrm{n}=$ número de elementos injetados

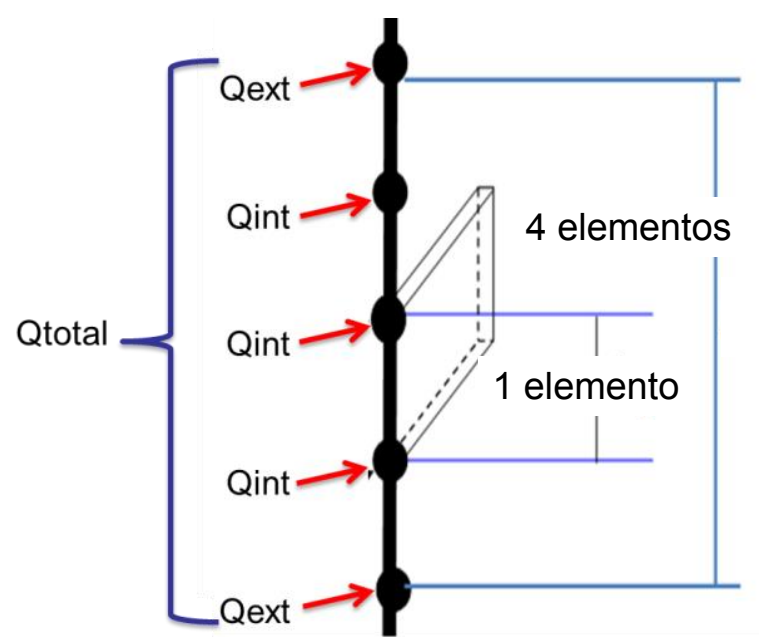

Figura 4.13: Cálculo da vazão total por unidade de comprimento

$\mathrm{Na}$ figura 4.14, observa-se que um aumento no comprimento do intervalo injetado (um elemento, três elementos e cinco elementos) diminui o valor da pressão necessária para fraturar, mas como o passar do tempo a pressão de injeção tende a ser igual em todos os casos.

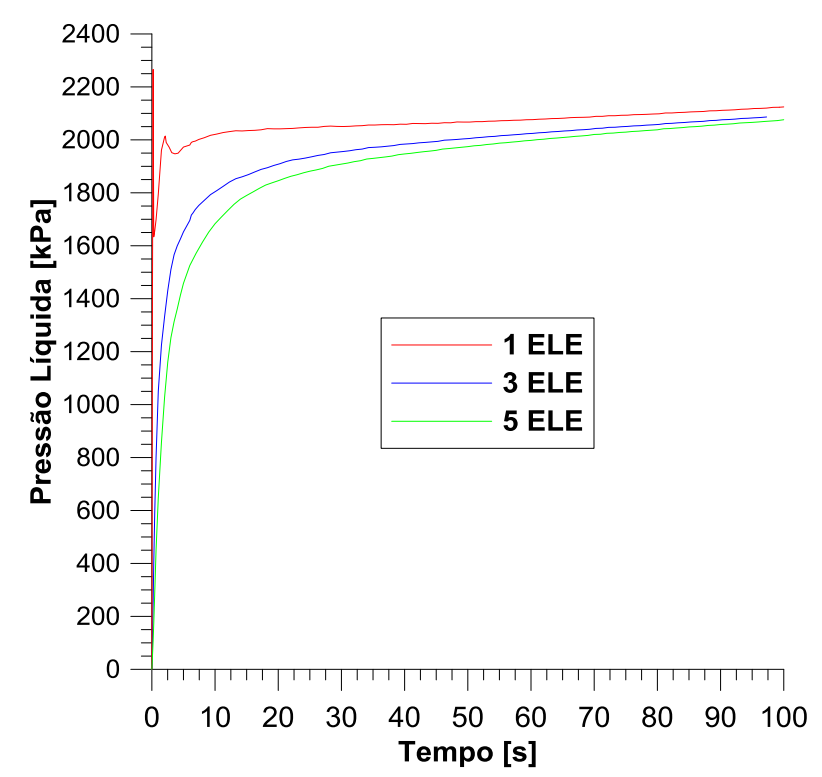

Figura 4.14: Efeito do comprimento do intervalo injetado na pressão de injeção. 
Considerando um volume total de fluido injetado por unidade de comprimento constante, a Figura 4.15 mostra que a abertura máxima da fratura é a mesma, enquanto que a Figura 4.16 e 4,17 indicam também permanecer constante o comprimento da fratura e a distribuição de pressão ao longo dela.

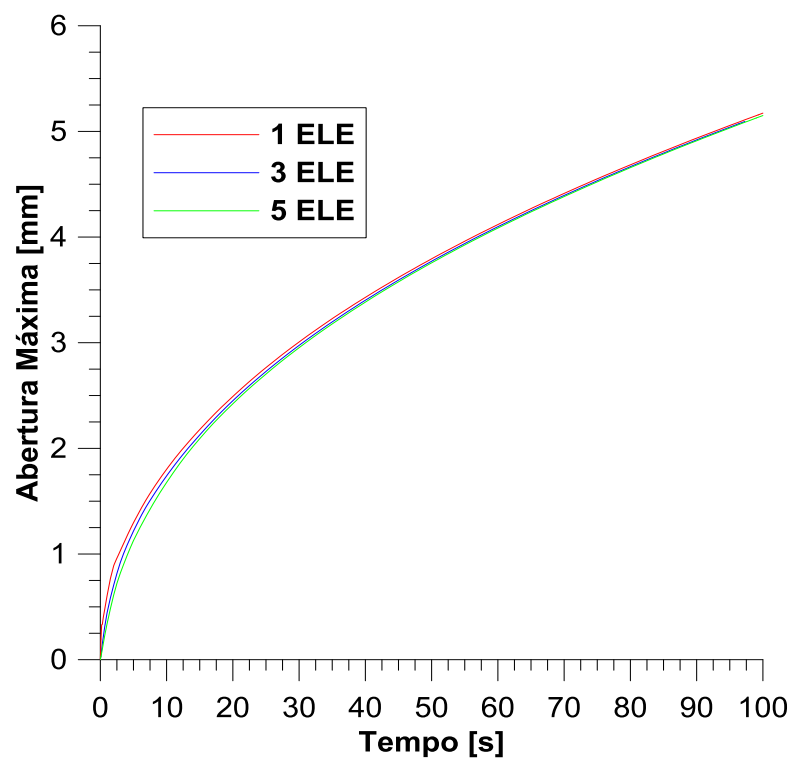

Figura 4.15: Efeito do comprimento do intervalo injetado na abertura máxima.

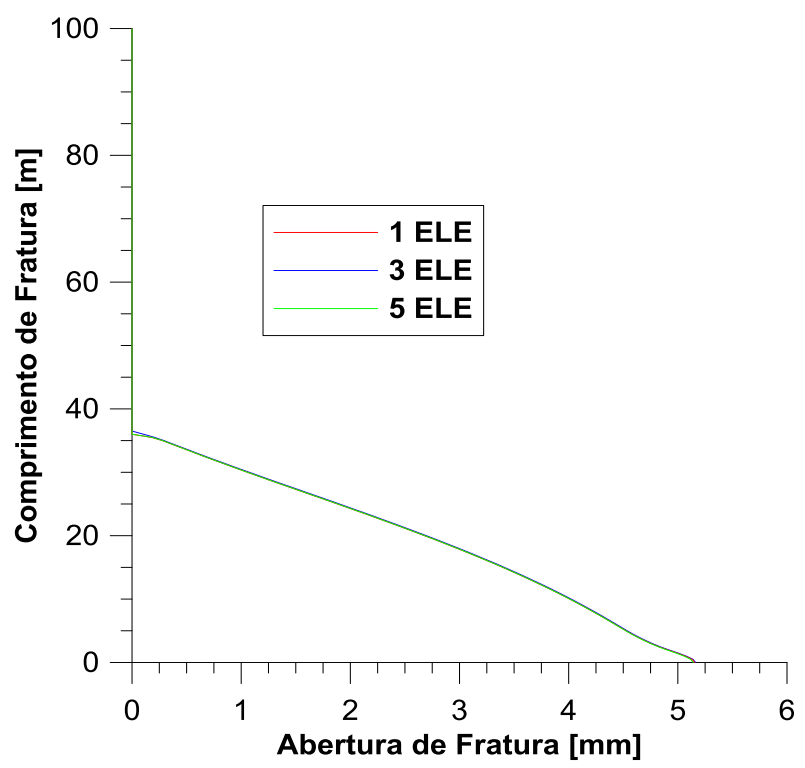

Figura 4.16: Efeito do comprimento do intervalo injetado na geometria da fratura. 


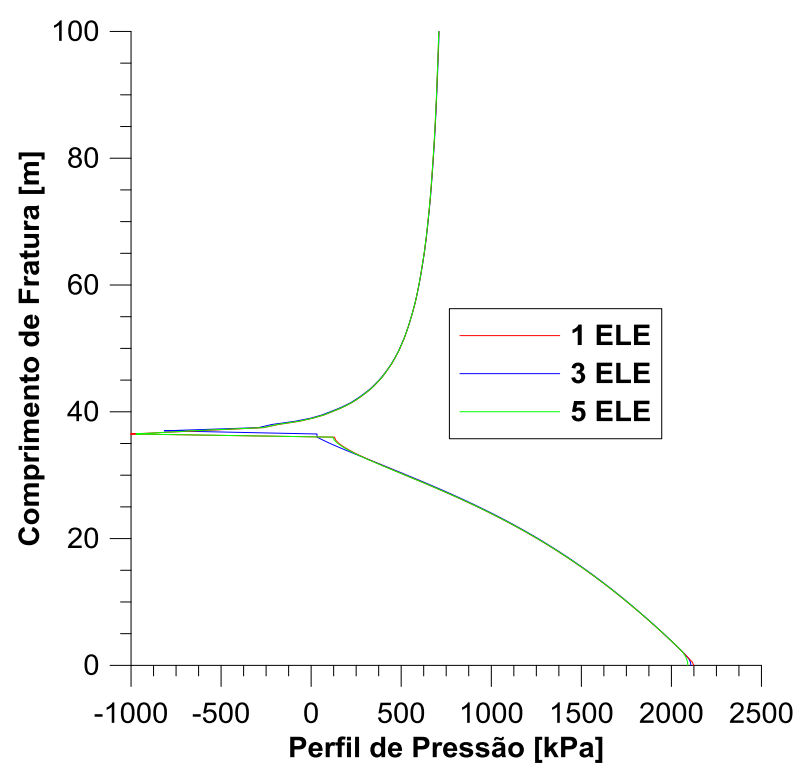

Figura 4.17: Efeito do comprimento do intervalo injetado na geometria da fratura

\subsection{Análise permanente vs Análise transiente}

Nesta seção pesquisam-se as diferenças na geometria da fratura e no perfil de pressões ao longo da fratura considerando o fraturamento hidráulico em regime de fluxo transiente e permanente. Em ambos os casos a injeção do fluido fraturante foi controlada em termos de pressão e de vazão, admitindo-se graus de liberdade de poropressão ativados e desativados (impermeável) nos elementos sólidos adjacentes à fratura.

$\mathrm{Na}$ tabela 4.2, mostra-se a terminologia utilizada para descrever os oito tipos de análise efetuados.

Tabela 4.2: Terminologia assignada para cada tipo de análise

\begin{tabular}{|c|c|c|c|c|}
\hline \multirow{1}{*}{} & \multicolumn{4}{|c|}{ Tipo de análise } \\
\cline { 2 - 5 } & \multicolumn{2}{|c|}{ Transiente } & \multicolumn{2}{c|}{ Permanente } \\
\cline { 2 - 5 } & $\begin{array}{r}\text { Elem. } \\
\text { Solido } \\
\text { C/poro }\end{array}$ & $\begin{array}{r}\text { Elem. } \\
\text { Solido } \\
\text { S/poro }\end{array}$ & $\begin{array}{l}\text { Elem. } \\
\text { Solido } \\
\text { C/poro }\end{array}$ & $\begin{array}{l}\text { Elem. } \\
\text { Solido } \\
\text { S/poro }\end{array}$ \\
\hline $\begin{array}{c}\text { CF } \\
\text { controle de } \\
\text { fluxo }\end{array}$ & $\cdots$ CFT & - CFT & $\cdots$ CFP & - CFP \\
\hline $\begin{array}{c}\text { CP } \\
\text { controle de } \\
\text { poro }\end{array}$ & $\cdots$ CPT & - CPT & $\cdots$ CPP & - CPP \\
\hline
\end{tabular}


A Figura 4.18 apresenta os efeitos da ativação do grau de liberdade de poropressão nos elementos sólidos, nas análises em regime transiente e permanente, para situações com controle de fluxo. Os resultados ilustrados na cor azul, correspondentes à situação de regime permanente com grau de poro (traço descontínuo) e sem grau de poro (traço contínuo), mostraram igual comportamento em relação à pressão de injeção, sem ocorrência de excessos de poropressão nos elementos sólidos adjacentes aos elementos coesivos deformados. Na situação de regime transiente, exibida na cor vermelha para análises com grau de poro (traço descontínuo) e sem grau de poro (traço contínuo), os excessos de poropressão influenciaram de forma significativa os valores da pressão de injeção no caso de análises com elementos com graus de liberdade em poropressão. Para o caso de elementos sem graus de poro, os resultados em regime permanente e transiente, como esperado, foram os mesmos para as situações de regime transiente e permanente.

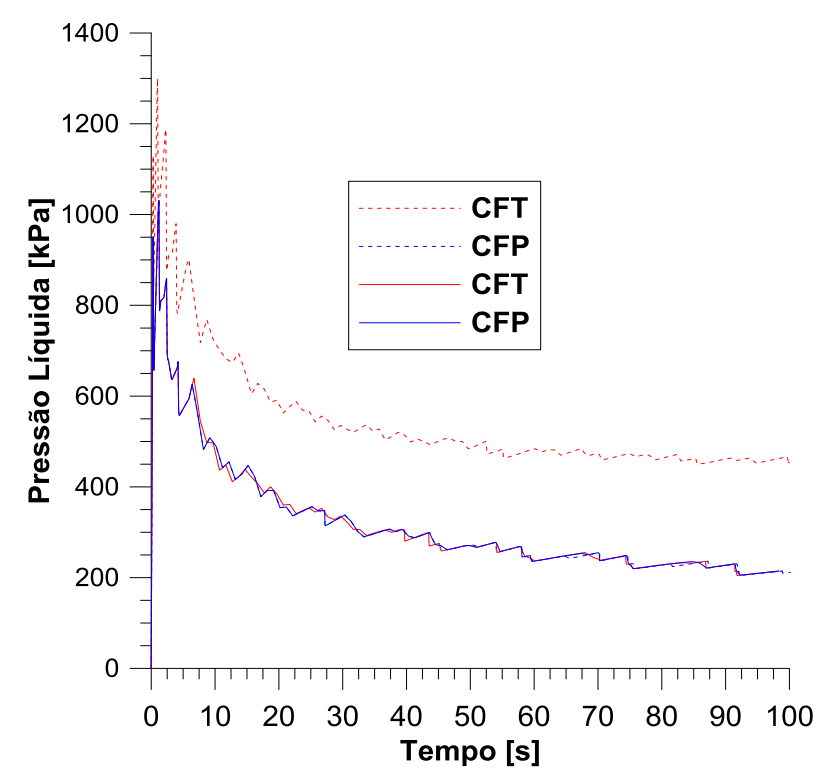

Figura 4.18: Efeito do grau de poro na pressão de injeção.

A Figura 4.19 indica que também para análises em regime transiente utilizando elementos com grau de poro a abertura máxima da fratura é diferente dos demais resultados, apresentando valores inferiores. 


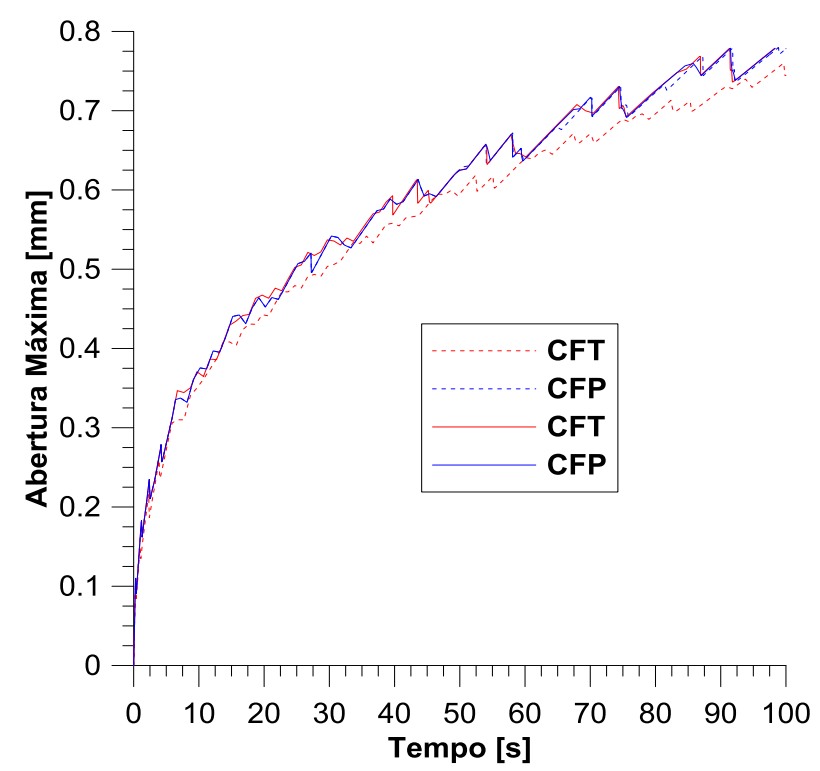

Figura 4.19: Efeito do grau de poro na abertura máxima da fratura.

Na Figura 4.20 o fraturamento foi feito com controle de fluxo e grau de poro ativado para as duas situações de fluxo (permanente e transiente) e resultados da distribuição de pressão ao longo da fratura são apresentados para os tempos $\mathrm{t}=10$, 50 e $100 \mathrm{~s}$.

Na situação de fluxo transiente, como já verificado na figura 4.18, a pressão de injeção deve ser maior devido aos excessos de poropressão nos elementos sólidos adjacentes, o que também causa um perfil de distribuição de pressão no interior da fratura com maiores valores do que na situação de fluxo permanente para provocar a propagação da fratura (Figura 4.20). Observe também na ponta da fratura a ocorrência de pressões líquidas negativas (pressão liquida igual à subtração entre pressão na fratura e a tensão confinante) nas análises em regime de fluxo transiente, pois o fluido fraturante não chega na ponta da fratura mas o fluido do meio poroso preenche esta região. 


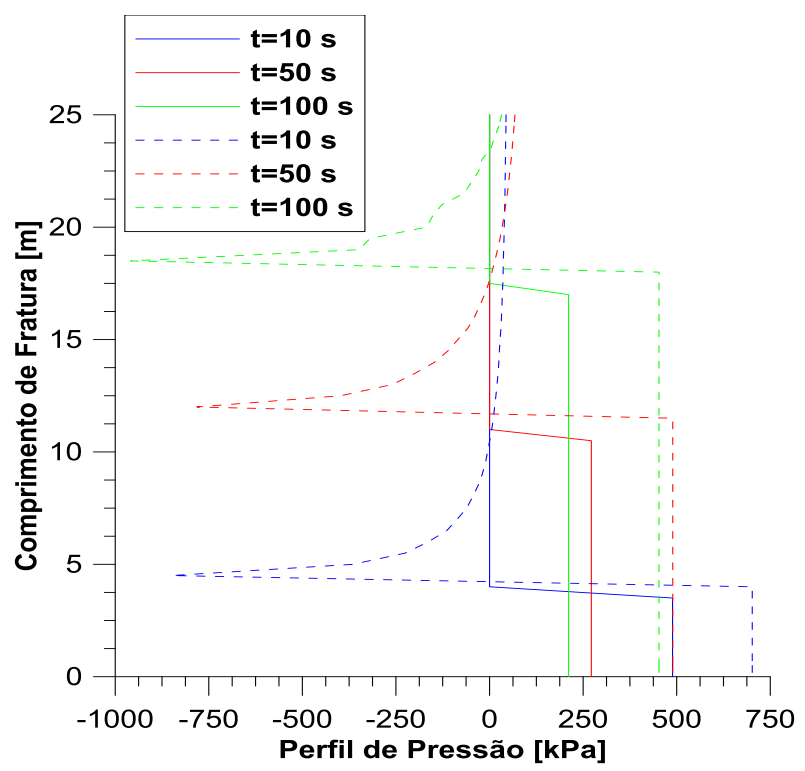

Figura 4.20: Perfil de distribuição de pressões nas situações de regime de fluxo transiente (traço descontínuo) e permanente (traço contínuo).

A Figura 4.21 mostra o comportamento da geometria da geometria da fratura nos instantes $\mathrm{t}=10,50$ e 100s para ambos os tipos de análises, mostrando menor abertura da fratura no caso transiente.

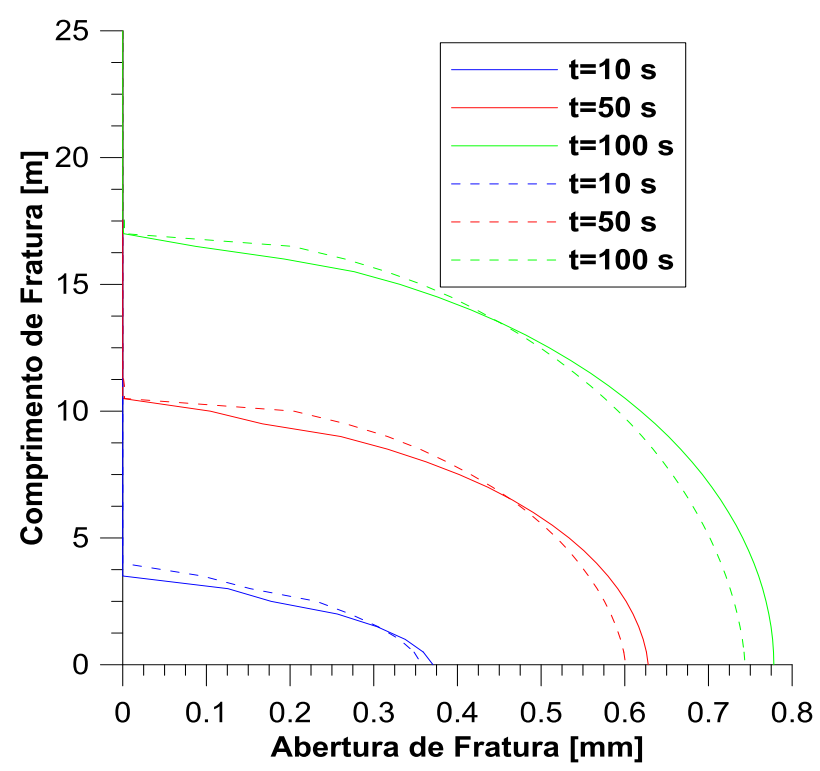

Figura 4.21: Geometria da fratura nas análises em regime de fluxo transiente (traço descontínuo) e permanente (traço contínuo).

Como demonstrado, o fraturamento hidráulico é afetado nas análises transientes quando o grau de liberdade de poropressão dos elementos sólidos é ativado, provocando excessos de poropressão devido à deformação dos elementos 
coesivos decorrente da abertura da fratura. Os resultados das próximas figuras procuram investigar de maneira mais detalhada os efeitos destes excessos de poropressão na propagação da fratura.

A Figura 4.22 ilustra o campo de poropressões no interior e ao redor da fratura na situação de regime de fluxo permanente. Fora da fratura estes valores são nulos e no interior da mesma, onde existem nós específicos para cálculo da pressão do fluido fraturante, as pressões diminuem gradualmente da linha central para as paredes da fratura.

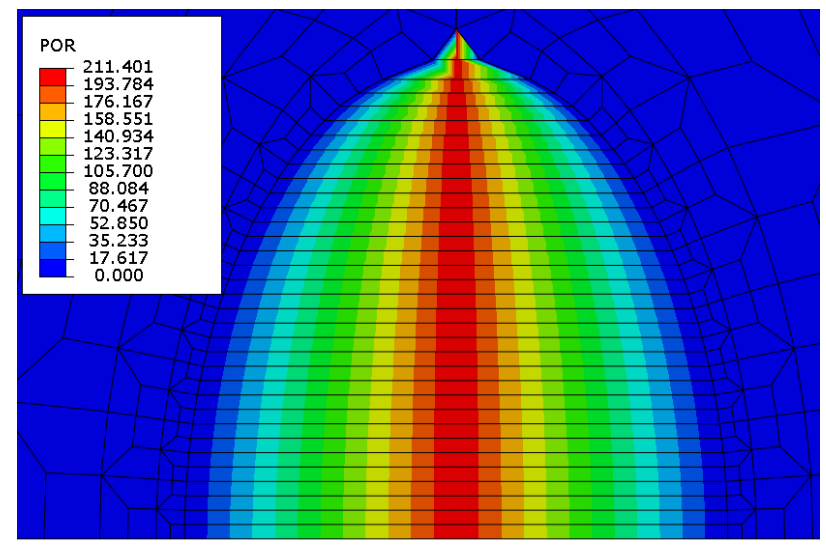

Figura 4.22: Poropressões na fratura em regime de fluxo permanente.

Para a situação de fluxo transiente, a Figura 4.23 mostra a distribuição de poropressões no interior e fora da fratura. Aqui observa-se que os valores das poropressões nos elementos sólidos junto às paredes da fratura não são nulos e também a existência de uma pequena região, junto à ponta da fratura, onde estes são negativos (sucção). $\mathrm{O}$ modelo de zona coesiva permite uma pequena região vazia entre a ponta da fratura e a frente do fluido (fluid lag). As poropressões no interior da fratura são constantes. 


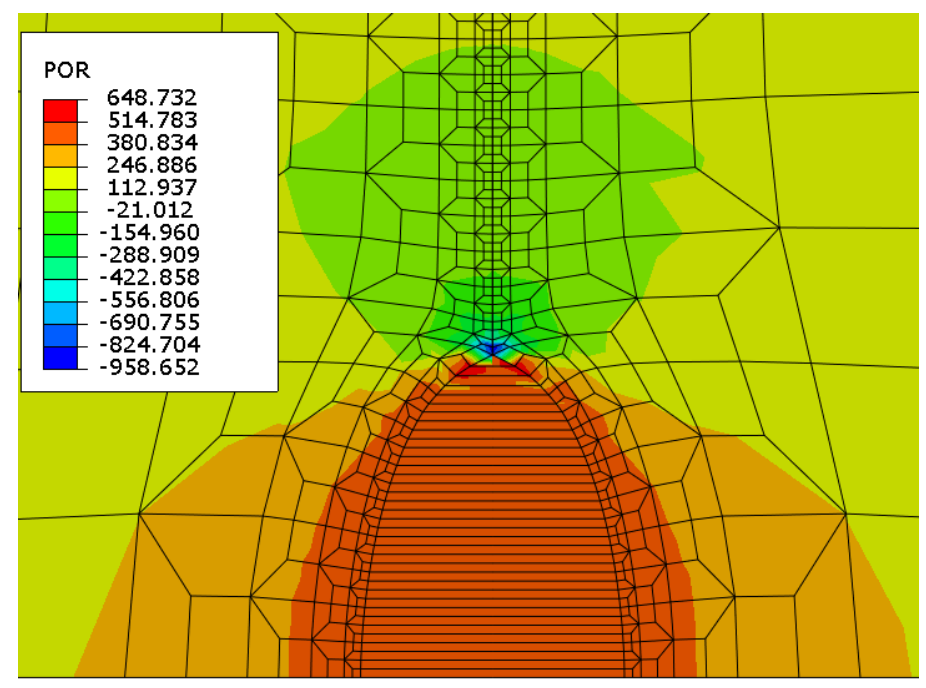

Figura 4.23: Poropressões na fratura em regime de fluxo transiente

Para os nós dos elementos sólidos adjacentes aos elementos coesivos, ao longo do comprimento $\mathrm{AB}$ da Figura 4.24, foram calculadas as variações das tensões horizontais e de poropressão. As tensões positivas máximas (tração) acontecem na ponta da fratura, como esperado, enquanto que as tensões negativas máximas (compressão) ocorrem na região de abertura da fratura (Figura 4.25). A distribuição de poropressões é nula para a situação de fluxo em regime permanente (Figura 4.26 em traço contínuo) e variam ao longo do comprimento $\mathrm{AB}$ na situação de fluxo transiente (Figura 4.26 em traço descontínuo) devido à deformação dos elementos coesivos durante a propagação da fratura.

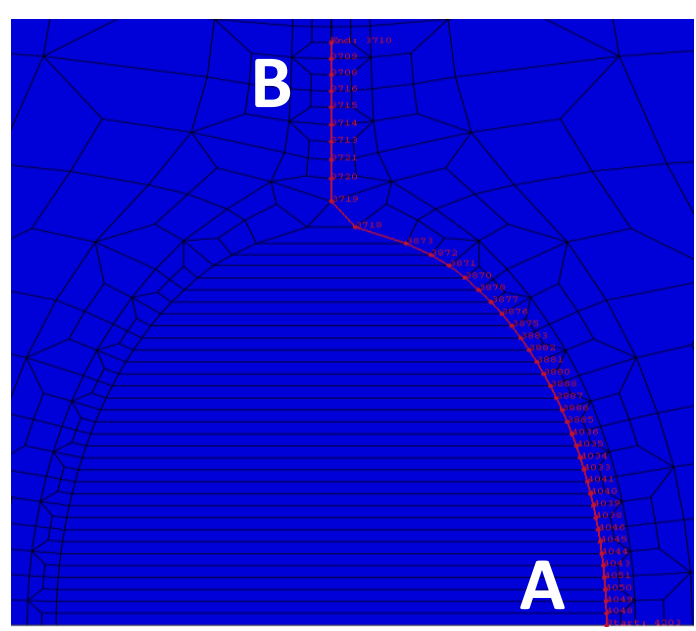

Figura 4.24: Nós selecionados para estudar os excessos de poropressão 


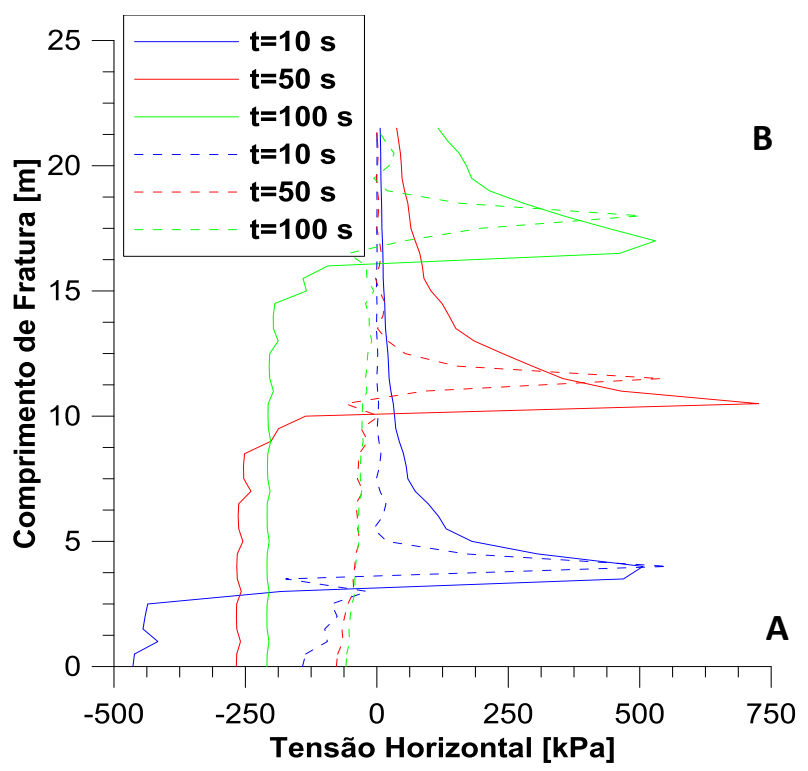

Figura 4.25: Tensões horizontais para situações de regime transiente (traço descontínuo) e permanente (traço contínuo).

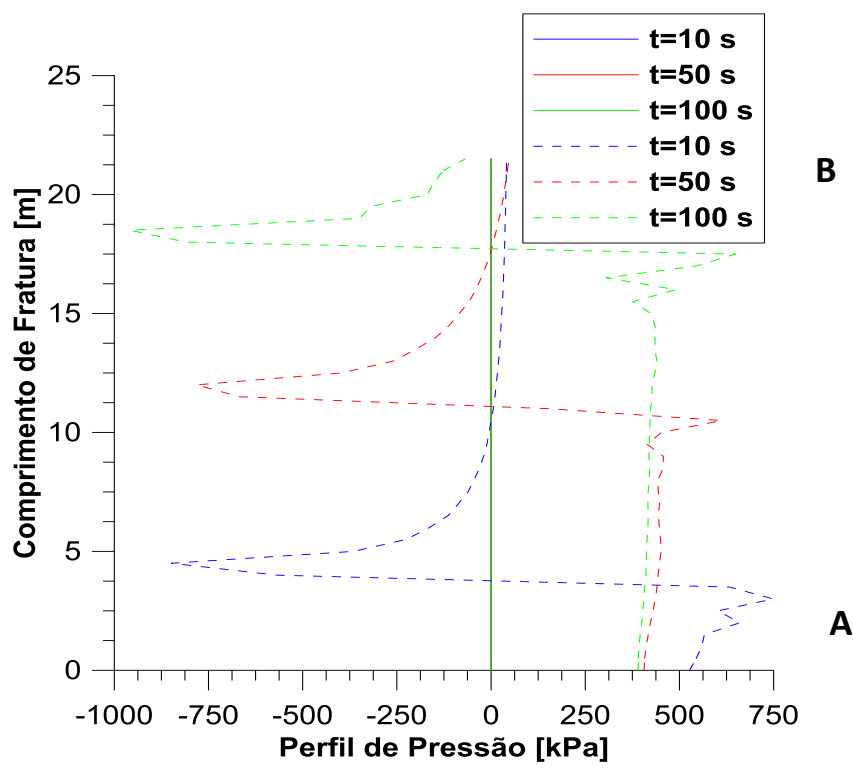

Figura 4.26: Perfil de poropressões nas situações de fluxo transiente (traço descontínuo) e fluxo permanente (traço contínuo) ao longo do comprimento $\mathrm{AB}$

A Figura 4.27 combina os resultados de distribuição de tensões horizontais (traço contínuo) e de poropressão (traço descontínuo) ao longo do comprimento $\mathrm{AB}$ para a situação de regime de fluxo transiente. Observa-se que os pontos de tração máxima correspondem àqueles onde as poropressões atingem valores máximos negativos junto à ponta da fratura, enquanto que os pontos de tensão de compressão máxima correspondem àqueles onde as poropressões são positivas. 


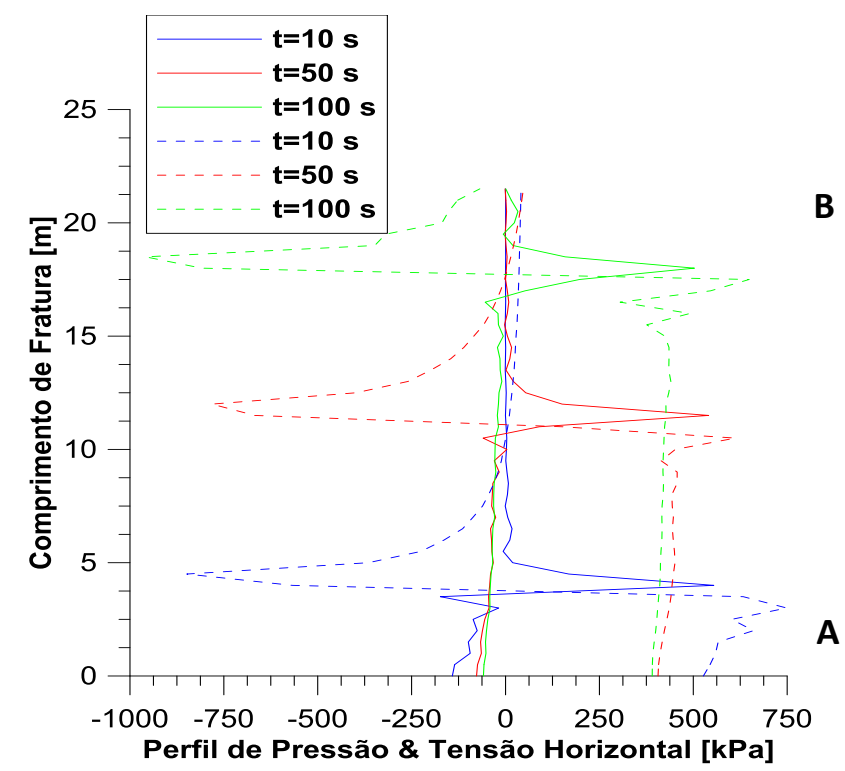

Figura 4.27: Perfil de poropressões (traço descontínuo) e de tensões horizontais (traço contínuo) ao longo do comprimento $\mathrm{AB}$ para a situação de fluxo em regime transiente.

A Figura 4.28 mostra que os acréscimos na pressão de injeção causados pelos excessos de poropressão nos elementos sólidos adjacentes à fratura podem ser controlados aumentando-se o coeficiente de permeabilidade destes elementos. $\mathrm{O}$ caso base refere-se à situação onde o grau de poro está desativado

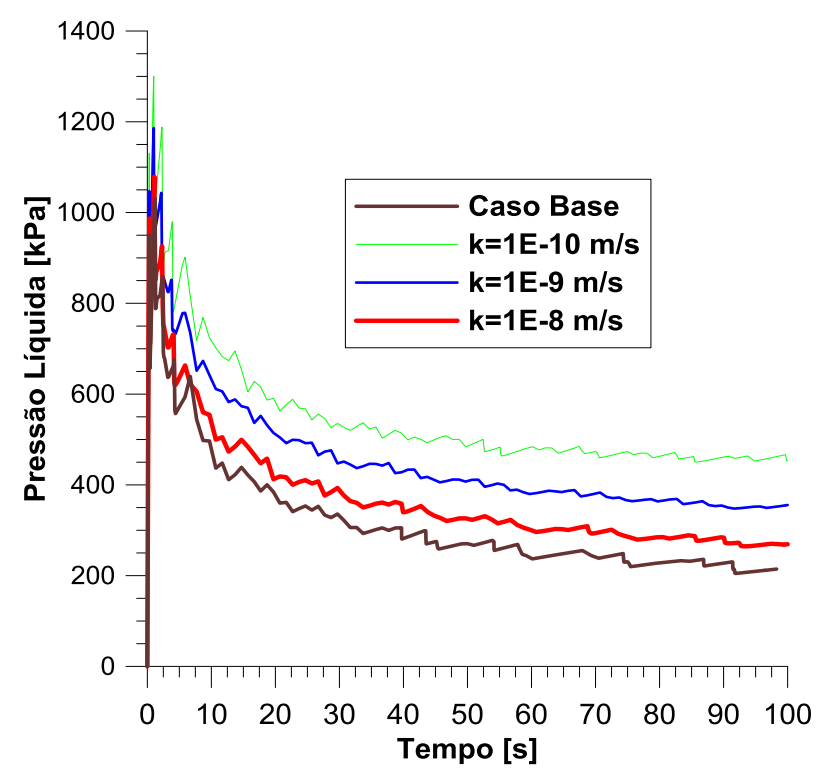

Figura 4.28: Efeito da permeabilidade na pressão de injeção

As simulações anteriores foram executadas com injeção controlada por fluxo (vazão) e, em seguida, análises serão repetidas considerando-se a injeção controlada em termos de pressão. Como foi descrito anteriormente, no caso de injeção com 
controle de pressão define-se a curva de pressão na qual o faturamento hidráulico é executado. Por esta razão, todas as situações aqui analisadas têm a mesma curva de pressão de injeção mostrada na Figura 4.29.

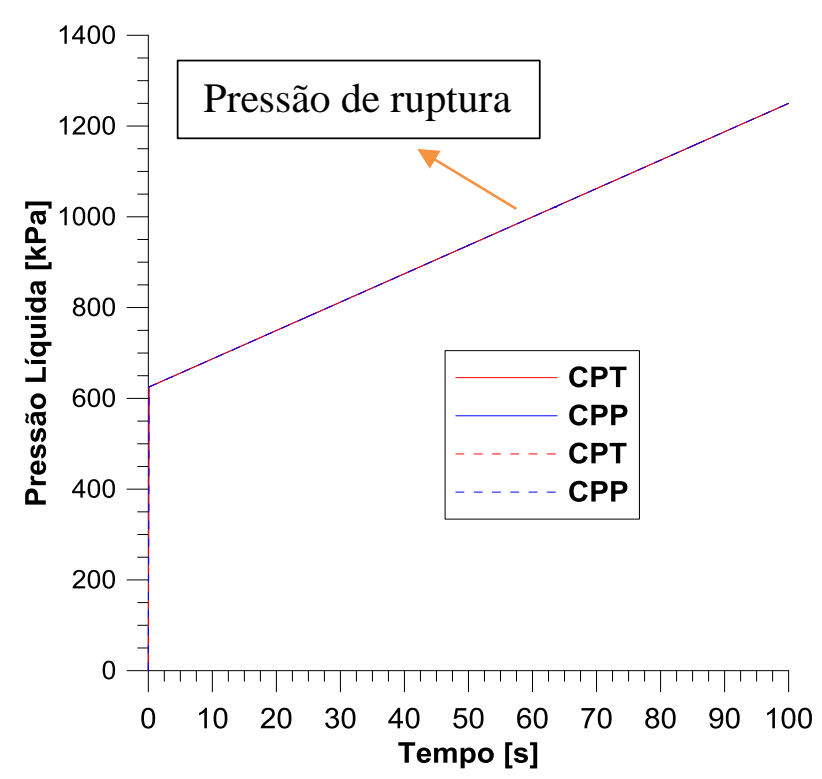

Figura 4.29: Pressão de injeção em controle de pressão

Na Figura 4.30 observa-se uma diferença significativa no comportamento da fratura na simulação com controle de pressão, com a abertura somente iniciada no tempo $t=63$ s quando a pressão de injeção atinge um valor suficientemente grande para provocar o início do faturamento do material. A partir deste instante os cálculos computacionais são feitos com intervalos de tempo muito pequenos, até a propagação da fratura chegar ao limite (contorno) do modelo, quando a inclinação da curva muda.

Como nas análises com controle de fluxo (Figura 4.18), as situações de regime de fluxo permanente com grau de poro ativado ou desativado fornecem os mesmos resultados numéricos da situação de regime de fluxo transiente sem grau de poro ativado (Figura 4.18). Novamente, diferenças de comportamento são observadas no regime de fluxo transiente com grau de poro ativo, devido aos excessos de poropressão decorrentes da deformação dos elementos coesivos junto aos elementos sólidos à medida que a fratura se propaga.

A abertura no caso transiente (linha vermelha descontinua) é muito menor comparado com os outros casos pelos excessos de poropressão que restringem a abertura (figura 4.30). Na figura 4.30, observamos também para o tempo final da 
simulação aberturas de fraturas de $40 \mathrm{~mm}$, devido a que em 65 segundos se propagou a fratura até o contorno do modelo e a injeção de fluido continuou até finalizar a simulação (100 segundos), por isso a abertura da fratura atinge valores exagerados. Neste tipo de injeção se recomenda realizar o processo até a fratura atingir o contorno do modelo.

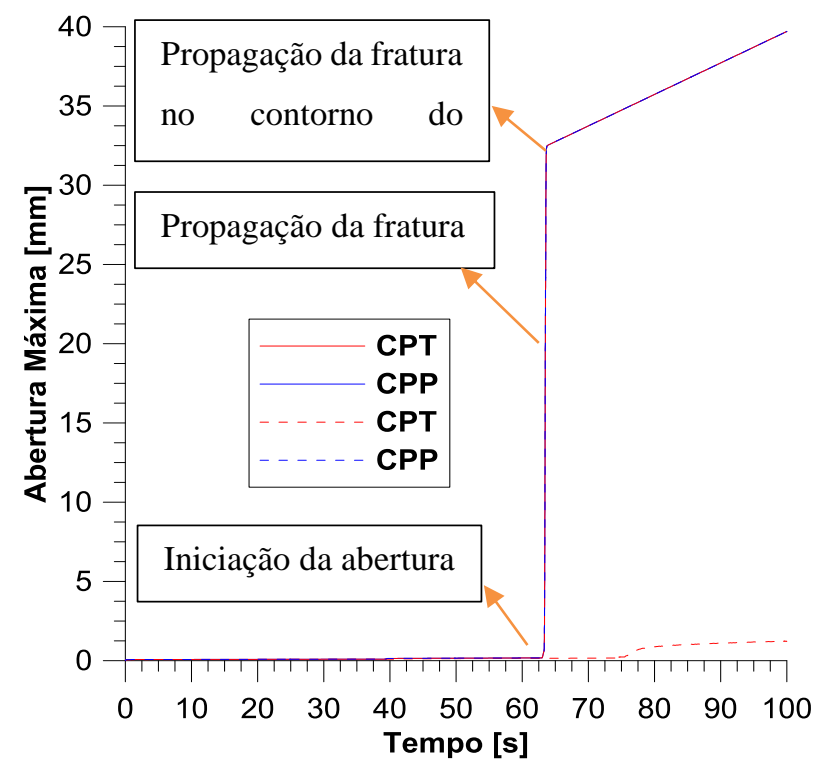

Figura 4.30: Abertura máxima da fratura em controle de pressão

A Figura 4.31 apresenta a distribuição do perfil de pressões ao longo da fratura para vários tempos considerando regimes de fluxo permanente (traço contínuo) e transiente (traço descontínuo), admitindo os elementos sólidos com grau de poro ativado. Observa-se que no regime transiente os excessos de poropressão gerados restringem a propagação da fratura e a aplicação da pressão de injeção deve ser maior do que na situação de fluxo permanente. No tempo final da

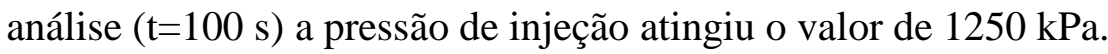




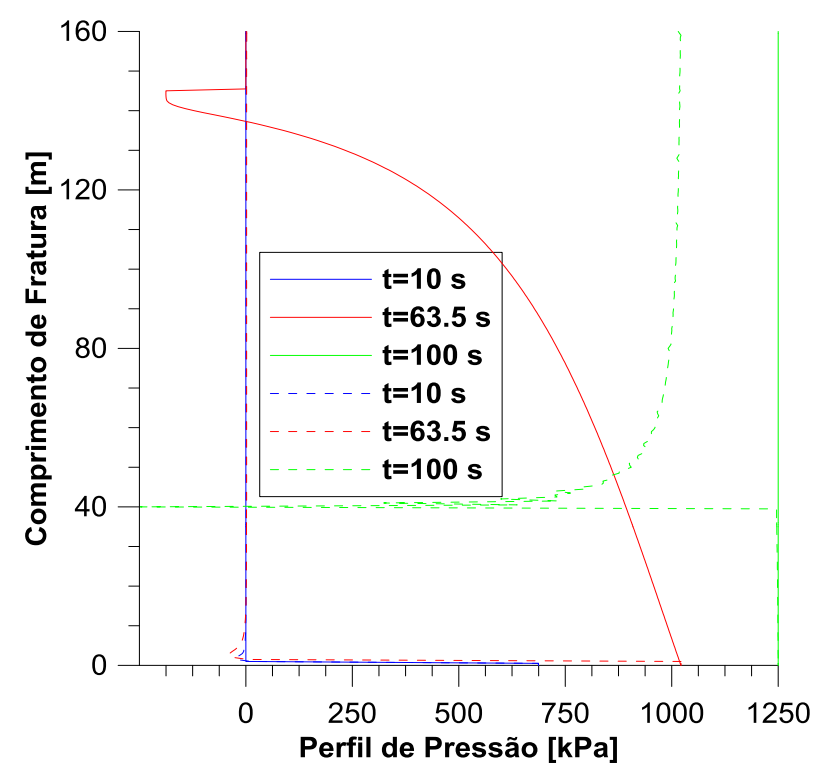

Figura 4.31: Perfil de pressão para análise transiente e permanente.

Finalmente a Figura 4.32 indica que para a situação de fluxo permanente (traço contínuo) a geometria da fratura é muito maior em comparação com a situação de fluxo transiente (traço descontínuo). No tempo final $\mathrm{t}=100 \mathrm{~s}$ na análise permanente (linha verde continua) toda a camada foi fraturada, enquanto que na análise transiente (linha verde descontinua) o fraturamento alcançou um comprimento muito menor de $40 \mathrm{~m}$.

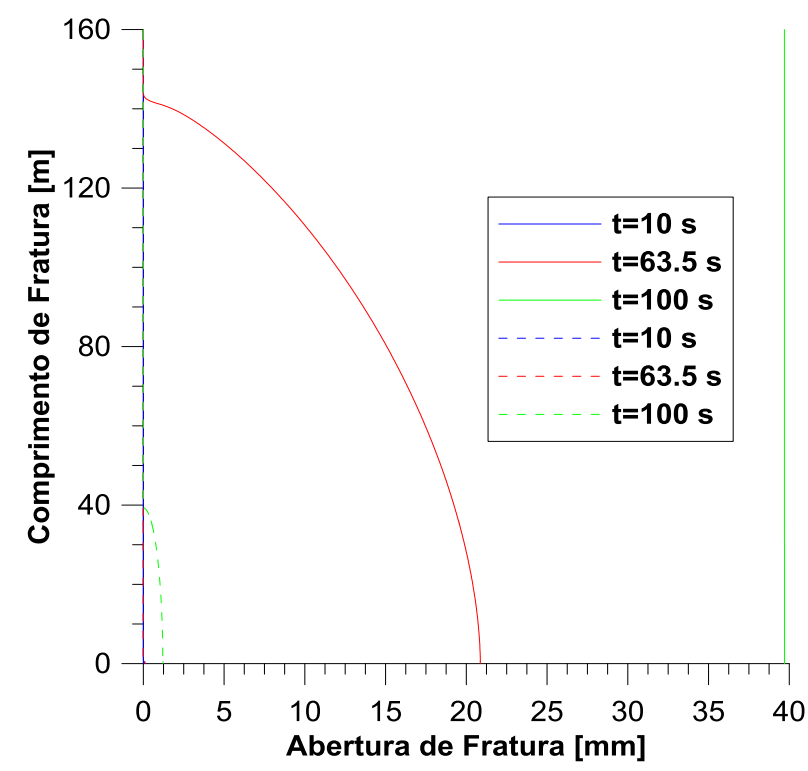

Figura 4.32: Geometria da fratura em situações de regime de fluxo transiente (traço descontínuo) e permanente (traço contínuo). 


\subsection{Modelo sintético de três camadas com barreiras impermeáveis}

Na figura 4.33, ilustra-se o modelo de três camadas com contraste de tensões e poropressões entre suas camadas, utilizado no fraturamento hidráulico. Isto com o objetivo de estudar o efeito de camadas adjacentes sobre-pressionadas na propagação de fraturas.

. Como se observa na figura 4.33, ao se executar o passo geostático para determinar a configuração de equilíbrio, ocorreu uma redistribuição das poropressões em relação àquelas inicialmente especificadas.

Passo Geostático
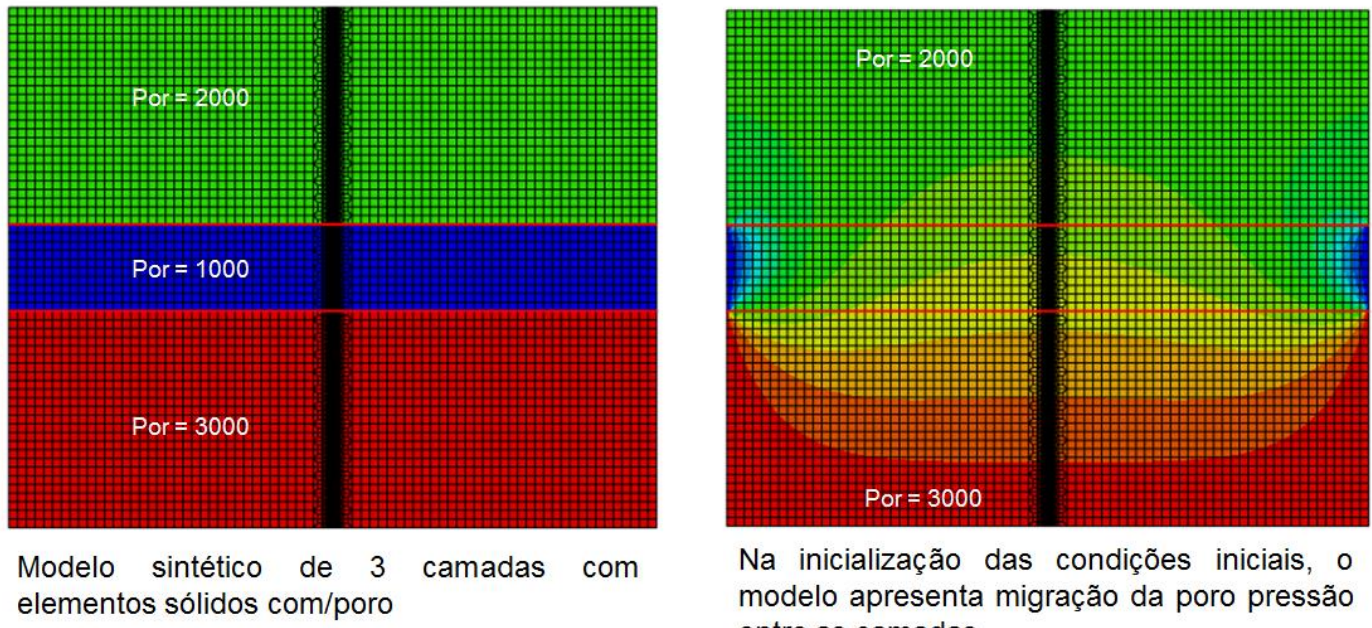

$\mathrm{Na}$ inicialização das condições iniciais, o modelo apresenta migração da poro pressão entre as camadas

Figura 4.33: Migração da poropressão no passo geostático

Para evitar este fato, implementou-se um modelo de três camadas com barreiras impermeáveis nas interfaces para restringir a redistribuição de poropressões na etapa de equilíbrio geostático, como mostra a figura 4.34

A malha esta composta por elementos contínuos bidimensionais de quatro nós com grau de liberdade de deslocamento e poropressão ativos, as barreiras impermeáveis por elementos contínuos bidimensionais de quatro nós só com grau de liberdade de deslocamento e para representar a fratura temos elementos coesivos bidimensionais de quatro nós com grau de liberdade de deslocamento e poropressão e dois nós só com grau de liberdade de poropressão onde será injetada a vazão para induzir o fraturamento hidráulico. 
As condições de contorno do modelo são: restrições de deslocamento na direção vertical para a base e topo do modelo e na direção horizontal para as bordas direitas e izquerda do modelo, para a condicão de contorno de poropressão tem-se asignado seus valores iniciais correspondentes a cada região do modelo.
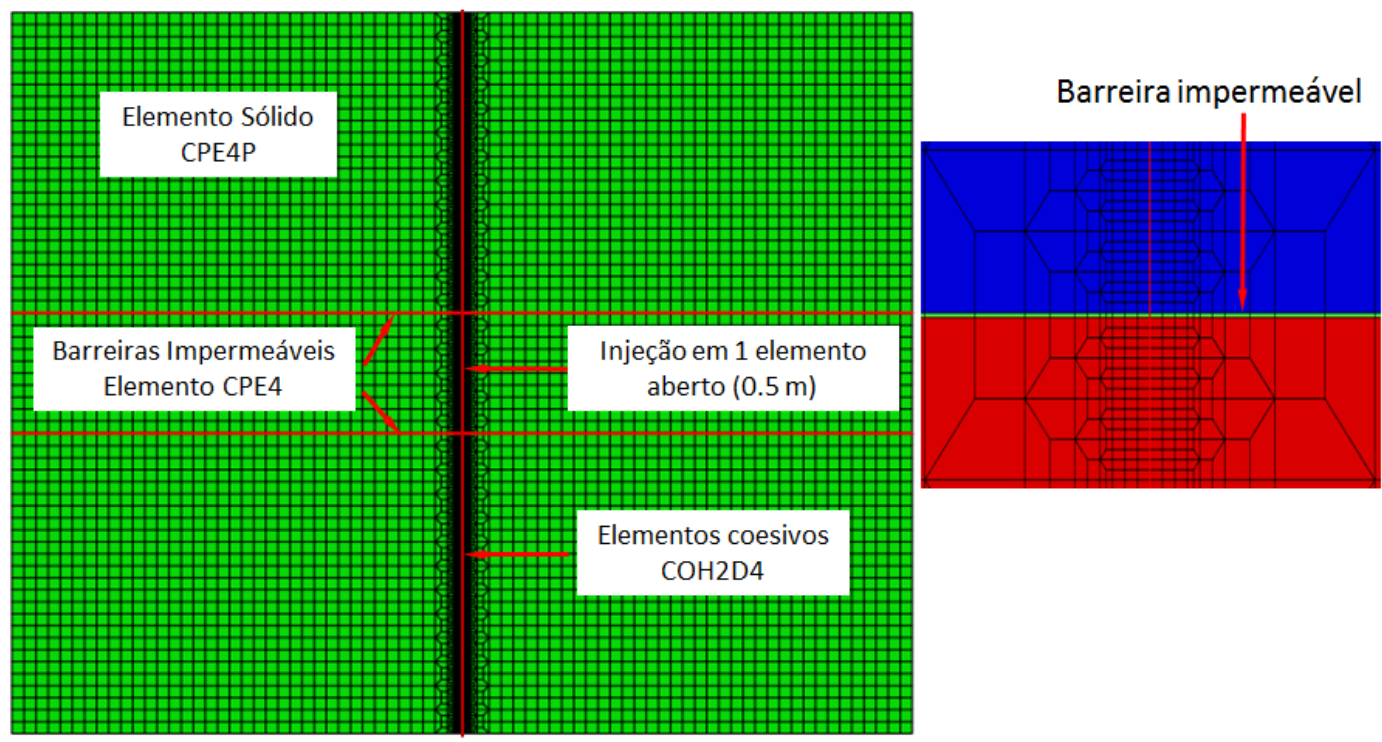

Figura 4.34: Modelo de três camadas com barreiras impermeáveis.

Na tabela 4.3, apresentam-se as condições iniciais de poropressão $P_{0}$ e tensões horizontais efetivas $\sigma_{e f}$ das três camadas para três casos de estudo:

Tabela 4.3: Condições iniciais do modelo de três camadas

\begin{tabular}{|c|c|c|c|c|}
\hline & & caso 1 & caso 2 & caso 3 \\
\hline \multirow{2}{*}{ camada 1} & $\sigma_{e f}[\mathrm{kPa}]$ & 3000 & 4000 & 2000 \\
\hline & $\mathrm{P}_{0}[\mathrm{kPa}]$ & 2000 & 2000 & 2000 \\
\hline \multirow{2}{*}{ camada 2} & $\left.\sigma_{\text {ef }}[\mathrm{kPa}]\right]$ & 1000 & 1000 & 1000 \\
\hline & $\mathrm{P}_{0}[\mathrm{kPa}]$ & 1000 & 1000 & 1000 \\
\hline \multirow{2}{*}{ camada 3} & $\sigma_{\text {ef }}[\mathrm{kPa}]$ & 2000 & 2000 & 4000 \\
\hline & $\mathrm{P}_{0}[\mathrm{kPa}]$ & 3000 & 3000 & 3000 \\
\hline
\end{tabular}

Com a introdução de barreiras impermeáveis de elementos sólidos nas interfaces das camadas consegue-se evitar na simulação computacional a ocorrência de uma redistribuição de poropressões, mantendo-se as condições prescritas iniciais. Estas barreiras impermeáveis podem afetar o comportamento do 
fraturamento hidráulico (pressão e abertura da fratura), razão pela qual pesquisa-se a influência das barreiras por meio de uma análise de sensibilidade para verificação de uma espessura adequada dos elementos que evitem, ou minimizem, perturbações no processo de faturamento hidráulico. Com este objetivo foram construídos dois modelos com espessuras de barreiras de $0.5 \mathrm{~m}$ e $0.25 \mathrm{~m}$.

A Figura 4.35 mostra duas seções de controle (A-B e C-D) para verificação da distribuição de poropressões: a primeira quanto a ponta da fratura atinge os pontos 1,2 e 3 e a seção C-D quando a ponta da fratura se encontra no ponto 1 .

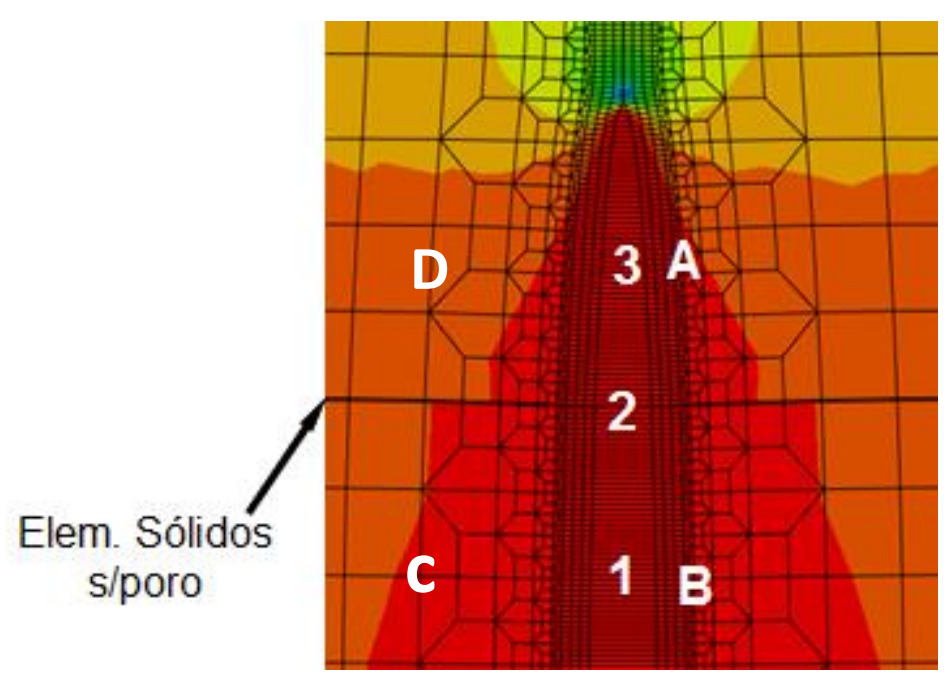

Figura 4.35: Seções A-B e C-D, pontos 1, 2 e 3, para verificação das poropressões.

Para o caso da espessura da barreira impermeável de $0.5 \mathrm{~m}$, a Figura 4.36 apresenta a variação das poropressões ao longo do comprimento da seção A-B em três tempos: tempo 1 quando a ponta localiza-se no ponto 1 , tempo 2 quando a mesma encontra-se no ponto 2 e tempo 3 quando a ponta da fratura atinge o ponto 3.

As linhas contínuas são para o caso de ausência de barreiras impermeáveis e as linhas descontínuas quando admitida suas existências. Verifica-se facilmente que nos tempos 2 e 3 há diferenças nos valores de poropressão, com oscilações e defasagem entre os valores máximos. 


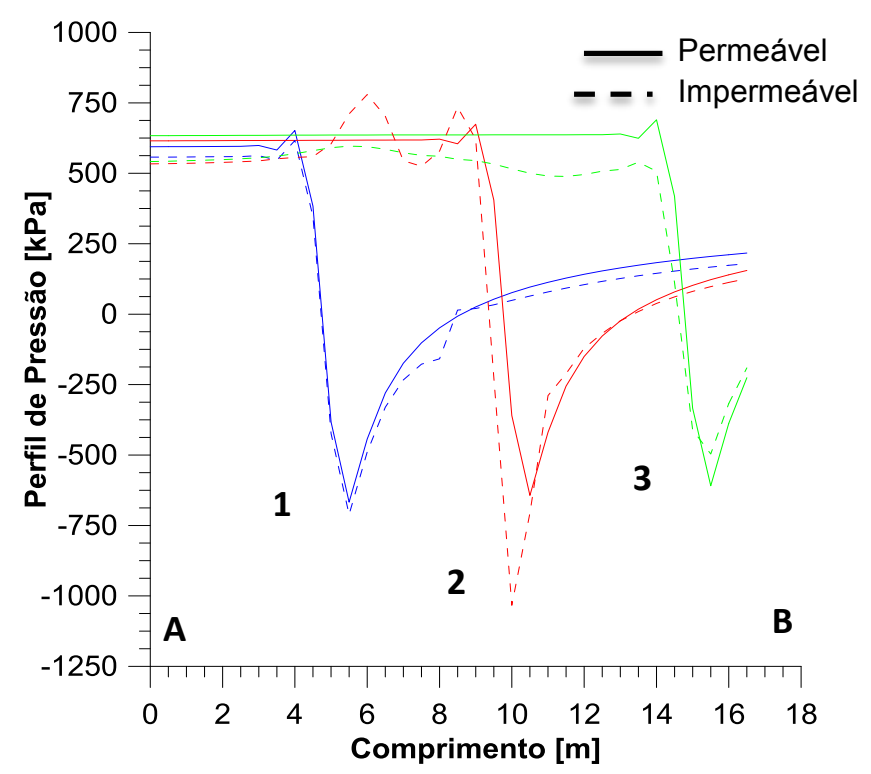

Figura 4.36: Distribuição de poropressões ao longo da seção A-B

A Figura 4.37 mostra a variação da poropressão ao longo do comprimento da seção C-D, mostrando curvas paralelas, porém separadas de um valor aproximado de $60 \mathrm{kPa}$. Conclui-se que a espessura do elemento da barreira impermeável $(0.5 \mathrm{~m})$ não é adequada para simulação do faturamento hidráulico.

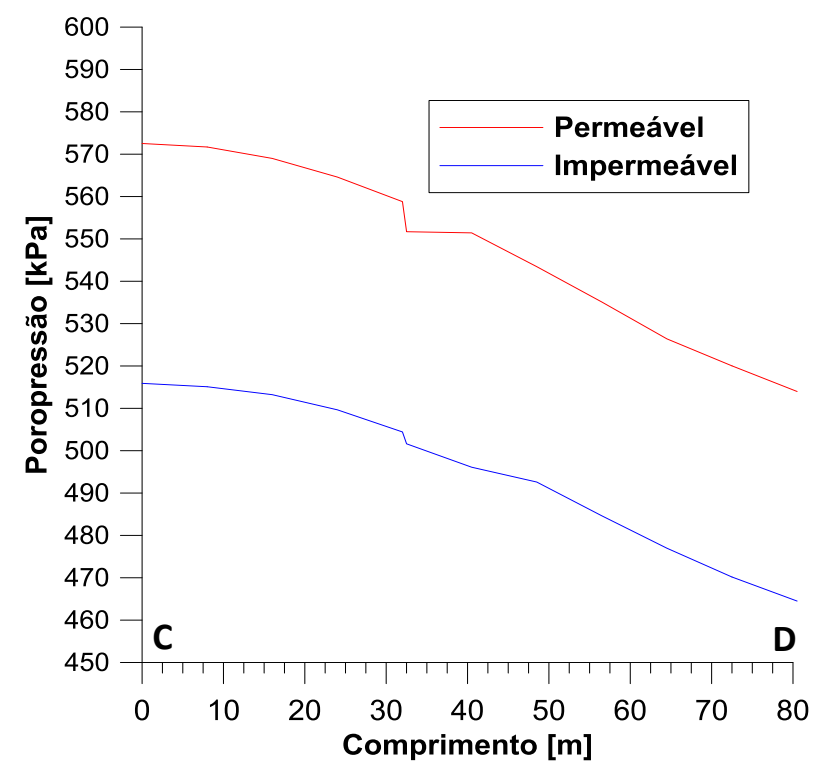

Figura 4.37: Distirbuição das poropressões ao longo da seção C-D.

As Figuras 4.38 e 4.39 mostram a influência da barreira impermeável na distribuição das poropressões pós-pico e na abertura máxima da fratura, respectivamente, ratificando a observação anterior de que se trata de modelagem 
inadequada para investigação do problema. O caso permeável não tem barreiras impermeáveis, enquanto que a barreira impermeável tem valor de permeabilidade nula.

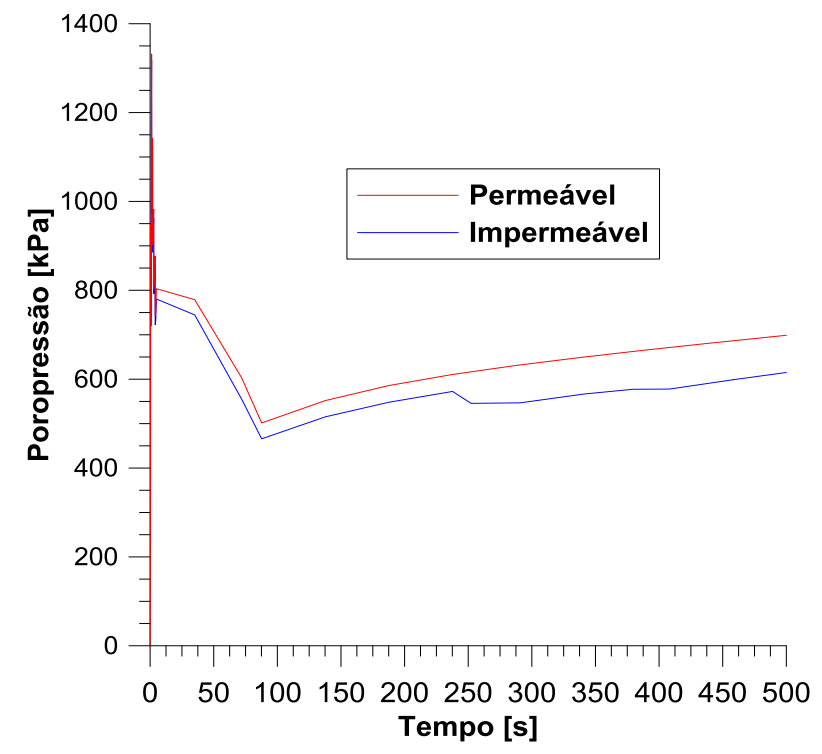

Figura 4.38: Pressão de injeção com e sem barreira impermeável

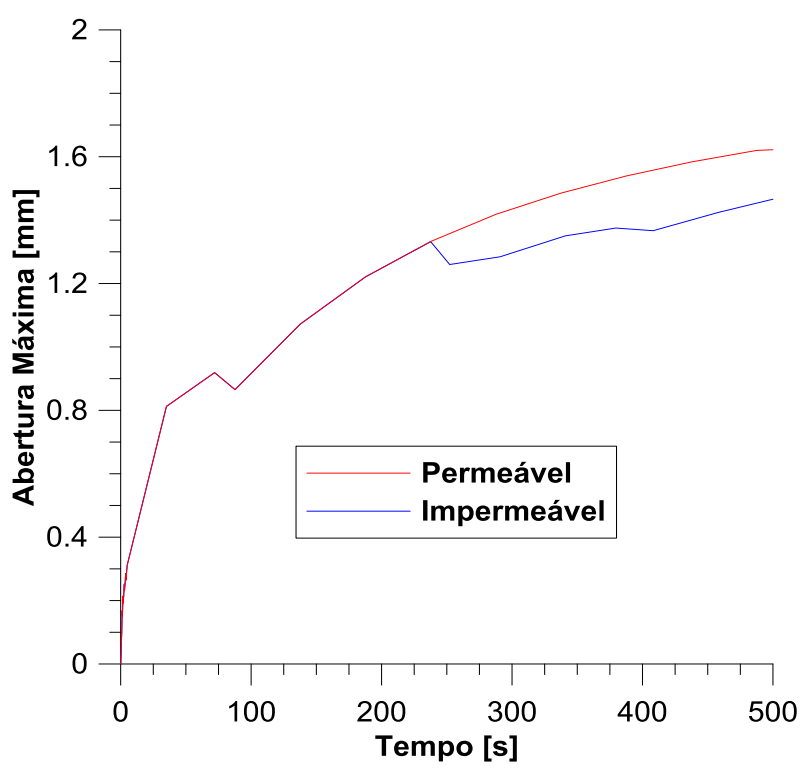

Figura 4.39: Abertura máxima da fratura com e sem barreira impermeável

No caso de espessura da barreira impermeável 0.25 m, a Figura 4.40 mostra em linhas contínuas as poropressões calculadas sem barreiras impermeáveis e, em linhas descontinuas, os valores determinados com barreiras impermeáveis. Neste caso verifica-se que ambas as distribuições exibem concordância bem mais 
satisfatória do que na situação anterior, considerando espessura de barreira impermeável $0.5 \mathrm{~m}$.

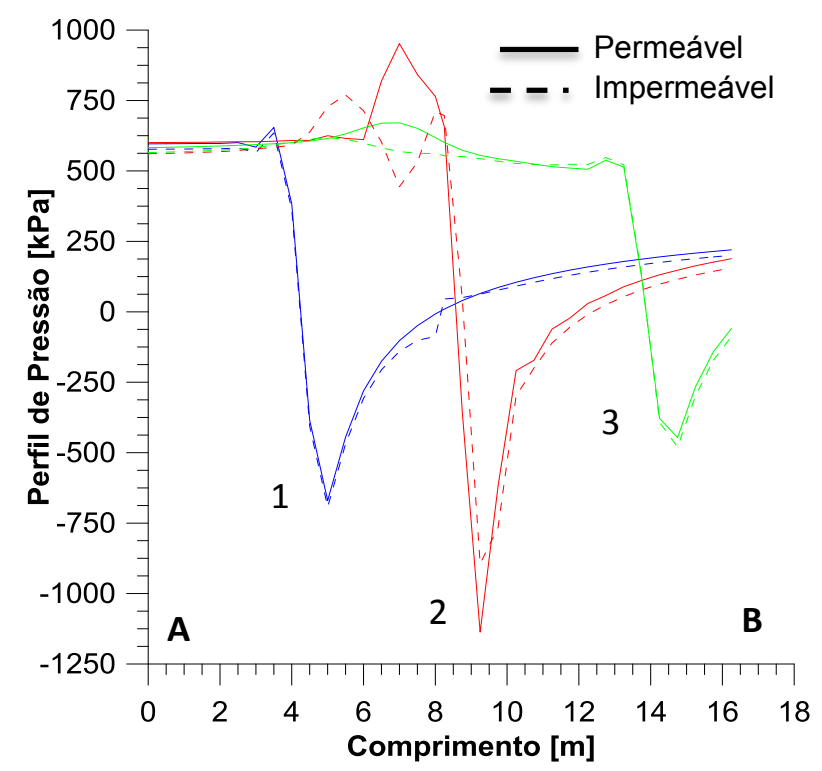

Figura 4.40: Distribuição de poropressões ao longo da seção A-B.

A Figura 4.41 ilustra a variação da poropressão ao longo do comprimento da seção C-D, com as curvas mostrando uma defasagem de aproximadamente $20 \mathrm{kPa}$ entre as situações de com e sem barreira impermeável na modelagem computacional.

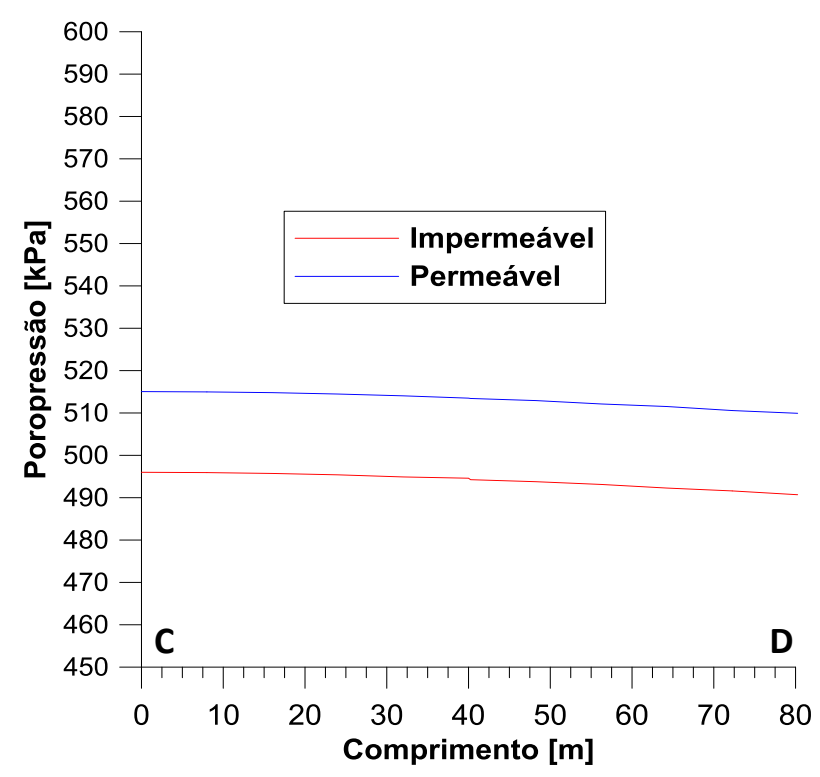

Figura 4.41: Poropressão ao longo da trajetória C-D 
$\mathrm{Na}$ figura 4.42, as curvas revelam bom ajuste entre si, indicando que a espessura do elemento de $0.25 \mathrm{~m}$ é adequada para simulação de barreira impermeável e assim evitar a redistribuição de poropressões na etapa de equilíbrio geoestático do problema.

Essa variação da poropressão depois de atingir o pico de ruptura é causado pela propagação nas camadas adjacentes com contrastes de tensões e poropressões. A poropressão aumenta para atingir a resistência de tração e propagar a fratura, logo da ruptura e propagação há uma diminuição da pressão por que o fluido deve preencher o novo espaço gerado, posteriormente aumenta para propagar na camada seguinte com contraste de tensões e poropressões.

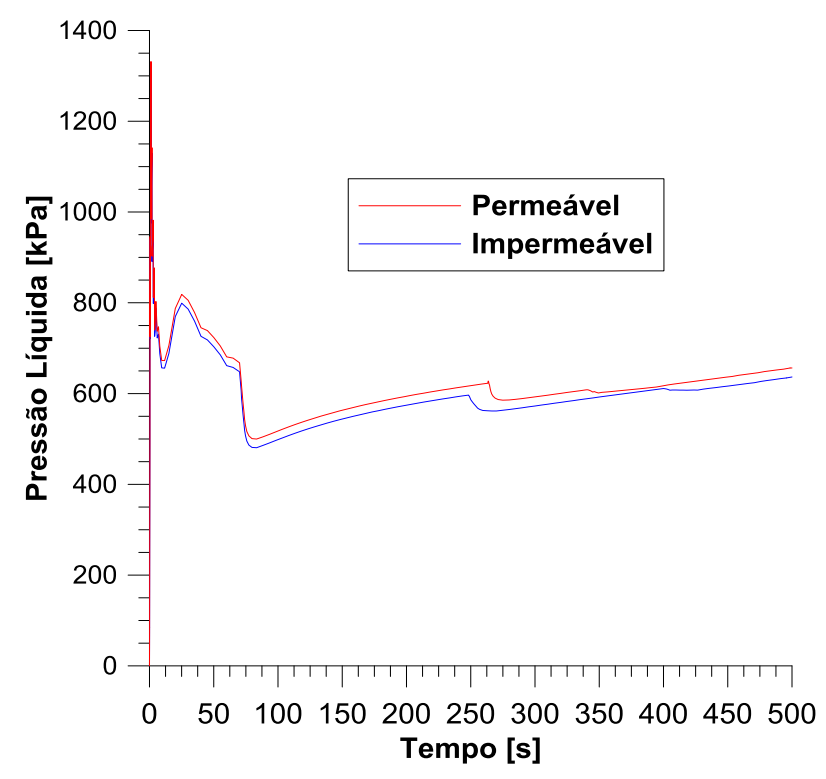

Figura 4.42: Pressão de injeção com e sem barreira impermeável

A Figura 4.43 mostra uma boa concordância entre os valores da abertura máxima da fratura, considerando os modelos propostos para solucionar o problema de migração de poropressão no passo geostático da análise. 


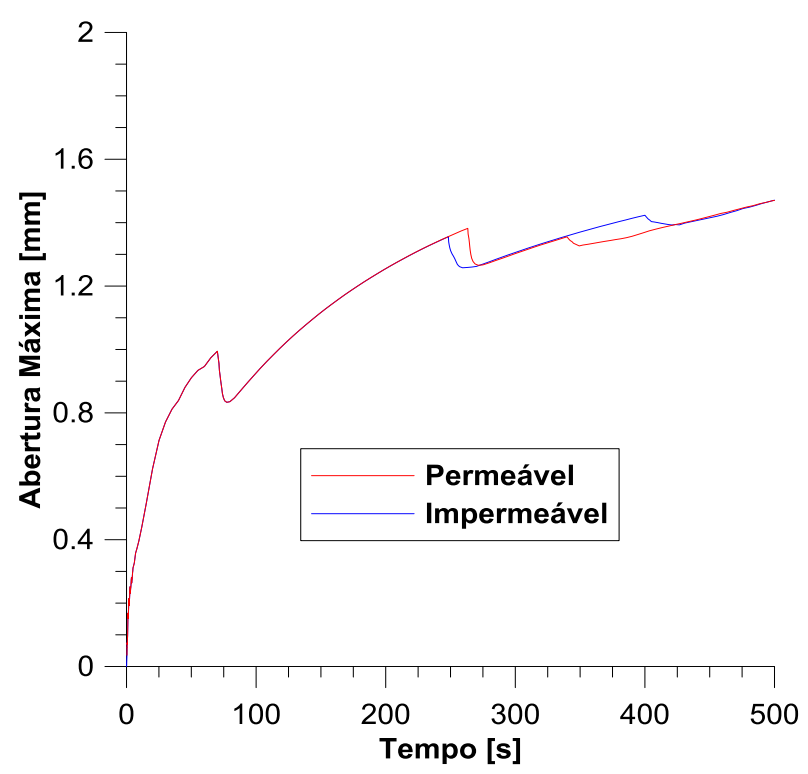

Figura 4.43: Abertura máxima da fratura com e sem barreira impermeável.

Para estimativa dos efeitos na geometria da fratura do contraste das tensões horizontais e de poropressões entre camadas adjacentes, análises foram feitas considerando três casos de condições iniciais conforme Tabela 4.3.

No primeiro caso, mesmo tendo contraste de tensões efetivas (sendo menor na camada adjacente inferior) a propagação da fratura é simétrica, pois os valores de poropressões iniciais somados com as tensões efetivas produzem igual contraste de tensões totais, como mostrado na figura 4.44 .

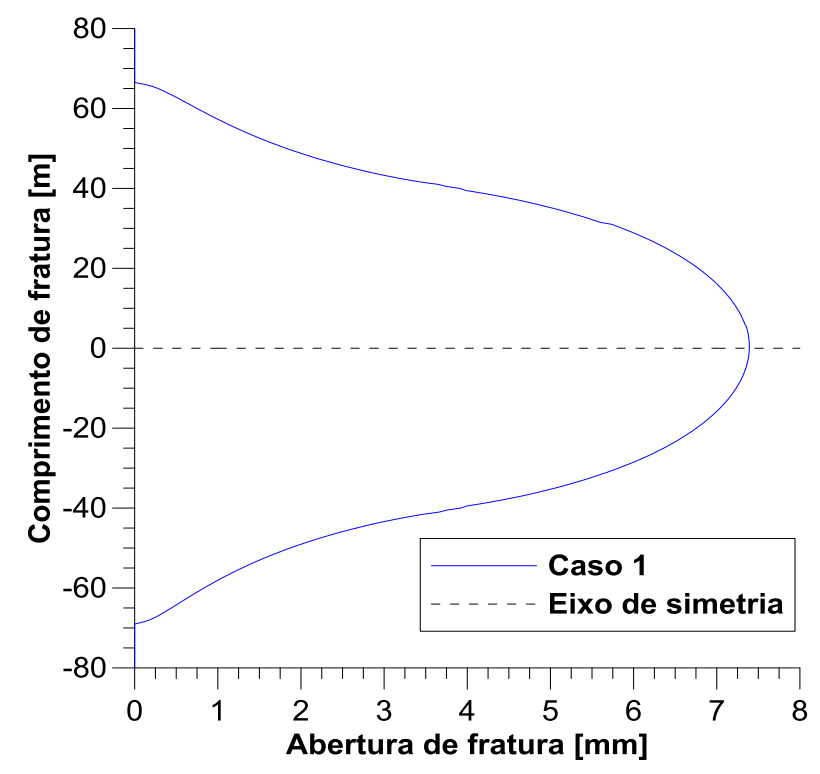

Figura 4.44: Geometria da fratura para o caso 1. 
Para o segundo caso, o contraste de tensão efetiva com a camada adjacente superior é maior (mesmo que se tenha poropressão menor, a tensão total é maior) causando que a propagação da fratura seja favorecida para a camada adjacente inferior com contraste de tensão efetiva, figura 4.45 .

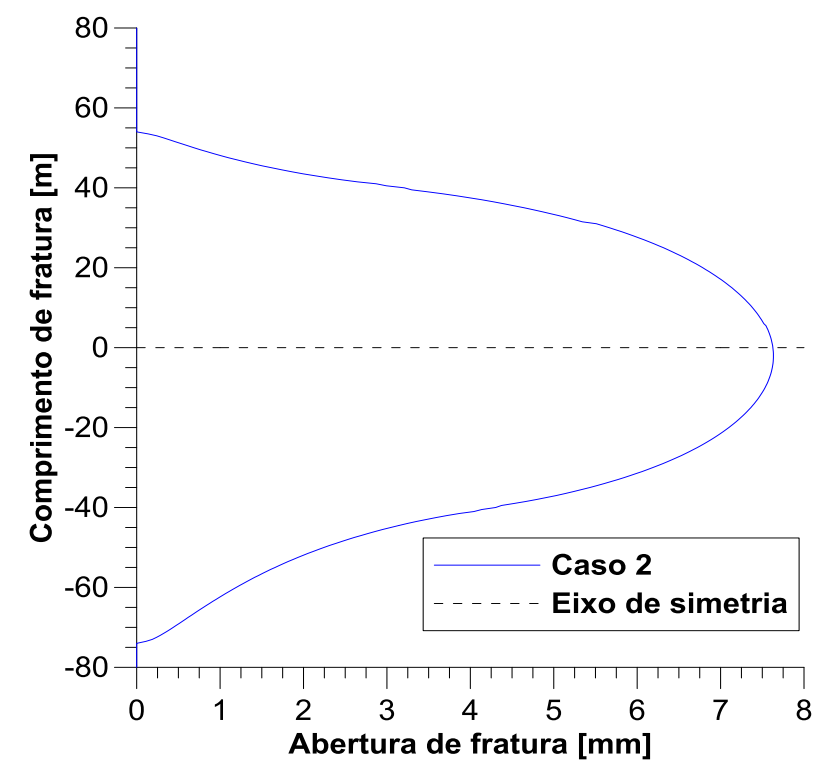

Figura 4.45: Geometria da fratura para o caso 2.

Para o terceiro caso, o contraste de tensão efetiva e poropressão com a camada adjacente superior é muito menor causando que a propagação da fratura seja favorecida nesta camada, figura 4.46 .

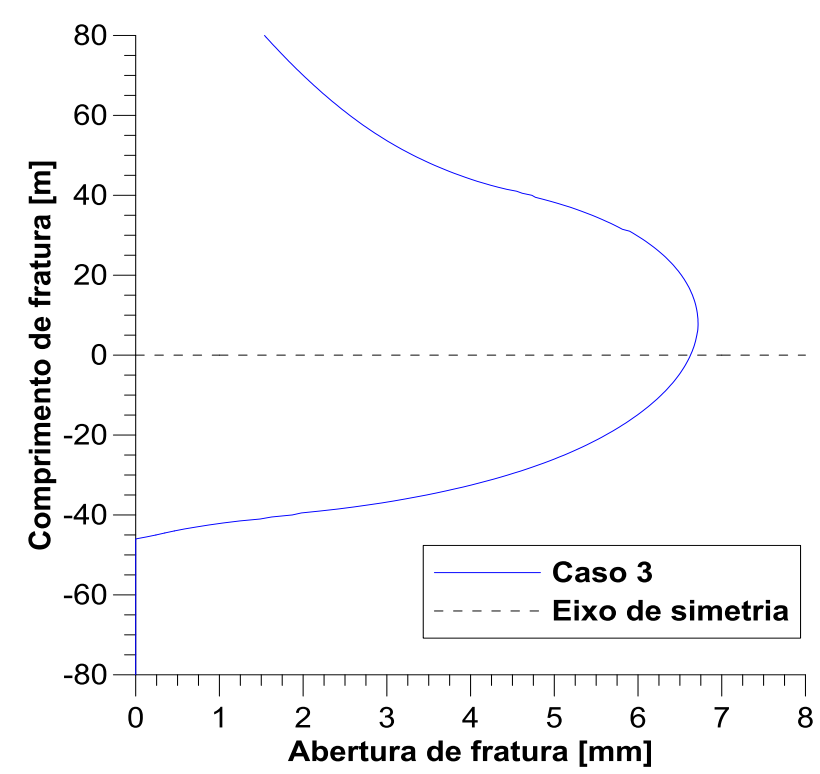

Figura 4.46: Geometria da fratura para o caso 3. 
Tabela 4.4 Anánlisis de fatores atuantes na modelagem numérica

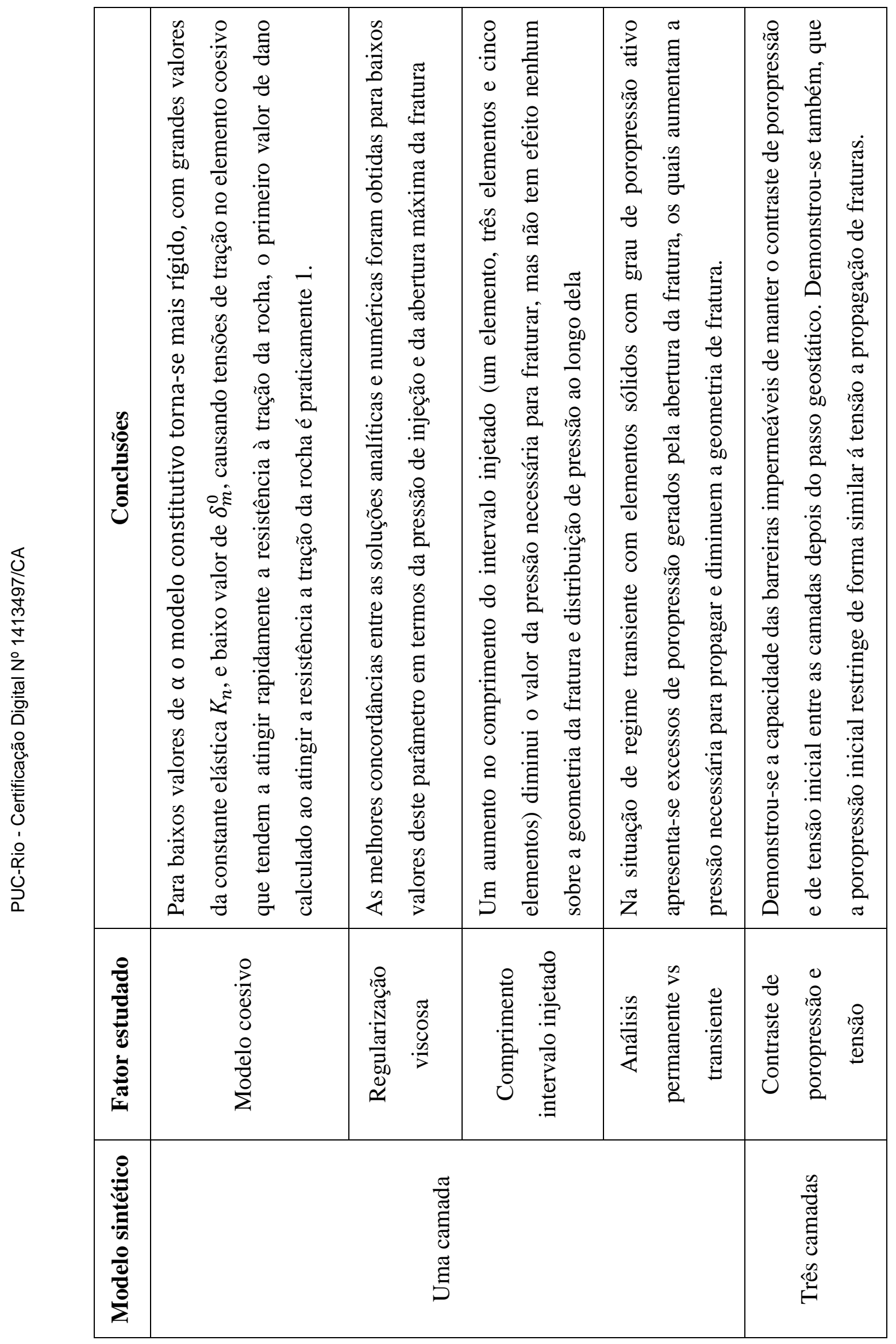




\section{5 Comparação dos resultados analíticos e numéricos}

Neste capítulo, apresenta-se a comparação dos resultados analíticos (KGD) e numéricos para o modelo de uma camada, em termos da abertura e comprimento da fratura e perfil de distribuição de pressões, apresenta-se também uma comparação do modelo analítico do regime de propagação de fratura dominado pela rigidez (K-vertice) com a simulação realizada em Abaqus. Para os modelos estudados de três camadas comparações são feitas com as soluções analíticas propostas por Simonson (1978) e Fung (1987).

Na figura 5.1 mostra-se o modelo de uma camada utilizado na simulação do fraturamento hidráulico, cujos resultados são comparados com as soluções analíticas KGD da seção 2.2.2. e do KGD no regime de propagação dominado pela rigidez da seção 2.3. Tensões e poropressão iniciais foram admitidas nulas pois as soluções analíticas utilizadas não levam em conta estes valores.

Apresenta-se também, um detalhe da malha de transição entre uma região mais densa, junto à fratura, e outra de menor discretização, mais distante. A malha esta composta por elementos contínuos bidimensionais bi-lineares de quatro nós só com grau de liberdade de deslocamento ativo e para representar a fratura temos elementos coesivos bidimensionais de quatro nós de deslocamento e dois nós de poropressão onde será injetada a vazão para induzir o fraturamento hidráulico.

As condições de contorno do modelo são: restrições de deslocamento na direção vertical para a base e topo do modelo e na direção horizontal para as bordas direitas e izquerda do modelo. 


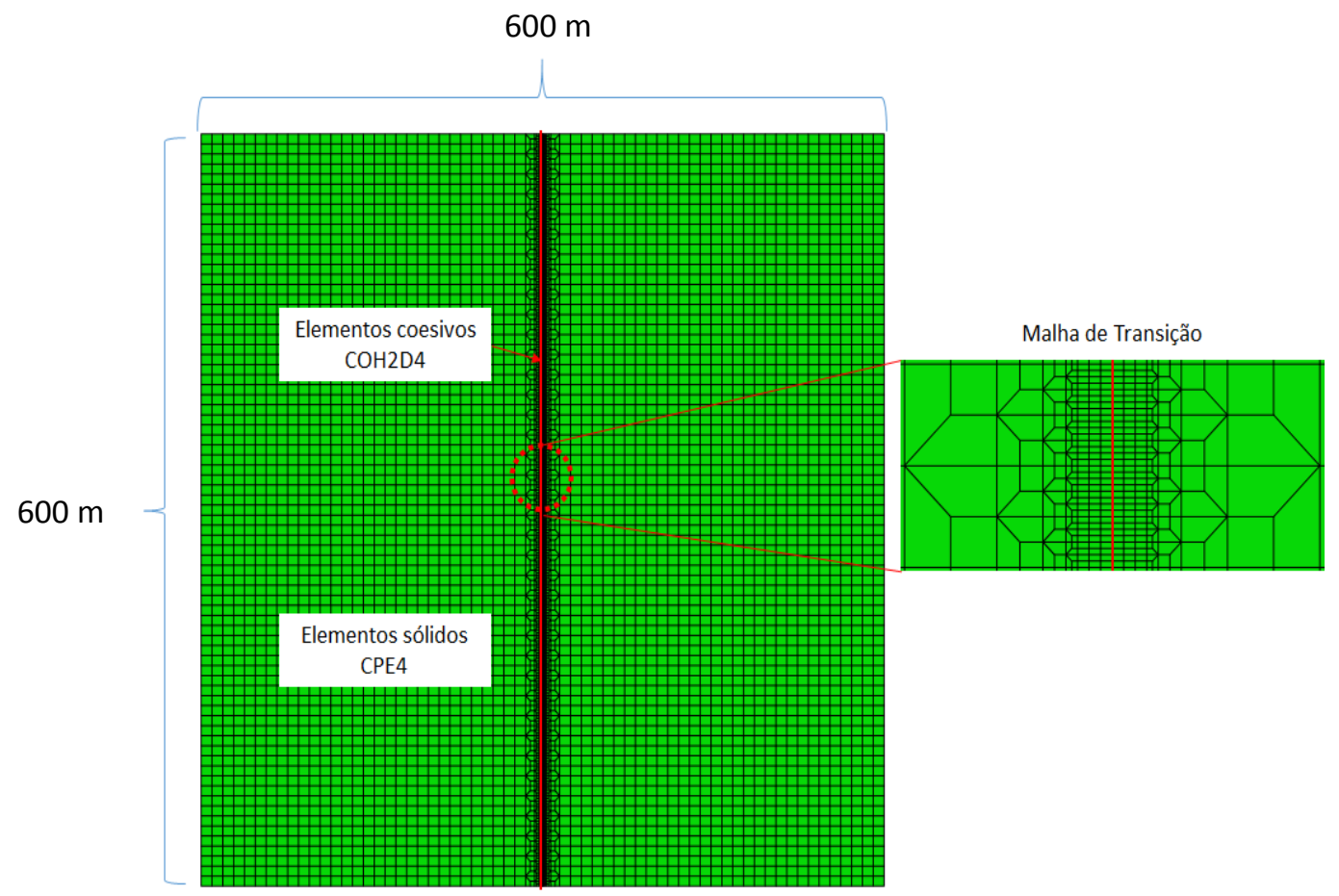

Figura 5.1: Modelo sintético de uma camada

- Na tabela 4.1 apresentam-se as propriedades utilizadas nos modelos, retiradas do artigo Zielonka (2014).

Como as soluções analíticas consideram injeção por vazão constante na formulação, todas as simulações numéricas são feitas em controle de fluxo.

\subsection{Modelo de uma camada}

A solução analítica para a abertura máxima (abertura no ponto de injeção), comprimento e pressão de injeção do modelo analítico KGD, descrito na seção 2.2.2, é comparada com resultados numéricos pelo método dos elementos finitos com modelo de zona coesiva.

Observa-se da análise dos resultados analíticos e numéricos uma concordância satisfatória para a abertura máxima da fratura (Figura 5.2), variação de pressão no ponto de injeção (Figura 5.3) e evolução do comprimento da fratura (Figura 5.4). 


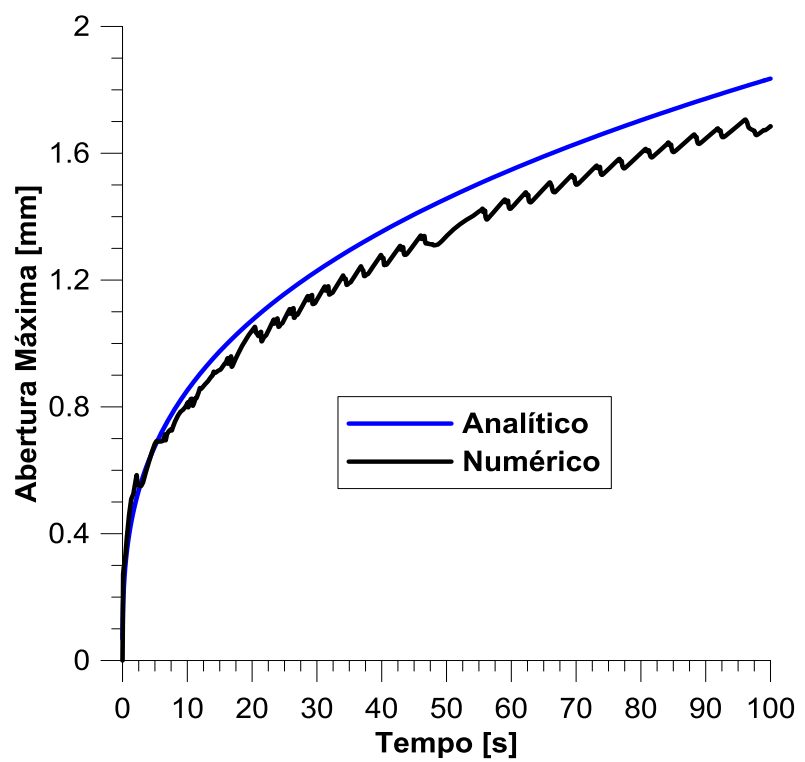

Figura 5.2: Abertura máxima da fratura ao longo do tempo

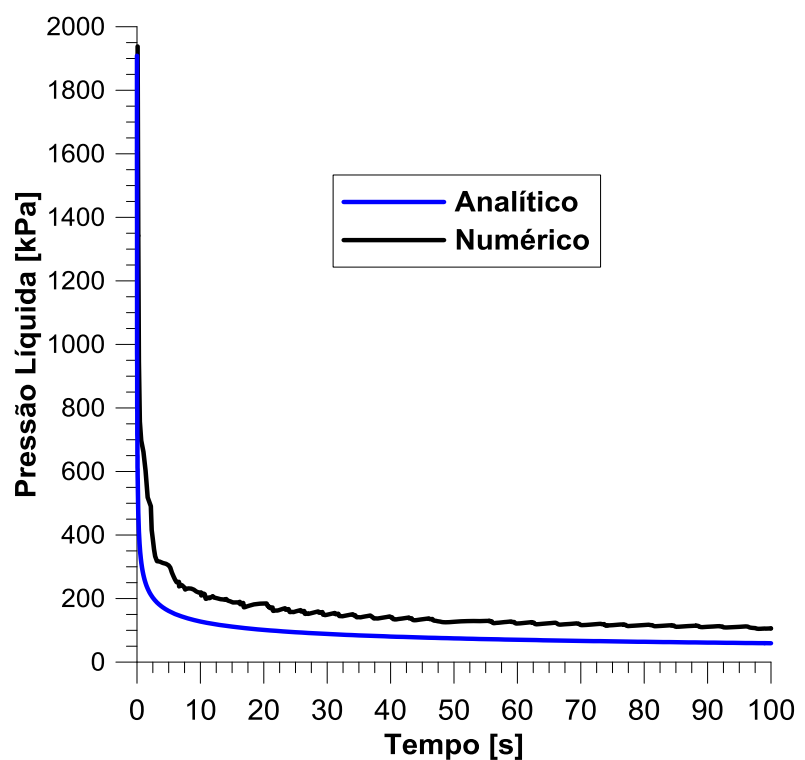

Figura 5.3: Pressão no ponto de injeção ao longo do tempo 


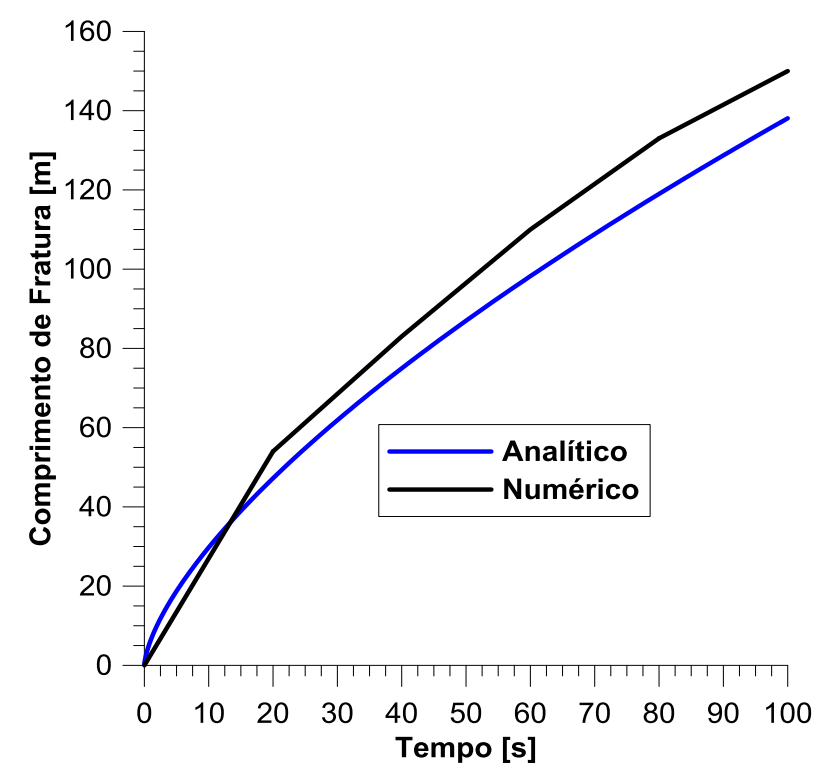

Figura 5.4: Comprimento da fratura ao longo do tempo

\subsection{Regime de propagação de fratura}

Na figura 5.5 mostra-se a solução analítica do regime dominado pela rigidez (K-vértice) para abertura máxima da fratura e a solução numérica, obtendo-se um bom ajuste entre as duas curvas.

No modelo numérico o fluido de injeção é considerado newtoniano e incompressível, e os elementos sólidos não tem grau de liberdade de poropressão ativos. Em comparação com o modelo numérico da secção (5.1), utilizaram-se as mesmas propriedades e determinou-se pelas equações (2.51) que o regime de propagação é dominado pela rigidez (vértice $K$ ) e a única diferença está na aplicação de uma tensão inicial horizontal de 3.7 MPa tirada do Carrier (2012), Yao (2014), Zielonka (2014). 


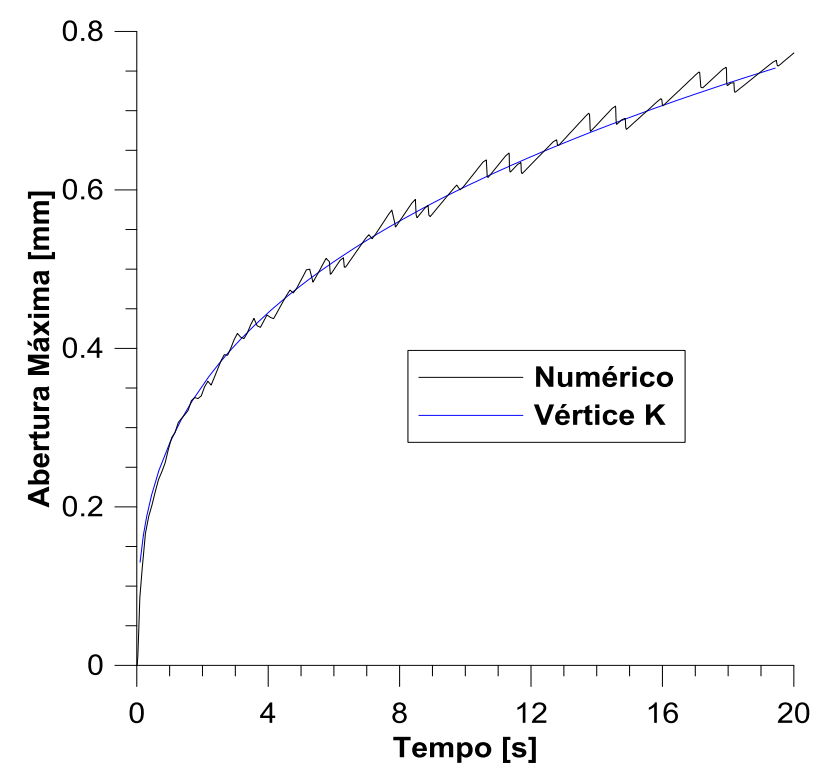

Figura 5.5: Abertura máxima da fratura no regime dominado pela rigidez.

Na figura 5.6, temos a curva variação da pressão de injeção com o tempo no regime de propagação de fratura dominado pela rigidez obtida da solução analítica e da solução numérica. Novamente observa-se um excelente ajuste entre as curvas.

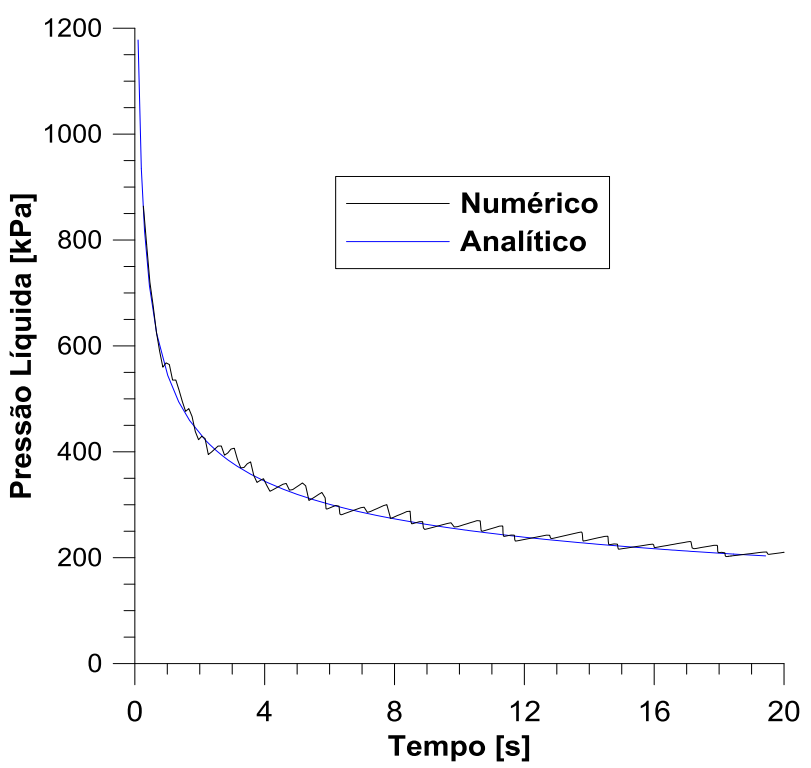

Figura 5.6: Pressão de injeção no regime dominado pela rigidez. 


\subsection{Validação dos modelos de três camadas}

\subsubsection{Comparação com o modelo analítico de Simonson}

$\mathrm{Na}$ figura 5.7, apresenta-se a malha de elementos finitos $(600 \mathrm{~m} \times 600 \mathrm{~m})$ desenvolvido para comparar a solução numérica do fraturamento hidráulico de três camadas com contraste simétrico de tensões horizontais (igual contraste de tensão horizontal com a camada adjacente inferior e superior), que será comparado com a solução analítica de Simonson (1978).

A malha esta composta por elementos contínuos bidimensionais de quatro nós só com grau de liberdade de deslocamento ativo (sem poropressão inicial) e para representar a fratura temos elementos coesivos bidimensionais de quatro nós de deslocamento e dois nós de poropressão onde será injetada a vazão para induzir o fraturamento hidráulico.

As condições de contorno do modelo são: restrições de deslocamento na direção vertical para a base e topo do modelo e na direção horizontal para as bordas direitas e izquerda do modelo.

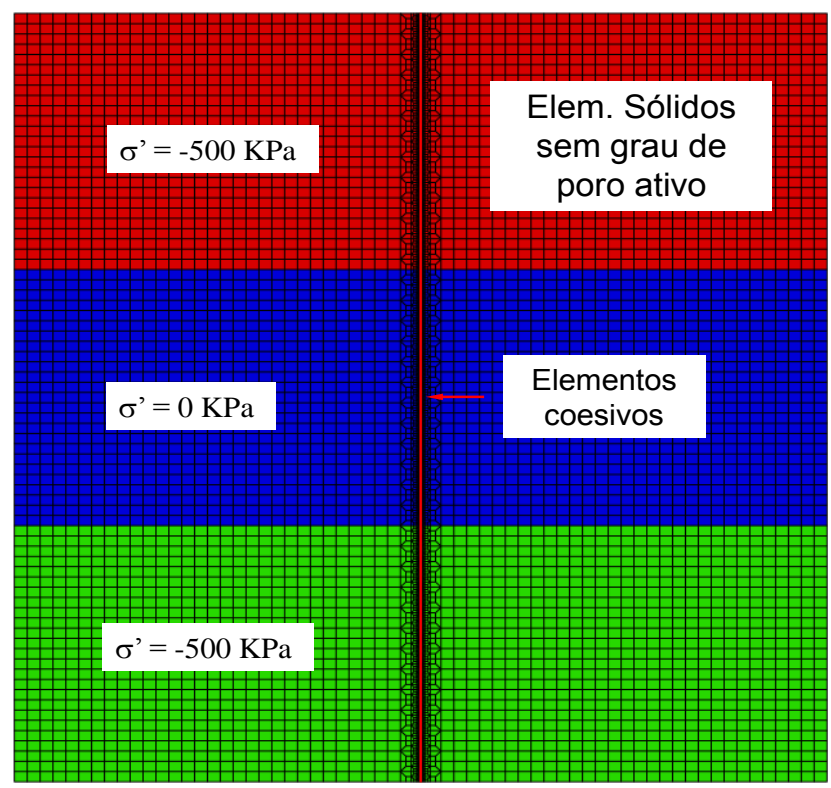

Figura 5.7: Modelo de três camadas contraste simétrico de tensões

A solução analítica de Simonson corresponde a um modelo pseudo 3D enquanto que o modelo numérico desenvolvido corresponde a um modelo $2 \mathrm{D}$ de deformação plana, razão pela qual comparou-se o comprimento de fratura do 
modelo numérico 2D com a altura de fratura do modelo pseudo 3D de Simonson para as pressões de injeção necessária para propagar nas camadas adjacentes.

Baseado nas equações do modelo analítico de Simonson (Eqs. 2.47 e 2.48) obtém-se valores de pressão requeridos para propagação da fratura com e sem contraste de tensões. Tais resultados são comparados com os obtidos através de análises numéricas pelo método dos elementos finitos, conforme mostra a Figura 5.8, que indica a pressão de injeção necessária para propagação da fratura em função de seu comprimento. Até uma altura de $100 \mathrm{~m}$ ambas as soluções estão em boa concordância, com a propagação efetuada na mesma camada onde a injeção é executada. A pressão de injeção necessária diminui com a altura da fratura e não se observa neste intervalo contraste de tensões.

Após este trecho inicial, a fratura penetra a camada adjacente onde as tensões horizontais são maiores, o que explica a ocorrência de pressões de injeção mais altas entre 100 e 150m de altura. As soluções numérica e analítica tendem a se desviar à medida que o comprimento da fratura aumenta, pois a solução analítica está baseada na mecânica clássica linear elástica e o modelo numérico está acoplado hidromecanicamente.
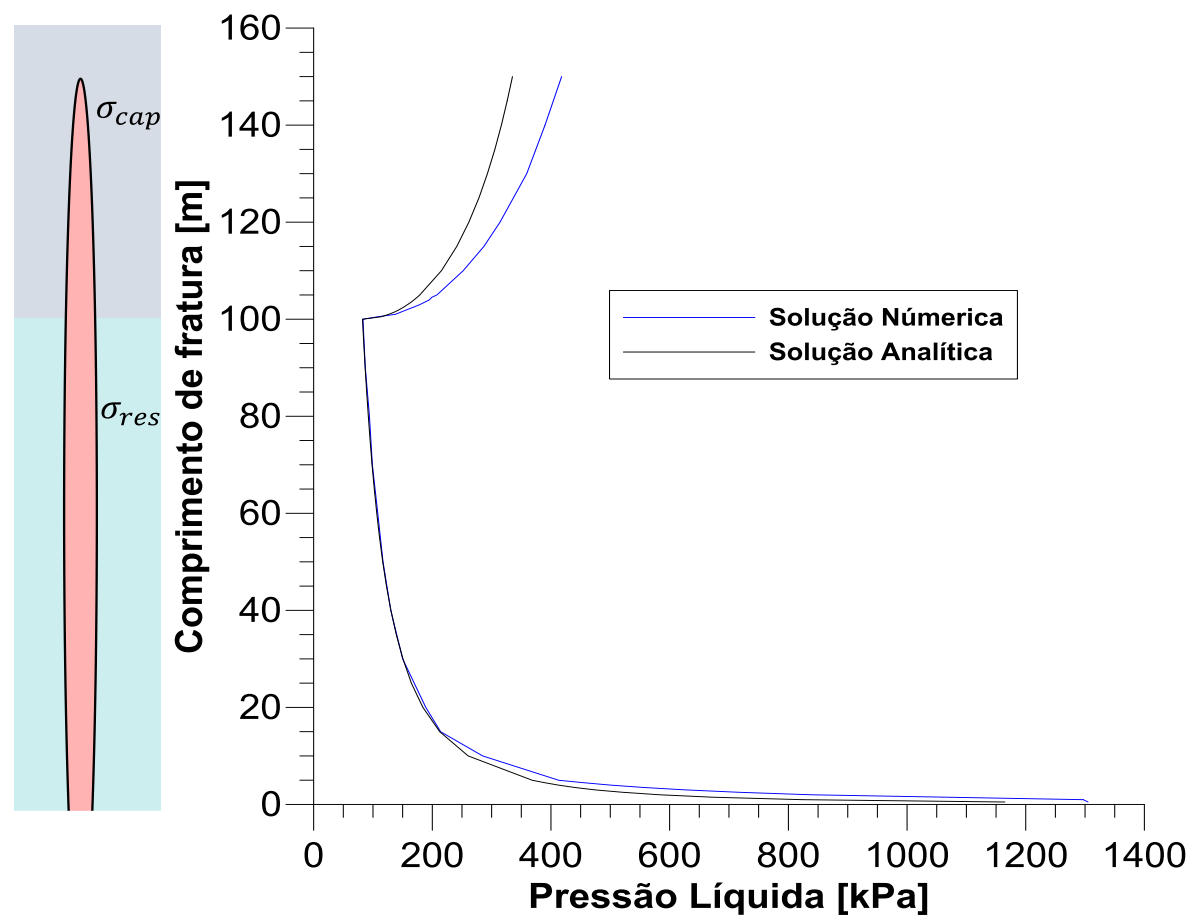

Figura 5.8: Comparação de resultados analíticos pela formulação de Simonson e valores numéricos obtidos pelo método dos elementos finitos. 


\subsubsection{Comparação com o modelo analítico de Fung}

Na figura 5.9 apresenta-se a malha de elementos finitos $(600 \mathrm{~m} \times 600 \mathrm{~m})$ desenvolvido para comparar a solução numérica do fraturamento hidráulico de três camadas com contraste assimétrico de tensões horizontais (diferente contraste de tensão horizontal com a camada adjacente inferior e superior), que será comparado com a solução analítica de Fung (1987).

A malha esta composta por elementos contínuos bidimensionais de quatro nós só com grau de liberdade de deslocamento ativo (sem poropressão inicial) e para representar a fratura temos elementos coesivos bidimensionais de quatro nós de deslocamento e dois nós de poropressão onde será injetada a vazão para induzir o fraturamento hidráulico.

As condições de contorno do modelo são: restrições de deslocamento na direção vertical para a base e topo do modelo e na direção horizontal para as bordas direitas e izquerda do modelo.

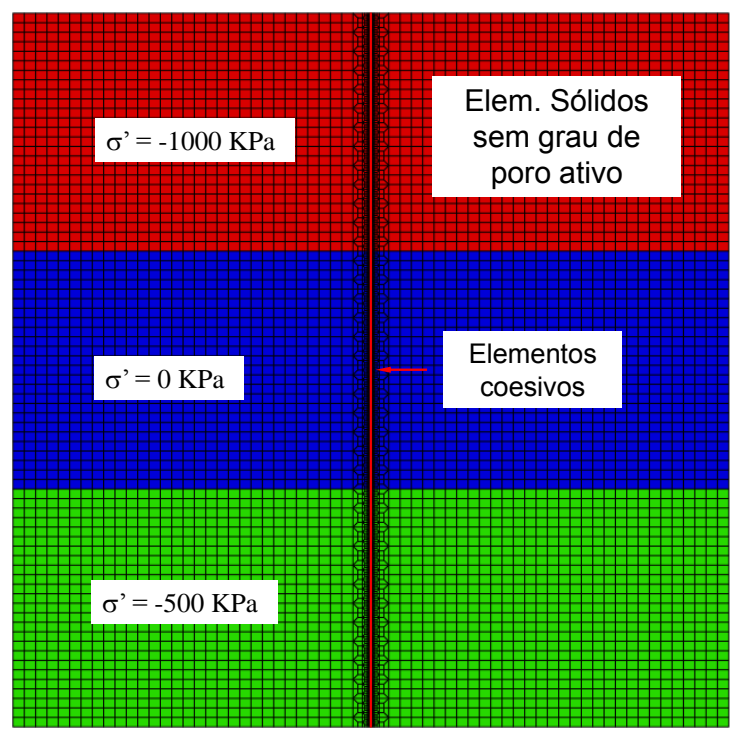

Figura 5.9: Modelo de três camadas com contraste assimétrico de tensões

A solução analítica de Fung corresponde a um modelo pseudo 3D enquanto que o modelo numérico desenvolvido corresponde a um modelo 2D de deformação plana, razão pela qual comparou-se o comprimento de fratura do modelo numérico 2D com a altura de fratura do modelo pseudo 3D de Fung para as pressões de injeção necessária para propagar nas camadas adjacentes. 
A figura 5.10 detalha a comparação entre os resultados numéricos do MEF e analíticos estimados pela formulação de Fung. Observam-se três regiões de análise: central, definida pela própria camada na qual a injeção é aplicada, sem contraste de tensões e propagação simétrica da fratura em relação ao ponto de injeção; a região esquerda, denominada camada inferior, com contraste de tensões de $500 \mathrm{kPa}$ que eleva a pressão de injeção necessária para o fraturamento, e a região da direita da figura, denominada camada superior, com contraste de tensões de $1000 \mathrm{kPa}$, razão pela qual a pressão de injeção atinge valores ainda maior para manter o fraturamento.

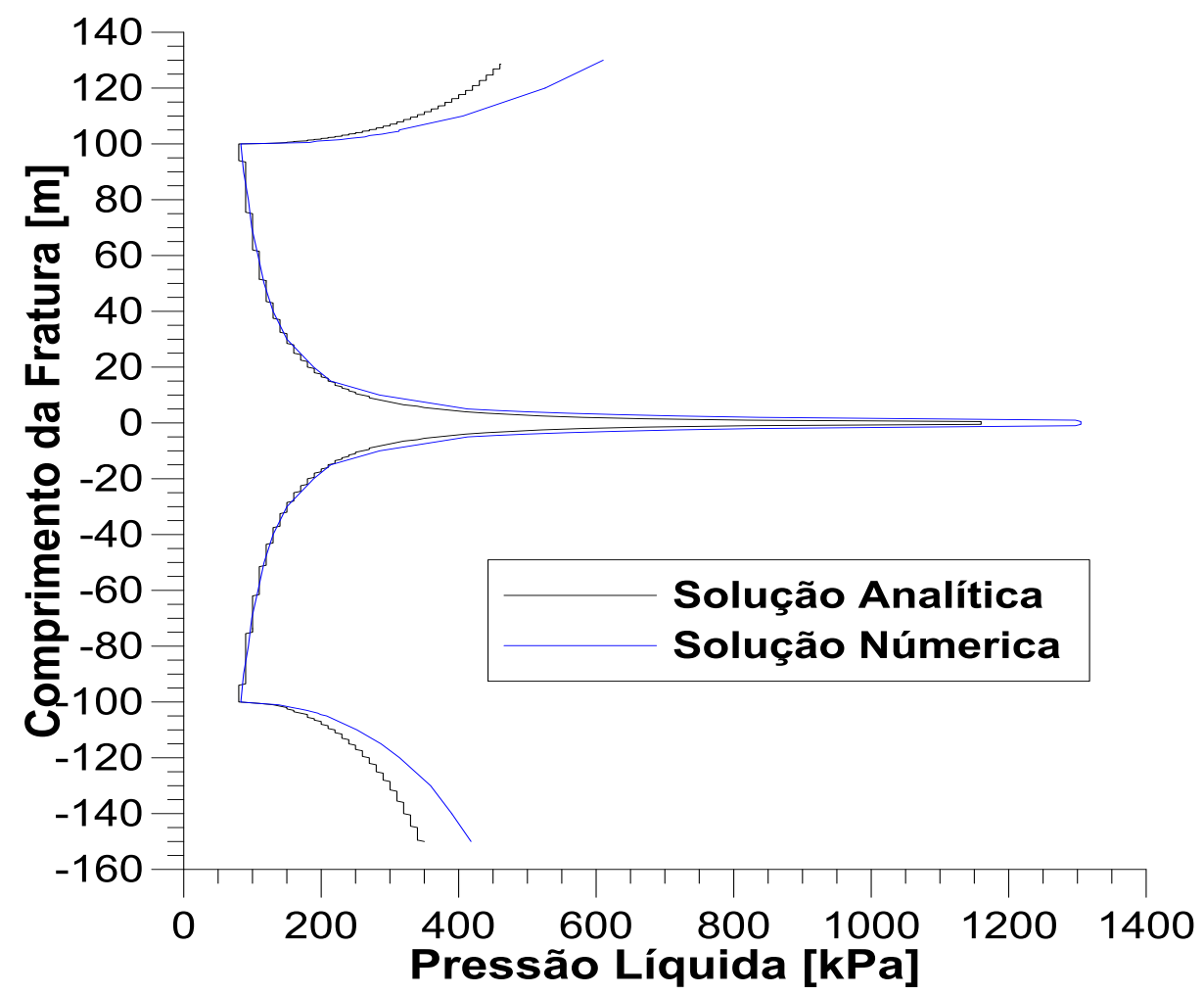

Figura 5.10: Comparação entre solução analítica de Fung e solução numérica do MEF 


\section{6 \\ Analise paramétrica dos fatores atuantes no fraturamento hidráulico}

\subsection{Viscosidade do fluido de fraturamento}

Nesta seção, pesquisa-se o efeito da viscosidade dinâmica do fluido injetado na geometria da fratura e no perfil da pressão de distribuição da pressão ao longo da fratura. Na figura 6.1, mostra-se o efeito do aumento da viscosidade do fluido de fraturamento na pressão de injeção para uma mesma vazão para todos os casos simulados em Abaqus. Para propagar a fratura à medida que viscosidade aumenta, a perda de carga na fratura aumenta e mantendo a mesma vazão tem-se uma maior pressão de injeção. A perda de carga é calculada conforme a equação de Poiseuille (Eq. 2,15)

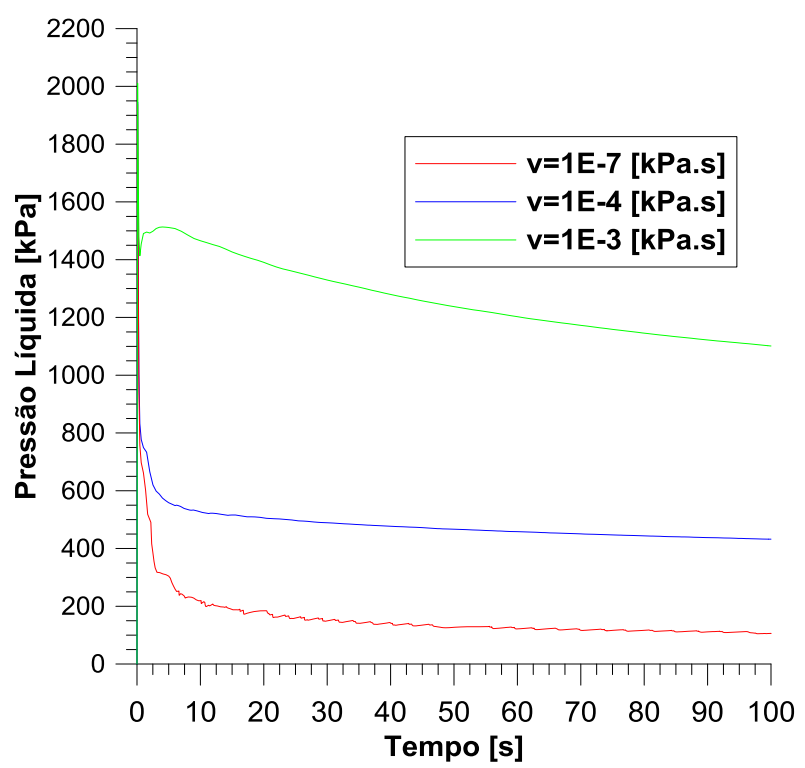

Figura 6.1: Efeito da viscosidade na pressão de injeção ao longo do tempo

Na Figura 6.2, mostra-se que quanto maior viscosidade do fluido injetado, tanto maior a abertura máxima da fratura (abertura no ponto de injeção), diretamente decorrente da maior pressão de injeção aplicada para propagar a fratura (Figura 6.1). 


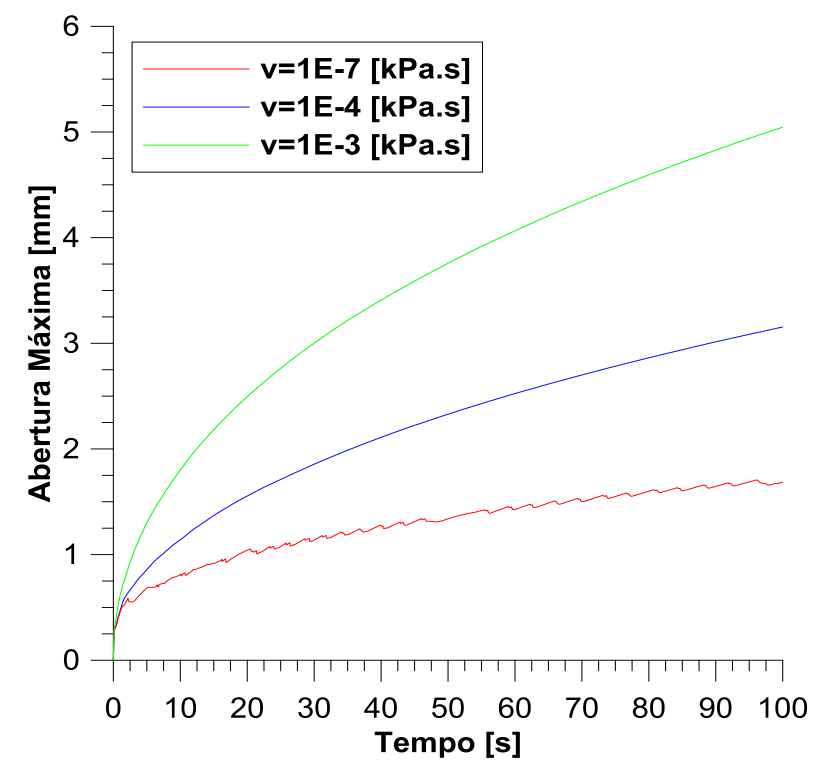

Figura 6.2: Efeito da viscosidade na abertura máxima da fratura ao longo do tempo

Na figura 6.3, podemos observar que para um baixo valor da viscosidade $(\mu=$ $\left.10^{-7} \mathrm{kPa} . \mathrm{S}\right)$ o perfil de pressão é constante ao longo da fratura, porém apresentando variações súbitas ao longo do perfil, com ocorrência de sucção na ponta da fratura, à medida que a viscosidade do fluido de fraturamento aumenta.

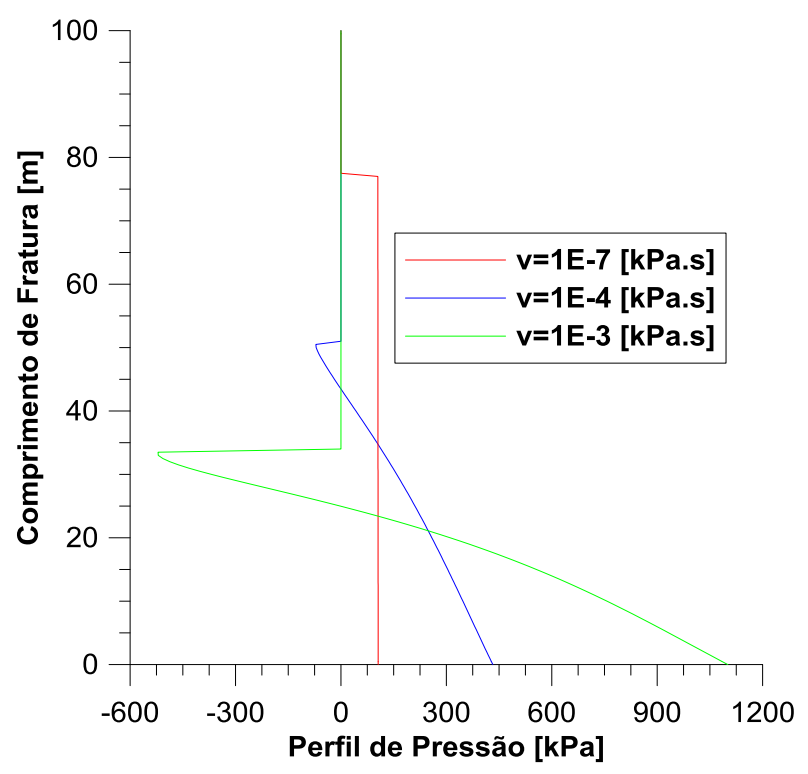

Figura 6.3: Efeito da viscosidade no perfil de pressão ao longo da fratura 
$\mathrm{Na}$ figura 6.4, verifica-se que com o aumento da viscosidade o comprimento da fratura diminui, mas, em contrapartida, sua abertura máxima (abertura no ponto de injeção) incrementa.

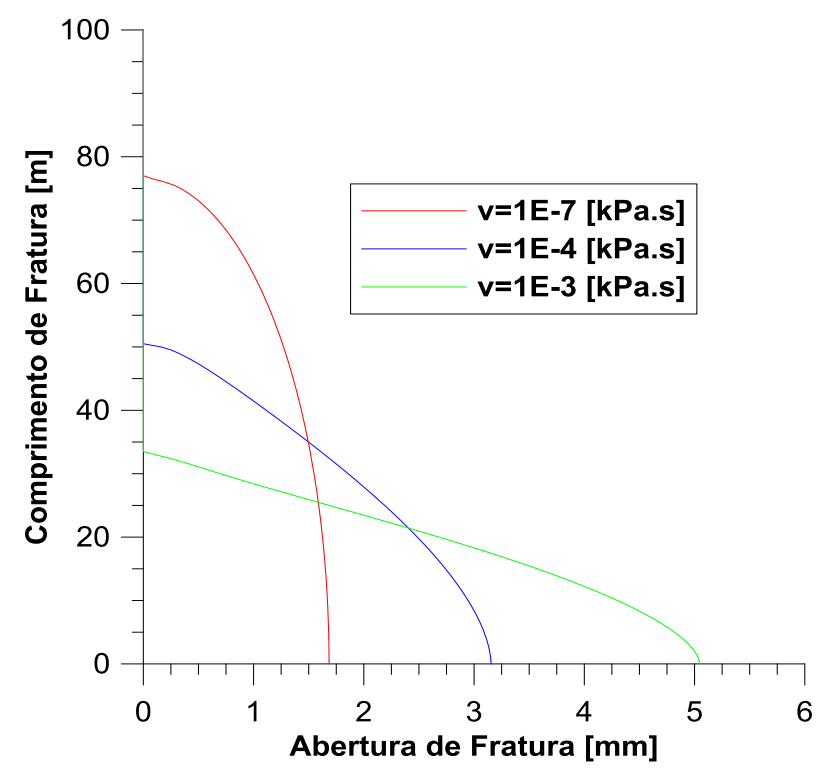

Figura 6.4: Efeito da viscosidade na geometria da fratura.

\subsection{Vazão de injeção}

Nesta secção, pesquisa-se o efeito da vazão do fluido injetado na geometria da fratura e no perfil da pressão ao longo da fratura para um modelo numérico com o grau de liberdade de poropressão ativo nos elementos sólidos adjacentes à fratura, as outras propriedades do modelo continuam sendo as mesmas da tabela 4.1.

Na figura 6.5, observa-se que quando a vazão de injeção aumenta, a pressão de pico de ruptura do material torna-se maior e a poropressão, após o pico, tende novamente a aumentar à medida que ocorrem deformações nos elementos coesivos que, por sua vez, induzem maiores valores de excessos de poropressão nos elementos sólidos adjacentes. Portanto, quanto maior a vazão, maiores as deformações dos elementos coesivos, maiores os excessos de poropressão nos elementos adjacentes, maiores as pressões injetadas para continuar a propagação da fratura. Isto contradiz o modelo KGD no qual a pressão diminui com o tempo, por isso no modelo numérico comparado com o KGD na secção 5.1 não considera o grau de liberdade de poropressão ativo nos elementos sólidos adjacentes à fratura, 
com a finalidade de evitar o efeito destes excessos de poropressão e reproduzir essa diminuição da pressão com o tempo.

Observa-se também que com o aumento da vazão, maior a abertura máxima da fratura (Figura 6.6), e para um tempo de $\mathrm{t}=100$ segundos maiores os valores das pressões no interior da fratura (Figura 6.7) e maiores os geometrias da fratura (maior volume injetado para um mesmo tempo gera maiores geometrias de fraturas)(Figura $6.8)$.

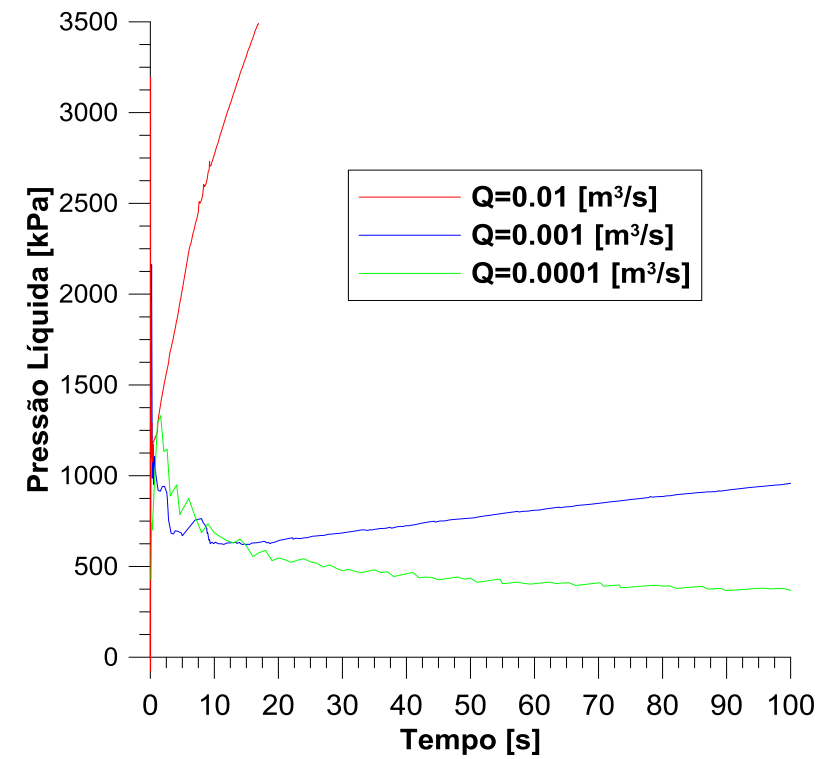

Figura 6.5: Efeito da vazão na resposta da pressão de injeção ao longo do tempo

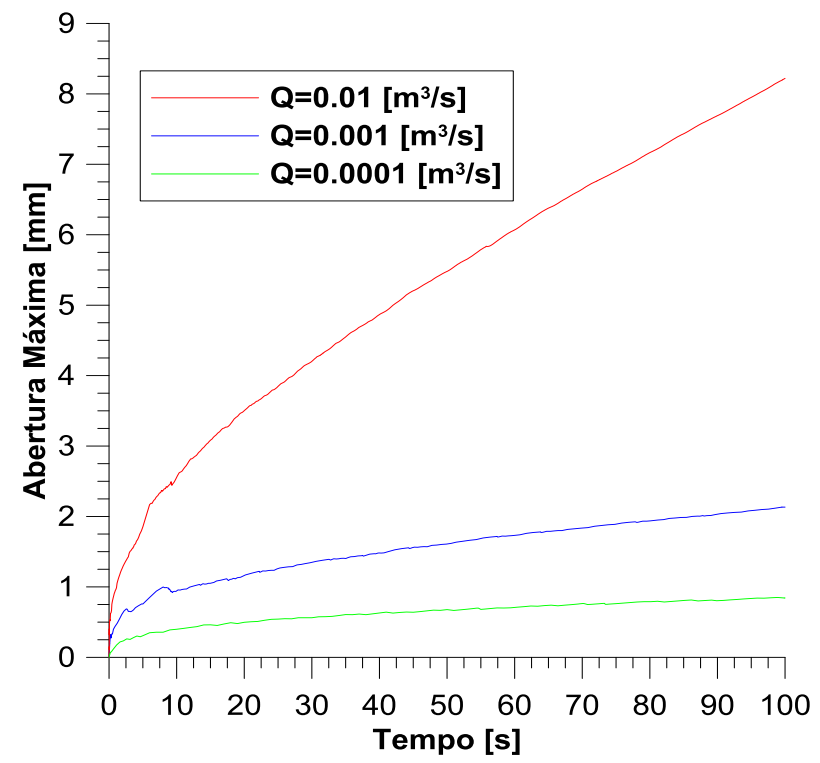

Figura 6.6: Efeito da vazão sobre a abertura máxima da fratura ao longo do tempo. 


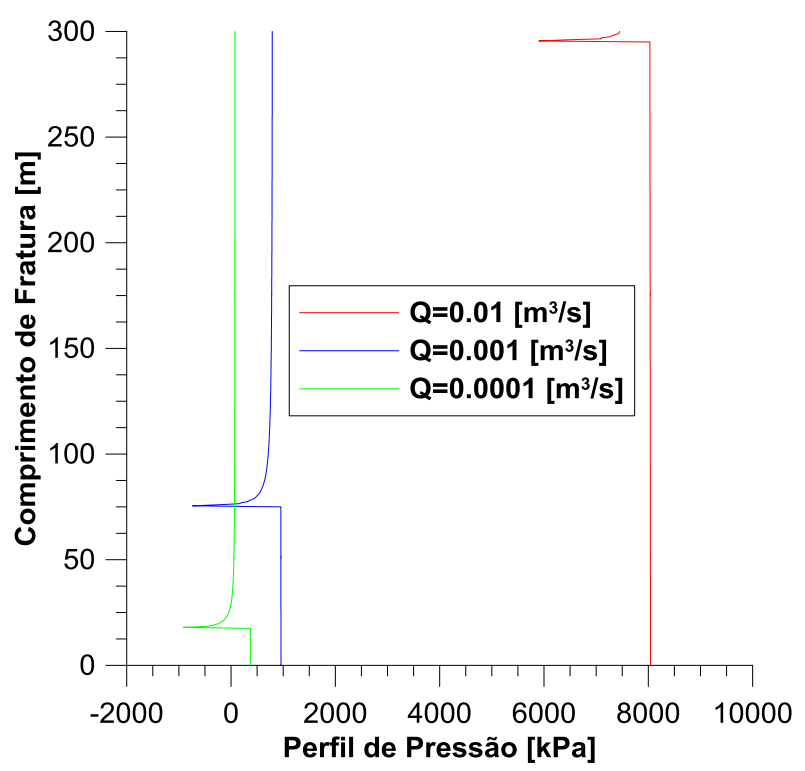

Figura 6.7: Efeito da vazão no perfil da pressão ao longo do comprimento da fratura.

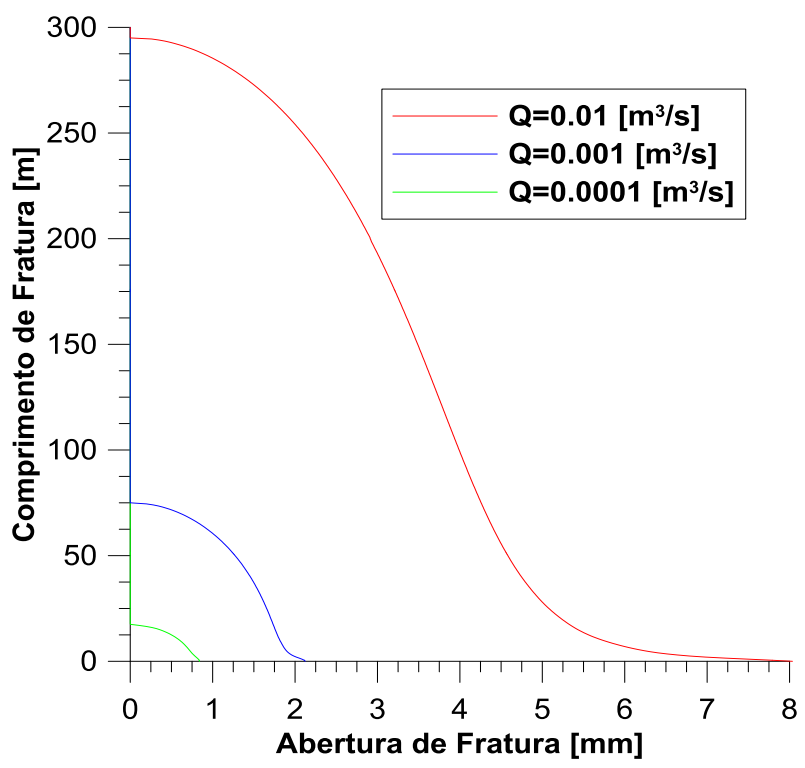

Figura 6.8: Efeito da vazão na geometria da fratura.

\subsection{Fator de intensidade de tensões}

Os efeitos do fator de intensidade de tensões na geometria da fratura (comprimento, abertura máxima) e no perfil de pressão ao longo da mesma são agora estudados. Nas Figuras 6.9 a 6.12 verifica-se, sequencialmente, que quanto maior o valor do fator de intensidade de tensão, maior o valor da pressão de injeção necessária para provocar a ruptura hidráulica, maiores os valores de pressão 
atuantes nas superfícies da fratura, maiores as aberturas máximas e menores os comprimentos de propagação.

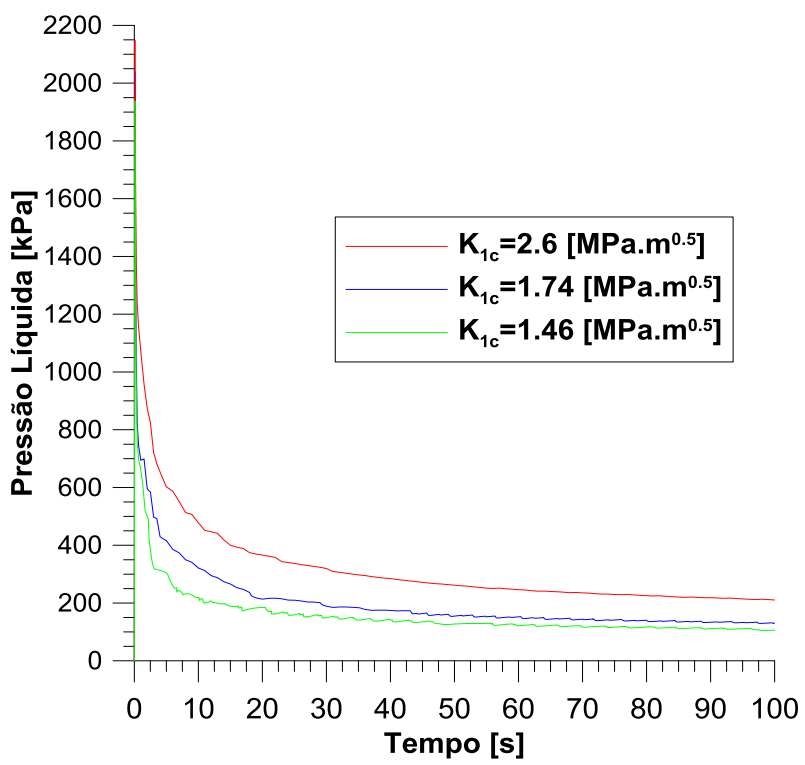

Figura 6.9: Efeito do fator de intensidade de tensões na pressão de injeção.

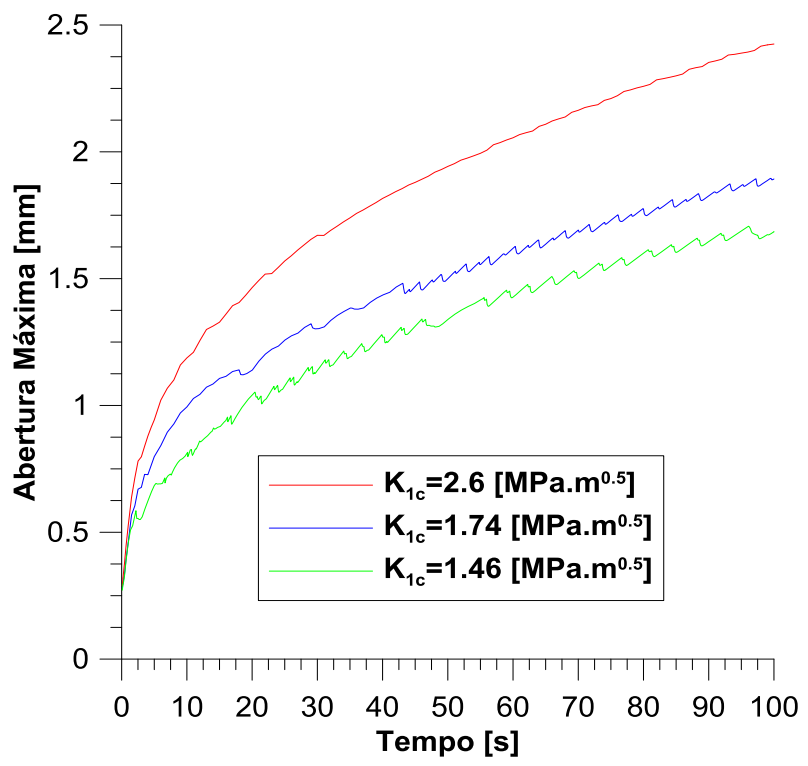

Figura 6.10: Efeito do fator de intensidade de tensões na abertura máxima 


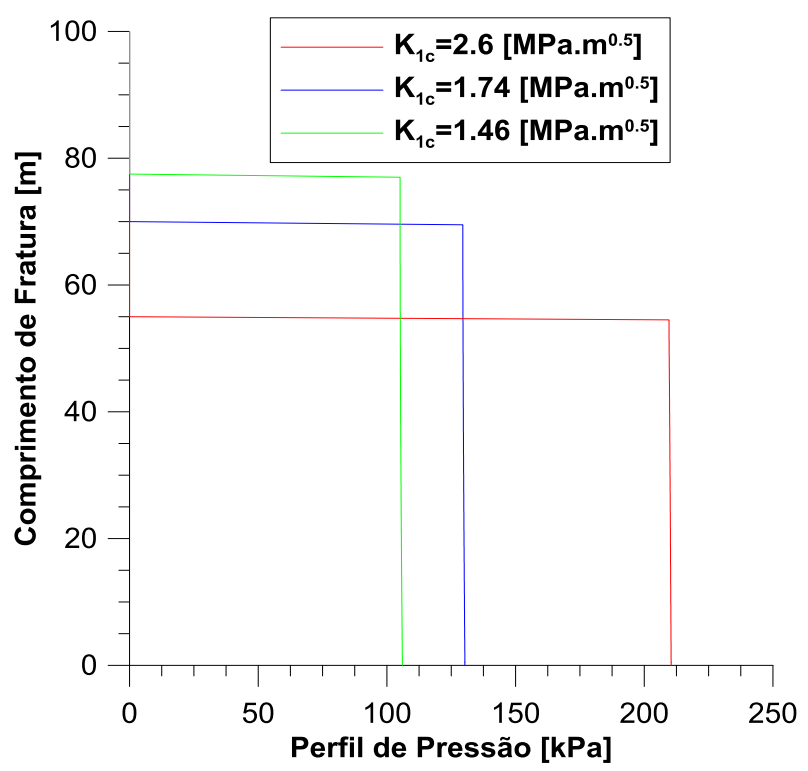

Figura 6.11: Efeito do fator de intensidade de tensões no perfil da pressão

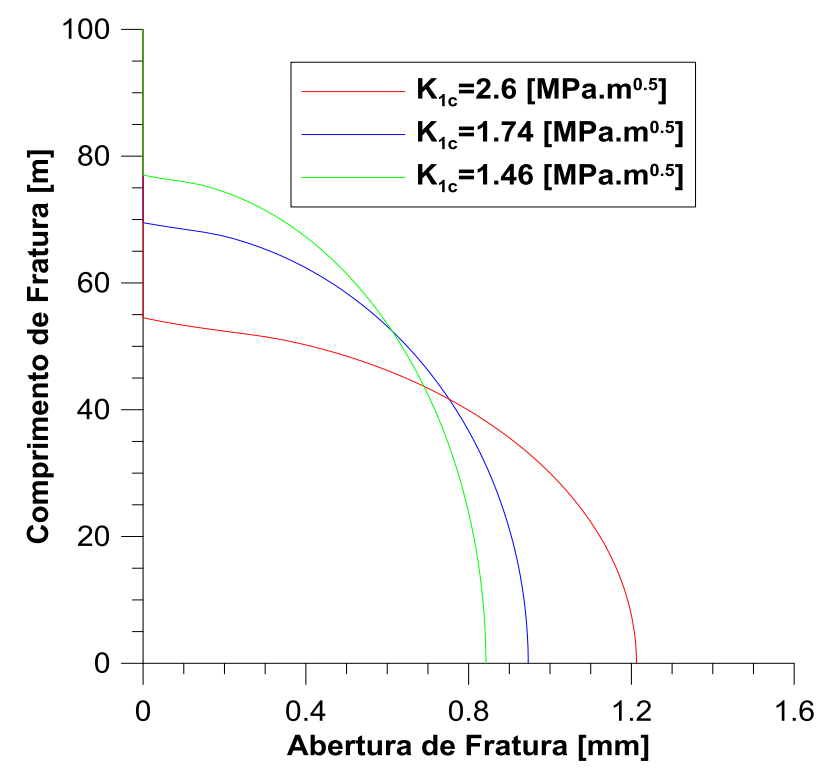

Figura 6.12: Efeito do fator de intensidade de tensões na geometria da fratura

\subsection{Condutividade Hidráulica}

Na Figura 6.13 observa-se que, após a ruptura hidráulica, a pressão de injeção diminui e tem a tendência de tornar-se constante para valores mais altos da condutividade hidráulica, pois a dissipação dos excessos de poropressão nos elementos sólidos adjacentes é consequentemente mais rápida. Logo, para um mesmo valor de leakoff, à medida que a condutividade hidráulica aumenta, pode-se esperar que a pressão de injeção deve ser majorada para propagação da fratura, tendo em vista a perda de pressão do fluido para o meio circundante (Figura 6.14). 
As Figuras 6.15 e 6.16 mostram, respectivamente, que os efeitos da condutividade hidráulica do meio poroso circundante na abertura máxima e no comprimento da fratura não são significativos, pois o aumento imposto à pressão de injeção produz resultados semelhantes aos obtidos no caso considerando ausência de leakoff.

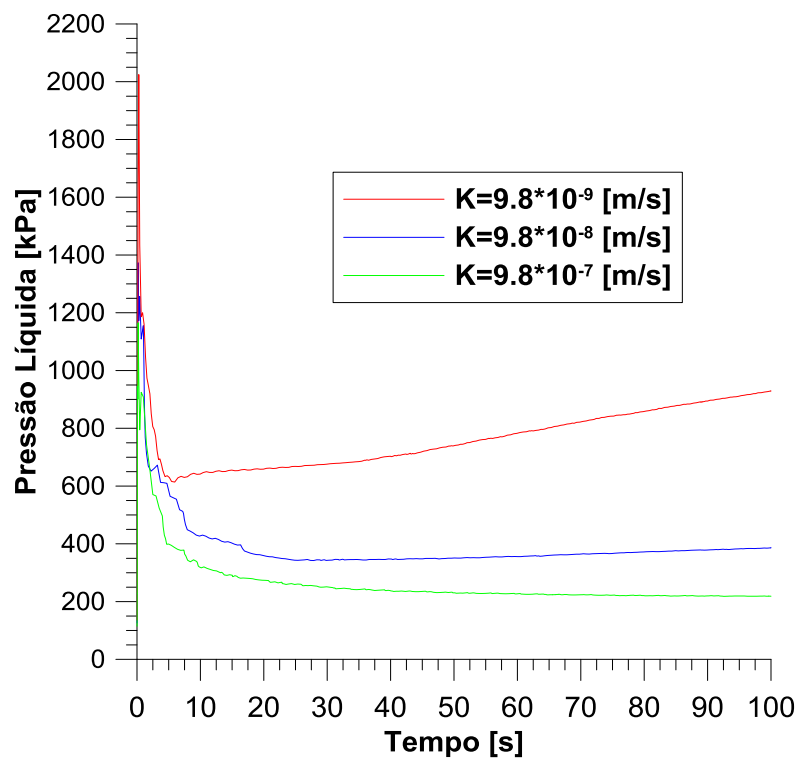

Figura 6.13: Efeito da condutividade hidráulica na pressão de injeção

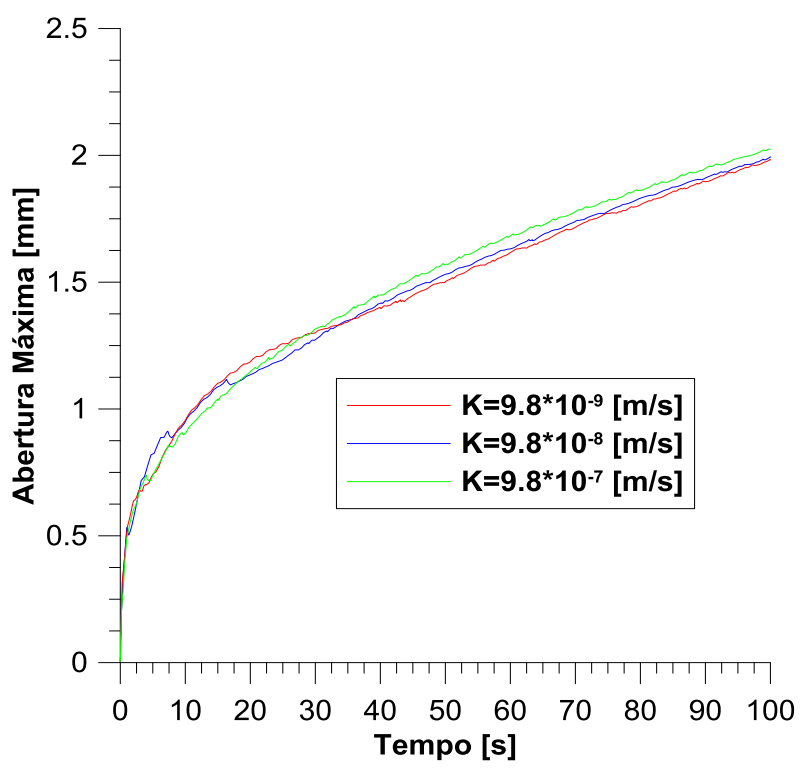

Figura 6.14: Efeito da condutividade hidráulica na abertura máxima da fratura 


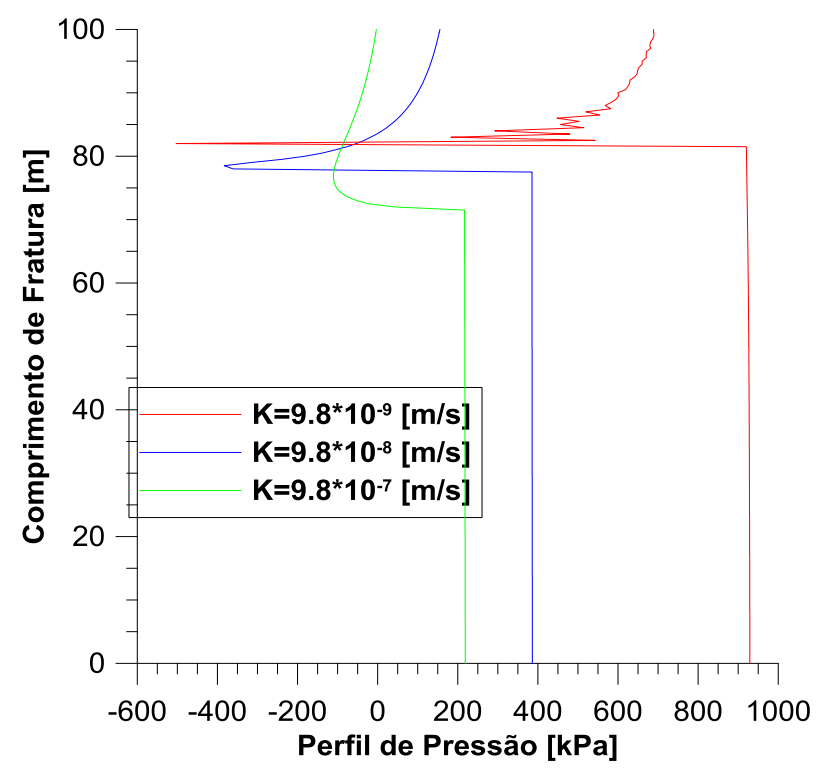

Figura 6.15: Efeito da condutividade hidráulica no perfil de pressão ao longo da fratura

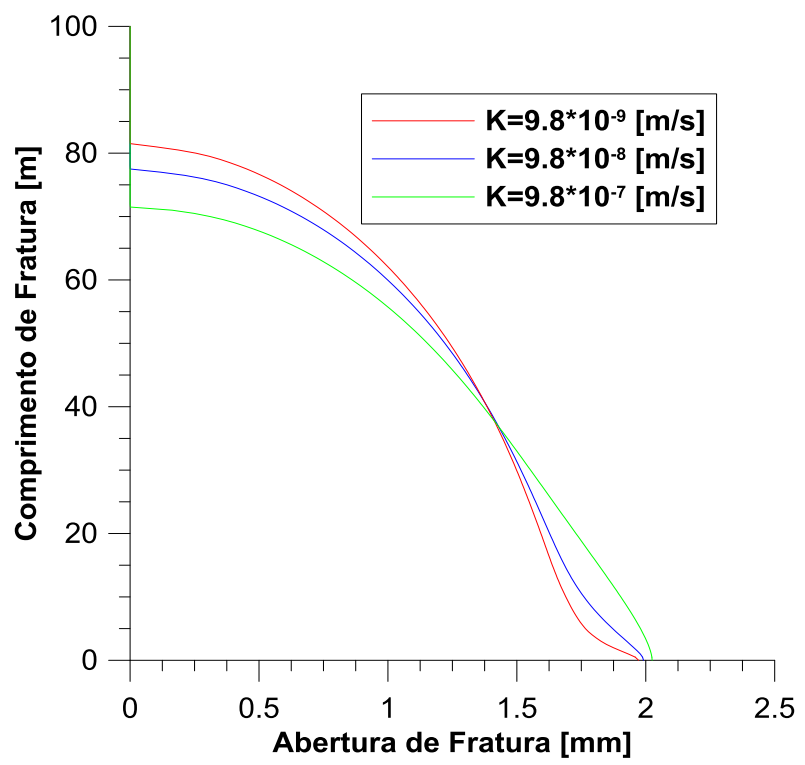

Figura 6.16: Efeito da condutividade hidráulica na geometria da fratura

\subsection{Módulo de Young}

A influência do módulo de Young no fraturamento hidráulico é aqui apresentada. Quanto maior o valor do módulo, tanto maior o valor da pressão de injeção para fraturar e propagar (Figura 6.17), menor a abertura máxima observada (Figura 6.18) e maior o comprimento da fratura (Figura 6.19).

Na figura 6.20 verifica-se que maior o módulo de Young, maiores os valores de pressão distribuição ao longo da fratura para assegurar sua propagação. 


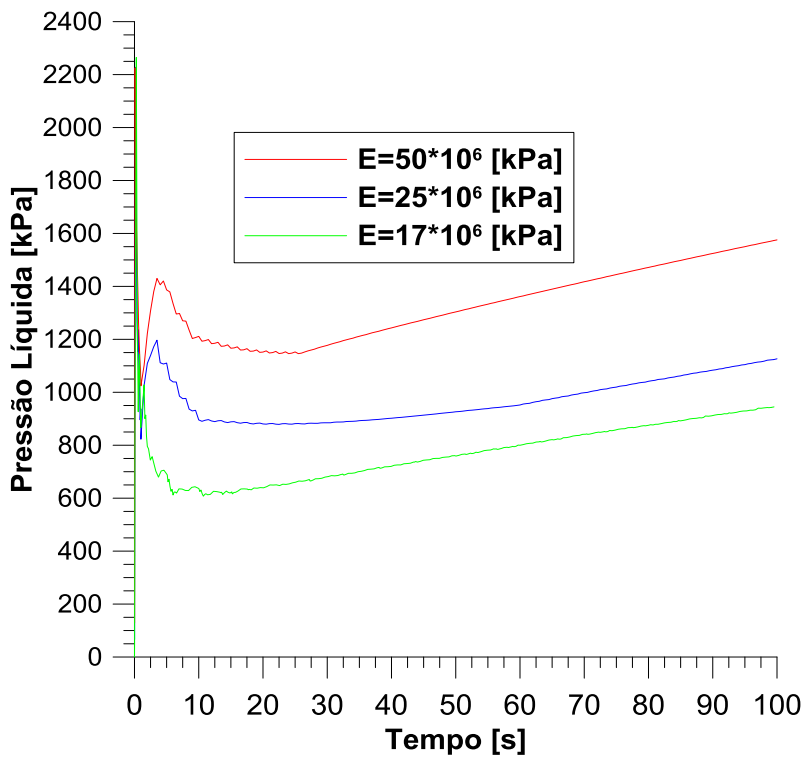

Figura 6.17: Efeito do modulo de Young na pressão de injeção

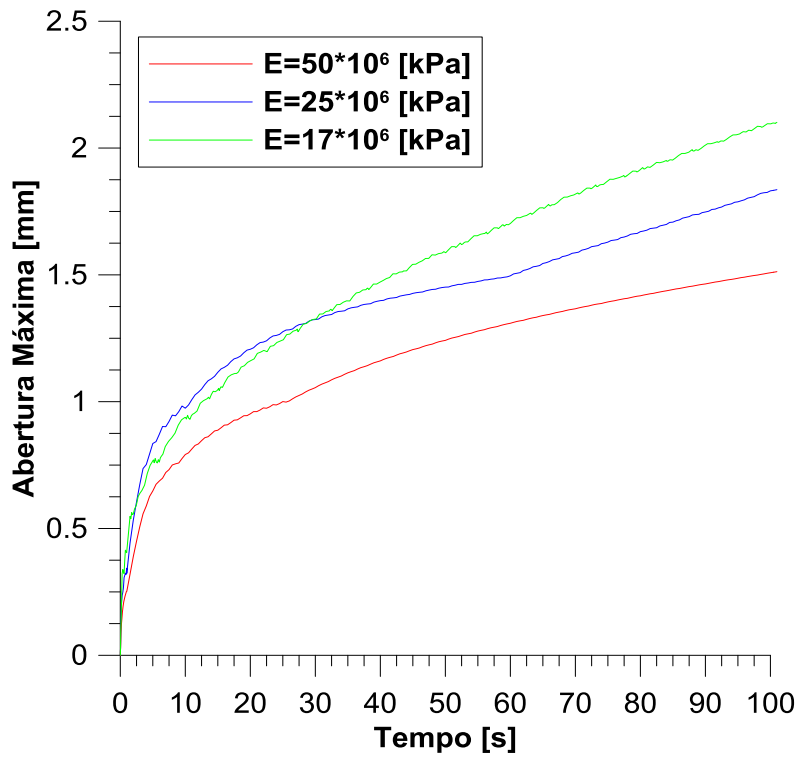

Figura 6.18: Efeito do módulo de Young na abertura máxima da fratura 


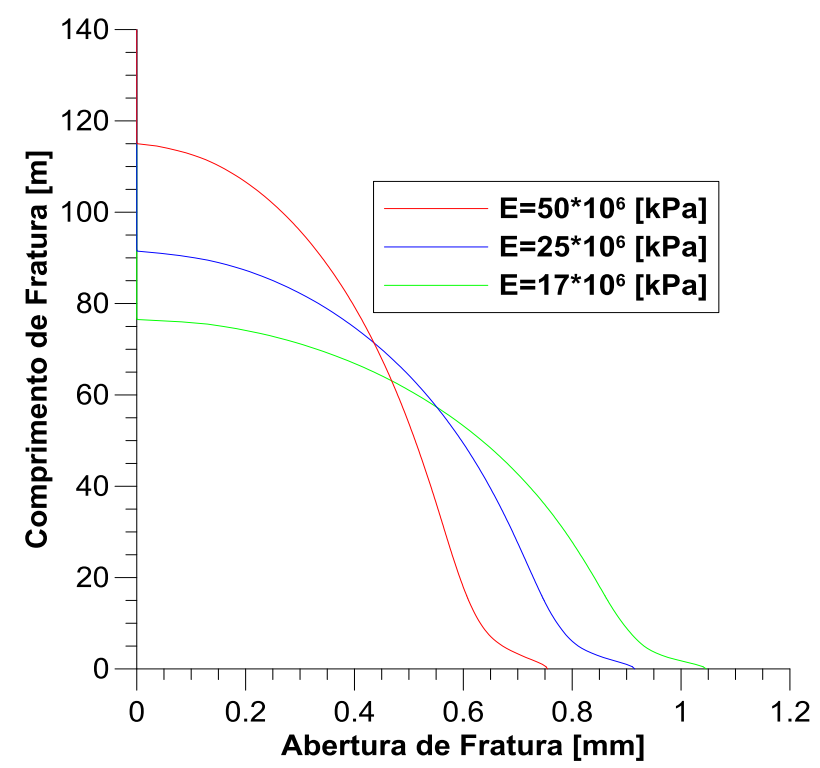

Figura 6.19: Efeitos do módulo de Young na geometria da fratura

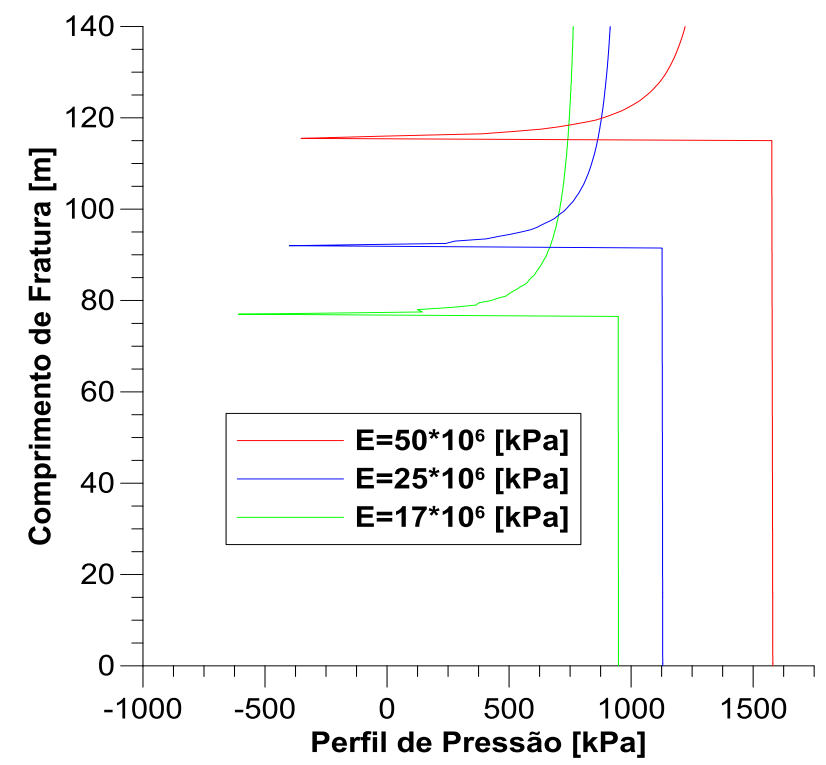

Figura 6.20: Efeito do módulo de Young no perfil de pressão na fratura

\subsection{Coeficiente de Poisson}

À medida que o coeficiente de Poisson se aproxima do valor 0.5 , menor a compressibilidade do material e, portanto, maior a pressão requerida para início e propagação da fratura (Figura 6.21) bem como a distribuição de pressões ao longo de seu comprimento (Figura 6.22).

$\mathrm{O}$ valor do coeficiente de Poisson também influencia o comprimento e abertura máxima da fratura, conforme resultados das Figuras 6.23 e 6.24. Note, 
porém, que para a variação deste parâmetro elástico entre os valores 0.2 a 0.4 não produz mudanças significativas na geometria da fratura.

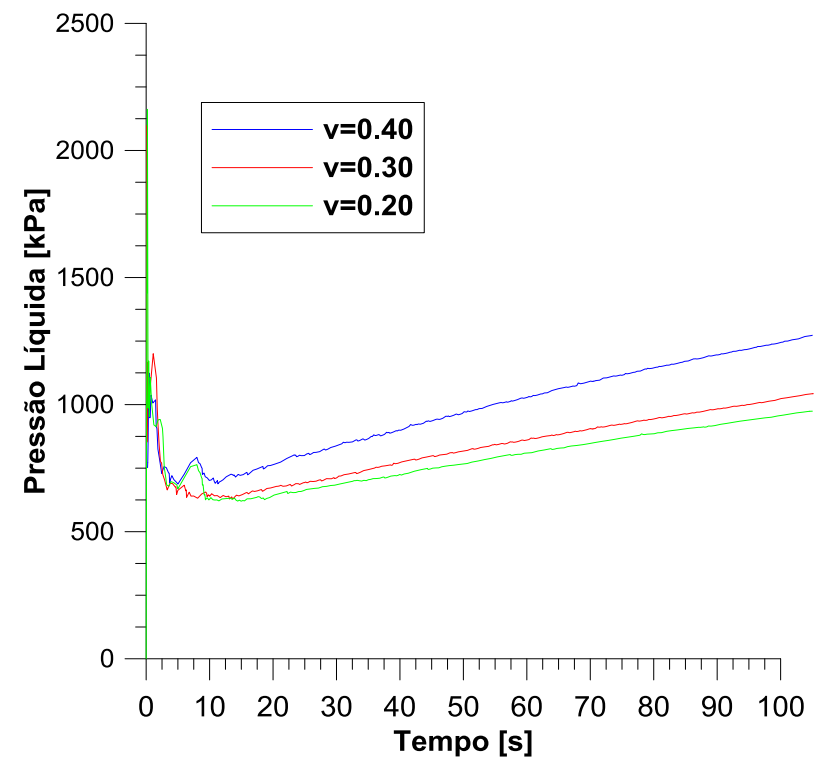

Figura 6.21: Efeito do coeficiente de Poisson na pressão de injeção

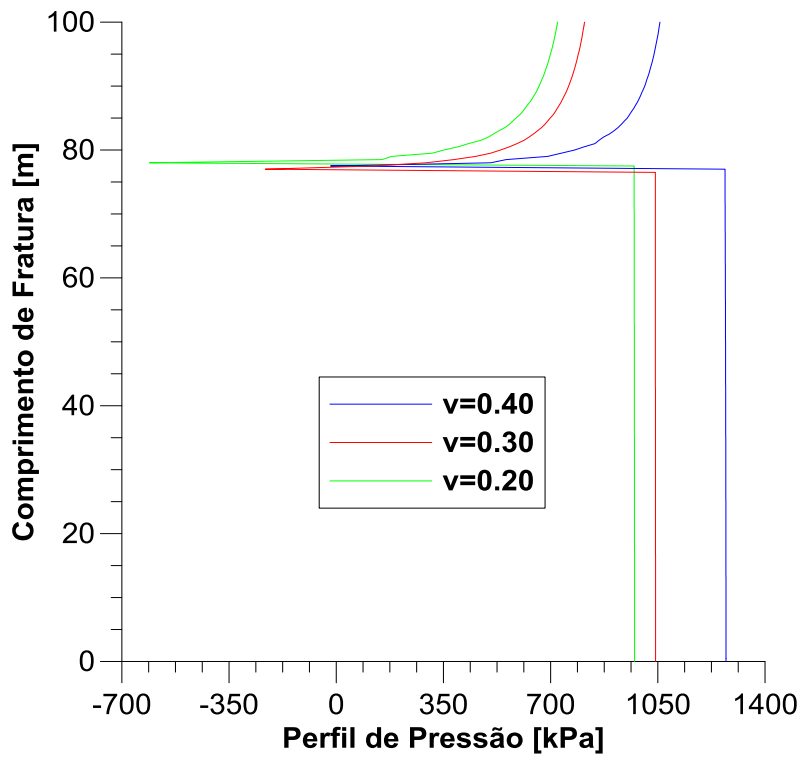

Figura 6.22: Efeito do coeficiente de Poisson no perfil de pressões na fratura 


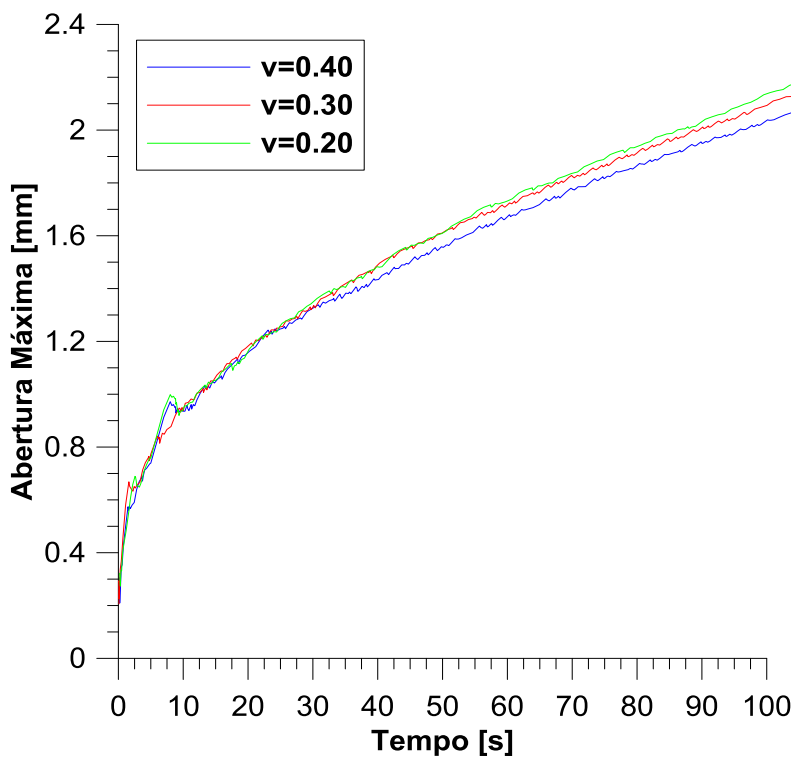

Figura 6.23: Efeito do coeficiente de Poisson na abertura máxima da fratura.

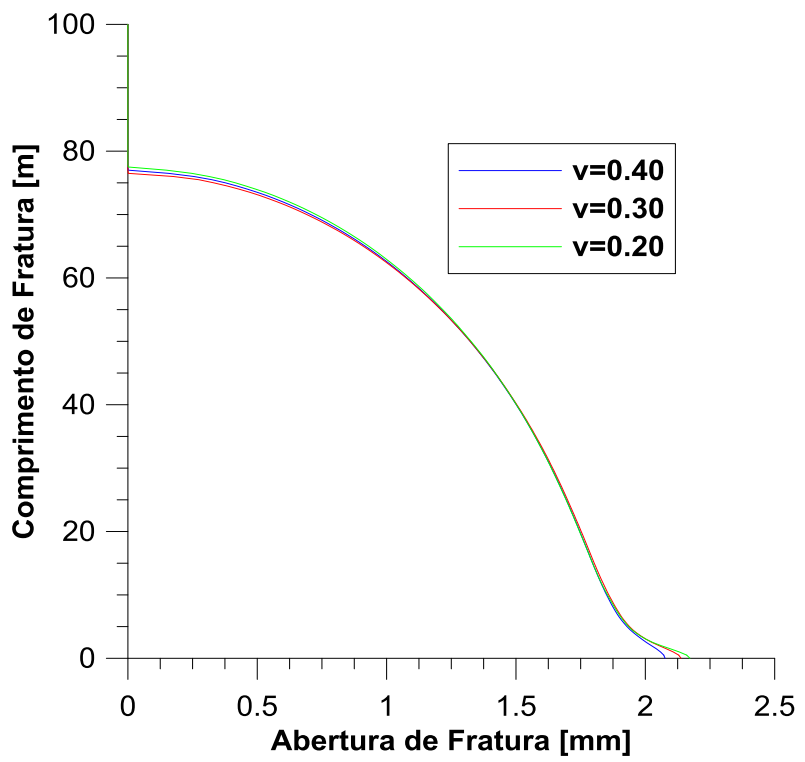

Figura 6.24: Efeito do coeficiente de Poisson na geometria da fratura 
Tabela 6.1 Análise paramétrica

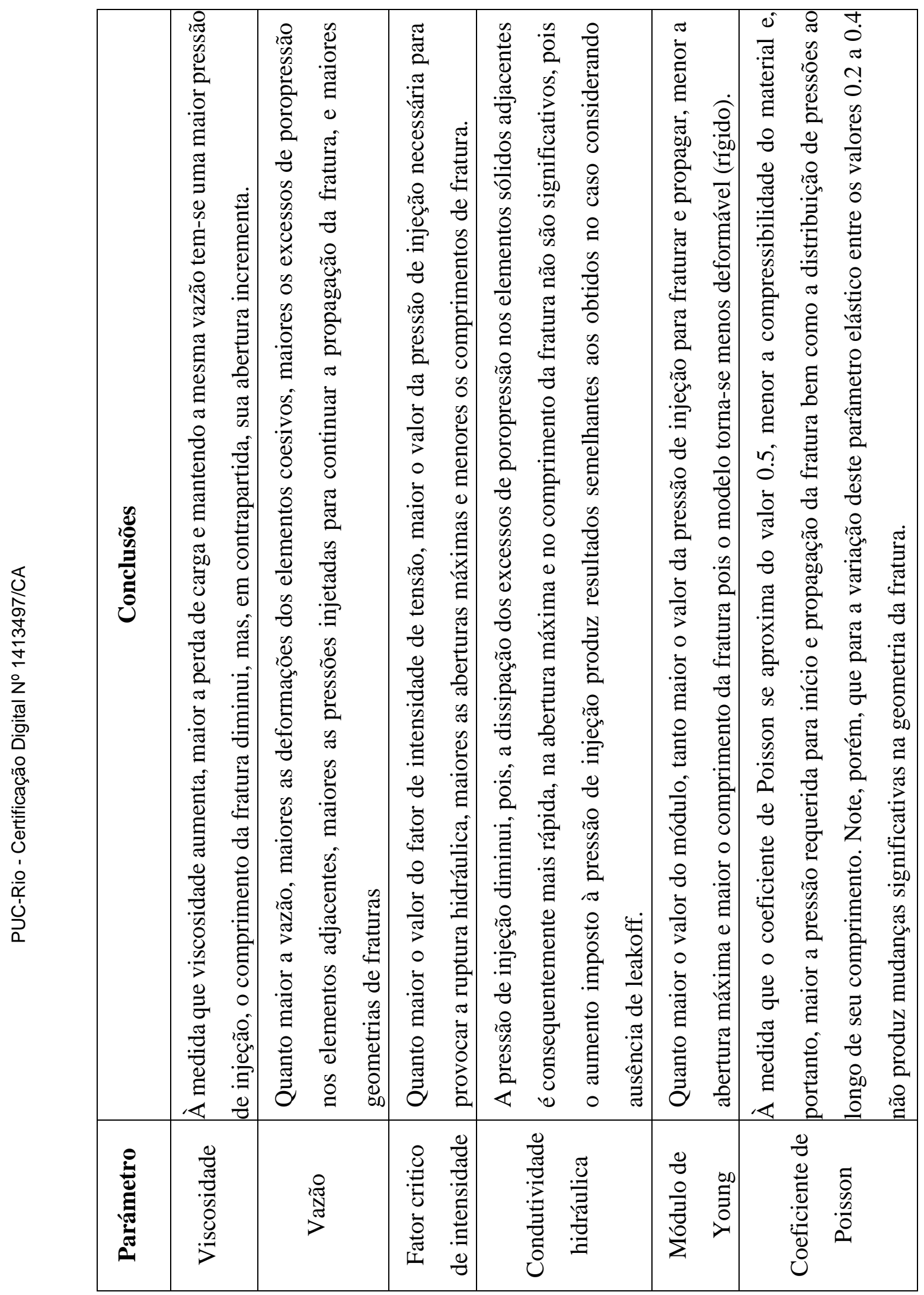




\section{Conclusões e sugestões}

\section{1. \\ Conclusões}

A influência dos fatores atuantes no fraturamento hidráulico foi estudada por meio de uma modelagem hidromecânica acoplada empregando o método dos elementos finitos com o modelo de zona coesiva, o qual permitiu avaliar os cenários mais favoráveis para a iniciação e propagação de fraturas.

A partir da utilização do software Abaqus 6.14, foi realizada uma modelagem computacional do fraturamento hidráulico em três etapas; a primeira corresponde à aplicação das sub-rotinas desenvolvidas pelo autor desta dissertação para atribuir as condições iniciais ao modelo, a segunda etapa foi o equilíbrio geostático entre as condições iniciais e de contorno e a terceira etapa refere-se ao fraturamento hidráulico feito a traves da injeção de fluido através elementos coesivos.

Foi realizada uma comparação entre a solução analítica do modelo KGD e a modelagem numérica do fraturamento hidráulico. Obteve-se um excelente ajuste para as curvas de abertura máxima de fratura, pressão de injeção, e comprimento de fratura.

Se demonstrou que o método dos elementos finitos com modelo de zona coesiva consegue reproduzir fielmente a solução analítica do modelo KGD no regime de propagação de fraturas dominado pela rigidez (vértice $\mathrm{K}$ ) assumindo tensões horizontais iniciais diferentes de zero, elementos sólidos sem grau de poro ativo e sem coeficiente de filtração (leakoff).

Os modelos analíticos de propagação de fraturas em camadas adjacentes com contrastes de tensões horizontais simétrico (Simonson, 1978) e contraste assimétrico (Fung, 1987) foram comparados com os modelos numéricos, observando-se uma concordância satisfatória na propagação da fratura na mesma 
camada de injeção. Quando a fratura penetra nas camadas adjacentes tendo em vista o contraste de tensões horizontais apresentam-se diferenças nos resultados, justificados pela simplicidade dos modelos analíticos baseado na mecânica clássica linear elástica em comparação com o modelo numérico de elementos finitos com zona coesiva acoplado hidro-mecanicamente.

No estudo de propagação de fraturas com contraste de tensões e poropressões, conseguiu-se equilibrar o modelo no passo geostático evitando a redistribuição de poropressões em relação àquelas inicialmente especificadas implementando barreiras impermeáveis nas interfaces. Para uma espessura de barreira impermeável de $0.25 \mathrm{~m}$, a influência negativa da barreira impermeável na propagação da fratura é reduzida e conseguiu-se avaliar a propagação de fraturas em camadas adjacentes sobrepressionadas.

\section{2.}

\section{Sugestões}

Nesta dissertação foi realizada o estudo sobre fraturamento hidráulico utilizando como modelo constitutivo dos elementos coesivos a lei tensão de tração vs separação, mas os elementos coesivos podem também ser definidos utilizando um enfoque continuo, o qual assume uma zona coesiva que pode ser modelada por meio de modelos de materiais convencionais ou modelos constitutivos criados pelo usuário.

Recomenda-se realizar modelagens numéricas tridimensionais, a fim de avaliar cenários de propagação de fraturas com contraste entre a tensão horizontal mínima e a tensão horizontal máxima, assim como estudar modelos analíticos de propagação conhecidos como pseudo 3D.

Reproduzir as soluções assimptóticas analíticas de todos os regimes de propagação de fraturas e suas combinações em modelos numéricos de elementos finitos com zona coesiva, com a finalidade de entender o comportamento das fraturas em cada um destes regimes. 
Desenvolver modelos numéricos com base no método dos elementos finitos estendidos (XFEM) com a finalidade de estudar a propagação de fraturas sem predefinição da direção de propagação como ocorre no caso de modelos numéricos de elementos finitos com zona coesiva, no qual a localização dos elementos coesivos define a direção de propagação

Recomenda-se avaliar a influência de fraturas naturais na propagação de fraturas, com a finalidade de realizar simulações mais realistas comparadas com as condições reais de reservatórios não convencionais de petróleo. 


\section{Referências bibliográficas}

Abaqus User's Manual, Version 6.14, Dassault Systèmes Simulia Corp., Providence, RI. 2014.

ADACHI, J. I., Fluid-driven fracture in permeable rock. $\mathrm{PhD}$. thesis, Univ. of Minnesota, Minneapolis, 2001.

BAREnBlatT, G. I., The Mathematical Theory of Equilibrium Cracks in Brittle Materials, Advances in Applied Mechanics, vol. 7, edited by Dryden, H. L. and von Karman, T. Academic Press, New York. 1962.

BOONE T.J., INGRAFFEA, A. R., A Numerical Procedure For Simulation Of Hydraulically-Driven Fracture Propagation In Poroelastic Media, International Journal for Numerical and Analytical Methods in Geomechanics, vol. 14, pp. 27 47, 1990.

BUNGER, A. P., DETOURNAY, E., GARAGASH, D. I., Toughness-Dominated Hydraulic Fracture with Leak-Off, International Journal of Fracture, vol. 134, pp.175-190, 2005.

CAMANHO, P. P., AND C. G. DAVILA, Mixed-Mode Decohesion Finite Elements for the Simulation of Delamination in Composite Materials, NASA/TM-2002-211737, pp. 1-37, 2002.

CARRIER B., GRANET S., Numerical Modeling Of Hydraulic Fracture Problem In Permeable Medium Using Cohesive Zone Model, Engineering Fracture Mechanics, vol. 79, pp. 312-328, 2012.

CARTER, R.D., Derivation of the General Equation for Estimating the Extent of the Fractured Area, Appendix I of Optimum Fluid Characteristics for Fracture Extension, Drilling and Production Practice, G.C. Howard and C.R. Fast, New York, New York, USA, American Petroleum Institute, pp. 261-269, 1957.

CHARLEZ P.A., Rock Mechanics, Volume 2, Petroleum Applications, Editions Technip, 1997.

CHENG, Z., BUNGER, A.P., ZHANG, X., JEFFREY, R. G., Cohesive zone finite element-based modeling of hydraulic fractures. Acta Mechanica Solida Sinica, Vol. 22, No. 5, October, 2009. 
CHENG, Z., Finite element modelling of viscosity-dominated hydraulic fractures, Journal of Petroleum Science and Engineering, 88-89, pp. 136-144. 2012.

DETOURNAY, E., ADACHI, J., GARAGASH, D. I., SAVITSKI, A., Interpretation and Design of Hydraulic Fracturing Treatments, United States Patent No. US 7111681B2, 2006.

DUGDALE, D.S., Yielding of steel sheets containing slits. Journal of the Mechanics and Physics of Solids, 8(2): 100-104.1960.

ECONOMIDES, M. J., AND NOLTE, K. N., Reservoir stimulation, Third Edition, Jhon Wiley \& Sons Ltd, 2000.

England, A. H. AND GREEN, A. E., Some Two-Dimensional Punch and Crack Problems in Classical Elasticity, Proceedings Cambridge Phil. Soc., vol. 59, pp.489-500, 1963.

FUNG, R. L., VIJAYAKUMAR, S., CORMACK, D. E., Calculation Of Vertical Fracture Containment In Layered Formations, Society of petroleum engineers journal, 1987.

GARAGASH, D. I., Plane-Strain Propagation Of A Fluid-Driven Fracture During Injection and Shut-In: Asymptotics Of Large Toughness, Engineering Fracture Mechanics, vol. 73, pp. 456-481, 2006.

GARAGASH, D. I., DETOURNAY, E., ADACHI, J., Multiscale Tip Asymptotics in Hydraulic Fracture with Leak-Off, J. Fluid Mech., vol. 669, pp. 260-297, 2011.

GEERTSMA, J. AND DE KLERK, F., A Rapid Method of Predicting Width and Extent of Hydraulic Induced Fractures, paper SPE 2458, Journal of Petroleum Technology, pp. 1571-1581, 1969.

GEERTSMA, J. AND HAAFKENS, R., A Comparison of the Theories to Predict Width and Extent of Vertical, Hydraulically Induced Fractures, Trans., AIME 101, 8, 1979.

HOWARD G. C., FAST. R., CARTER R.D. Optimum Fluid Characteristics for Fracture Extension, Drilling and Production Practices, pp. 261-270, 1957.

HU, J., GARAGASH, D. I., Plane-Strain Propagation Of A Fluid-Driven Crack in a Permeable Rock With Fracture Toughness, J. Eng. Mech., vol. 136(9), pp. 1152-1166, 2010. 
JIANG H. Cohesive Zone Model For Carbon Nanotube Adhesive Simulation And Fracture/Fatigue Crack Growth. PhD. thesis, Univ. of Akron, Ohio, 2010.

KHRISTIANOVIC, S. A. AND ZHELTOV, Y. P., Formation of Vertical Fractures by Means of Highly Viscous Liquid, Proceedings, Fourth Worm Petroleum Congress, Rome, Italy, pp.579-586, 1955.

KHRISTIANOVICH, S.A., ZHELTOV, Y.P., BARENBLATT, G.I., MAXIMOVICH, G.K., Theoretical Principles of Hydraulic Fracturing of Oil Strata, Proc., Fifth World Petroleum Congress, New York, 1959.

MOHAMmadneJAD, T., KHOEI, A.R., An Extended Finite Element Method For Hydraulic Fracture Propagation In Deformable Porous Media With The Cohesive Crack Model, Finite elements in analysis and design, Vol. 73, pp. 7795, 2013.

NORDGREN, R. P., Propagation of a Vertical Hydraulic Fracture, Society of Petroleum Engineers Journal, vol. 12, pp. 306-314, 1972.

ORTIZ, M., PANDOLFI, A., Finite-Deformation Irreversible Cohesive Elements For Three-Dimensional Crack-Propagation Analysis, Int. J. Numer. Meth. Engng. Vol. 44, pp. 1267-1282, 1999.

PEIRCE, A., DETOURNAY, E., An Implicit Level Set Method for Modeling Hydraulically Driven Fractures. Comput. Methods Appl. Mech. Engrg, vol. 197, pp. 2858-2885, 2008.

PERKINS, T.K. AND KERN, L.R., Widths of Hydraulic Fractures, Paper SPE 89, Journal of Petroleum Technology 13, No. 9, 937-949, 1961.

RICE, J. R., Mathematical Analysis in the Mechanics of Fracture, Treatise on Fracture, Academic Press Inc., New York Ch. 3, Vol. 2, 191, 1962.

RICE,J.R., The mechanics of earthquake rupture. In: Physics of the Earth's Interior. Amsterdam: North-Holland Publishing Company, 1980.

SACK, R.A., Extension of Griffith's Theory of Rupture to Three Dimensions, Proc. Phys. Soc. of London 58, 729-736, 1946.

SAVITSKI, A. A., DETOURnAY, E., Propagation Of A Penny-Shaped FluidDriven Fracture In An Impermeable Rock: Asymptotic Solutions, International Journal of Solids and Structures, vol. 39, pp. 6311-6337, 2002.

SIMONSON, E.R., ABOU-SAYED, A.S., and CLIFTON, R.J., Containment of Massive Hydraulic Fractures, SPEJ 27-32, 1978. 
SHET, C., CHANDRA, N., Analysis of energy balance when using cohesive zone models to simulate fracture processes. Journal of Engineering Materials and Technology-Transactions of the ASME, 124(4): 440-450, 2002.

SHEN, X., Cohesive crack for quasi brittle fracture and numerical simulation of hydraulic fracture. In: Drilling and Completion in Petroleum Engineering Theory and Numerical Application. Shen, X., Bai, M., and Standifird, W. (Editors). CRC Press Taylor \& Francis, London, UK, 175-191, 2012.

SNEDDON, I.N., The Distribution of Stress in the Neighbourhood of a Crack in an Elastic Solid, Proc., Royal Soc. London 187, Ser. A., 229-260, 1946.

SNEDDON, I.N., ELliOT, A.A., The Opening of a Griffith Crack Under Internal Pressure, Quarterly of Appl. Math. (1946) 4, 262-267.

YEW, C. H., Mechanics of Hydraulic Fracturing, Gulf Publishing Company, Houston, TX, 1997.

Yao, Y., Lu L., Leon M. K., Pore pressure cohesive zone modeling of hydraulic fracture in quase-brittle rocks, Journal of mechanics of materials 83, 17-29. 2014

ZIELONKA, M. G., SEARLES K. H., Development and validation of fullycoupled hydraulic fracturing simulation capabilities. Simulia community conference, 2014. 